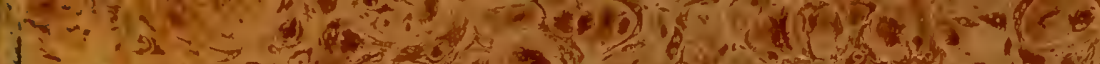

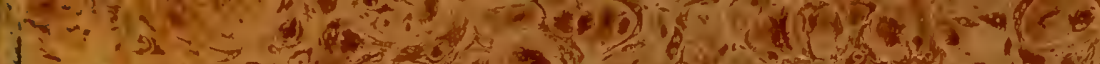

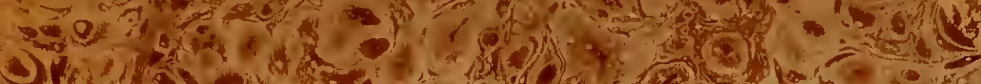

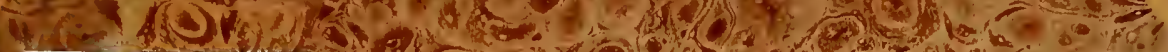
है

QK

569

L 2 F 74

1884

BOT

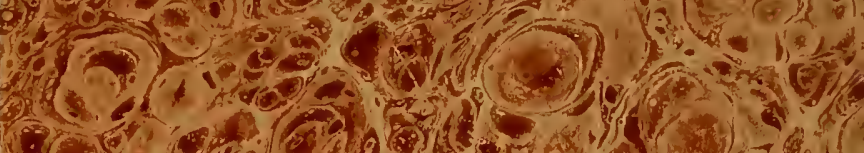

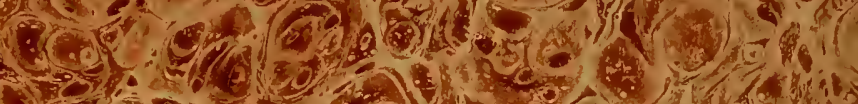

(2)

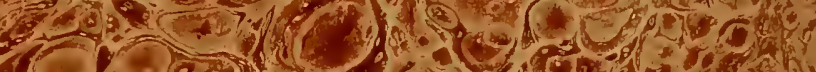

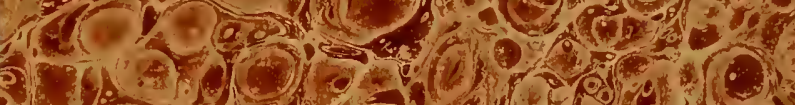

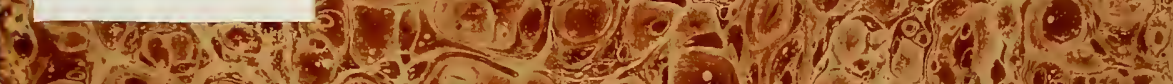

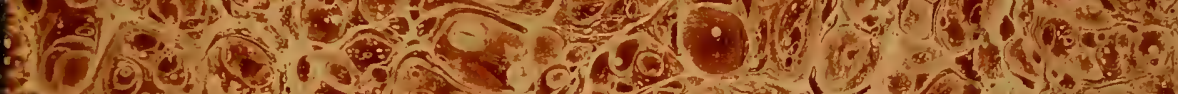
3.

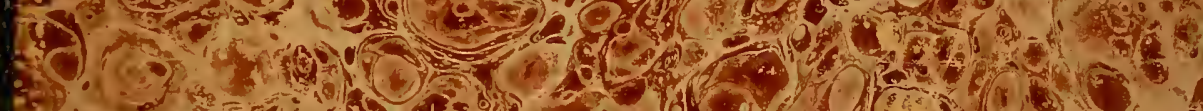

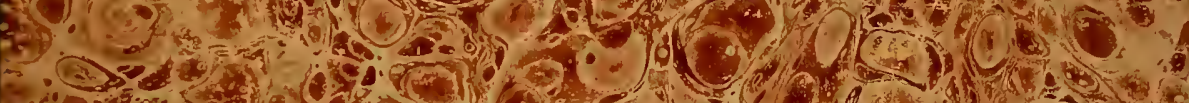

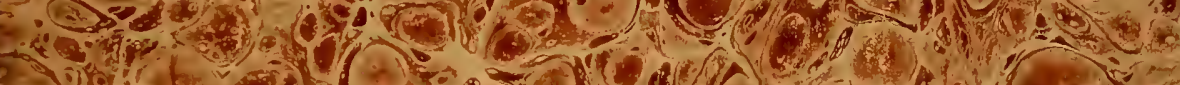

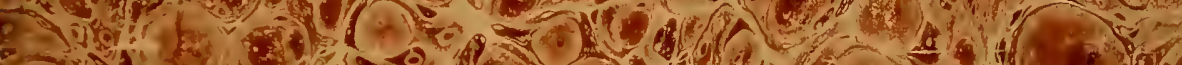

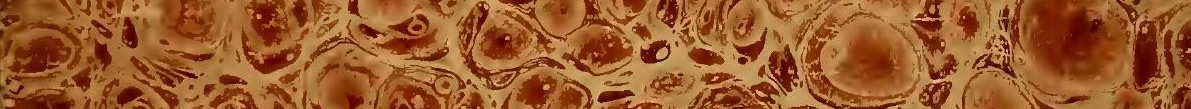

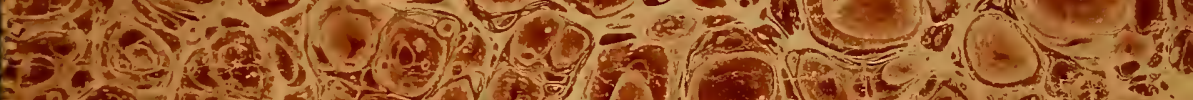

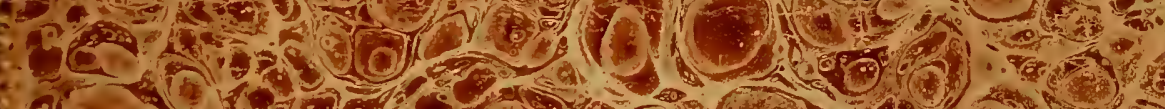
1.

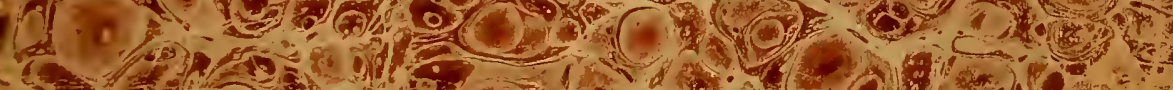

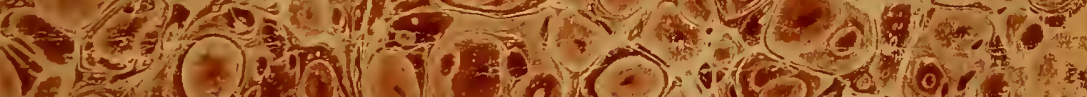

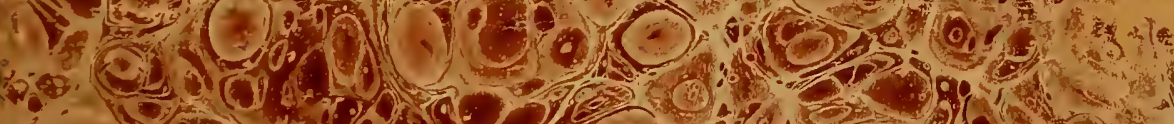

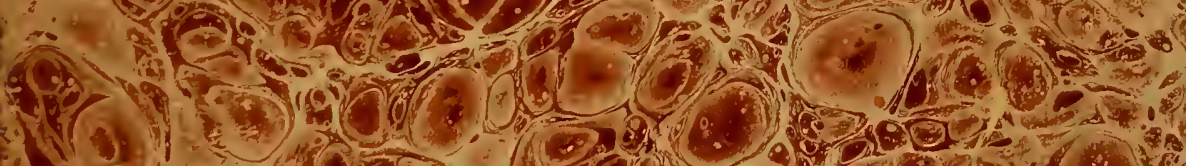
4 (1)

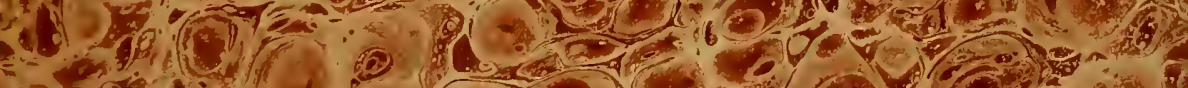
- Log.

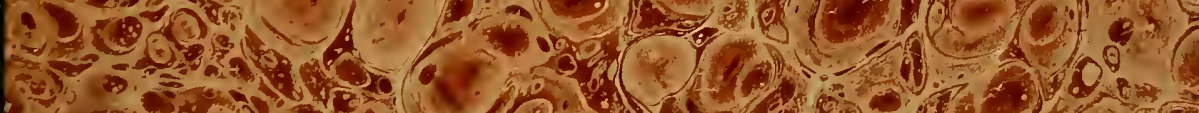

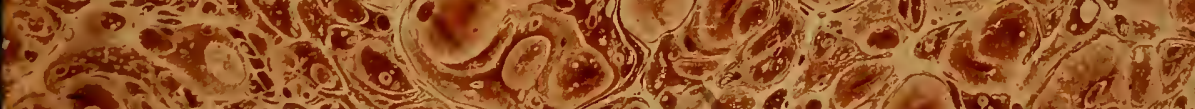

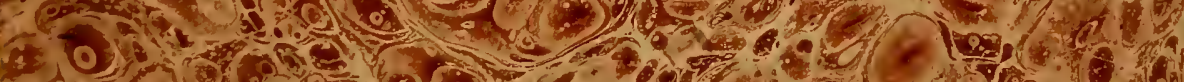
1)

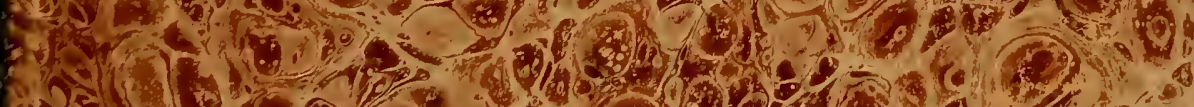

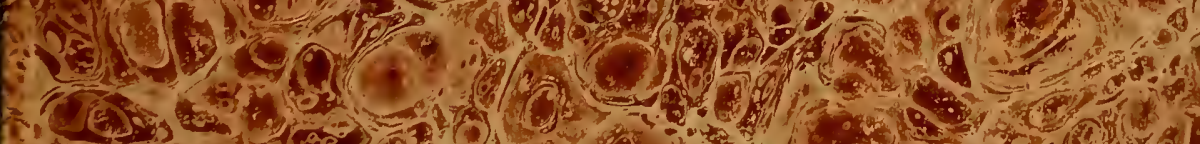

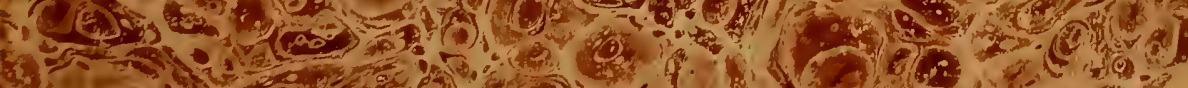

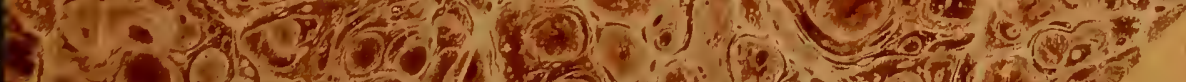



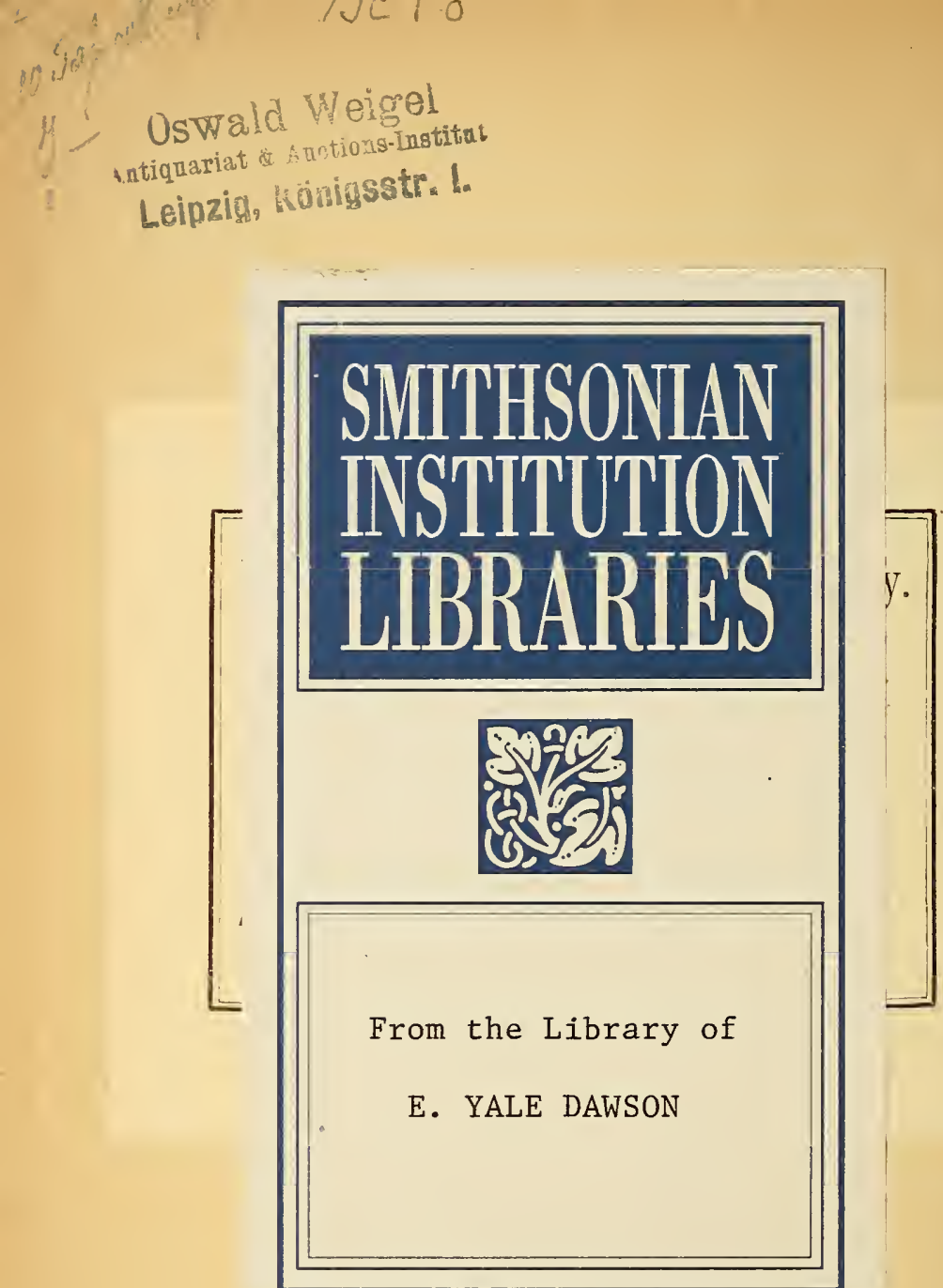
U E B E R

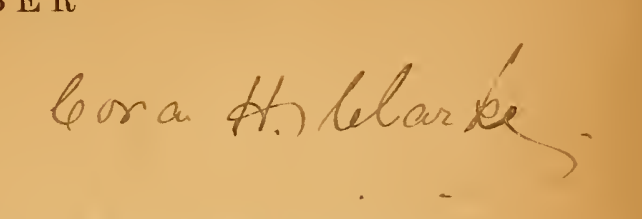

\section{DIE LAUINARIEN NORWRGRS}

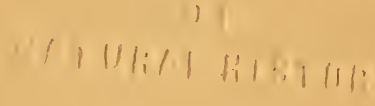

VON

M. FOSLIE.

(CHRISTIANIA VIDENSK.-SELSK. FORHANDL. 1884. No. 14.)

MITT 10 TAFELN.

\section{CHRISTIANIA.}

A. $W$. BRÖGERS BUCHDRUCKEREI. 


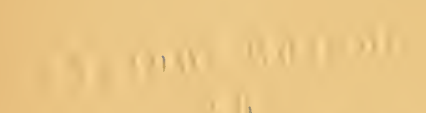

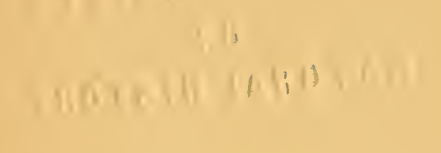



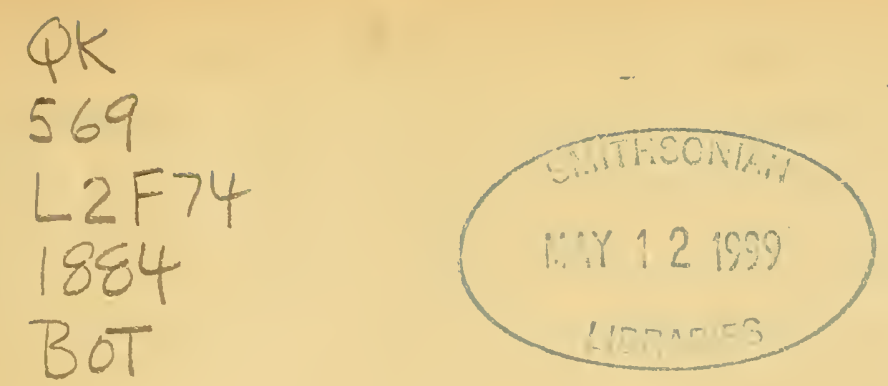

\title{
Ueber die Laminarien Norwegens
}

von

\author{
M. Fos 1 i e.
}

Mit 10 Tafeln.

(Fremlagt i det almindelige Møde den 12te December 1884.)

In einem kleinen, im Jahre 1883 erschienenen, Aufsatz gab ich eine vorläufige Uebersicht über das Vorkommen und die Verbreitung der zur Gruppe Digitatæ gehörenden Laminarien, die längs des nördlichen Theils der norwegischen Küsten auftreten. ${ }^{1}$ Dieser Aufsatz war das Resultat einer kurzen Reise in Nordland und Finmarken. Durch Unterstützung von Seiten der Universität in Christiania ward ich in den Stand gesetzt, meine Untersuchungen fortzusetzen und dieselben auch auf das südliche Küstengebiet auszudehnen. In Folge davon ist nicht nur das gesammelte Material bedeutend angewachsen, sondern es wurde mir auch Gelegenheit geboten, das Auftreten der gleichen Formen unter ganz verschiedenen Verhältnissen zu beobachten. Es versteht sich jedoch von selbst, dass die bisher angestellten Untcrsuchungen sich keineswegs für erschöpfend ausgeben wollen, vielmehr ist es meine $A b$ sicht, dieselben fortzusetzen und dabei speciell die Entwickelungsverhältnisse der Laminarien im Auge zu behalten, wie ich denn in

1 Bidrag til kundskaben om de til gruppen Digitatæ hørende Laminarier.

Vid.-Selsk. Forh. 1884. No. 14. 
dieser Richtung einige vorläufige Experimente angestellt habe. Neben so manchen anderen Lücken, die auf Ausfüllung warten, fühle ich es als eine besondere Unvollkommenheit dieser Untersuchungen, dass die Zahl der Winterobservationen eine so geringe bleiben musste, und ebenso war die Anzahl der fructificirenden Exemplare, die mir in die Hände kamen, äusserst klein. Letzteres dürfte jedoch vom systematischen Gesichtspunkt aus nicht grade von grösserer Bedeutung sein, da man, nach meiner Auffassung, aus der Gestalt u. s. w. des Sorus keine stabilen Kennzeichen abzuleiten im Stande ist, weil die betreffenden Formverhältnisse ziemlich bedeutenden Schwankungen unterworfen zu sein scheinen.

Beim Studium der algologischen Arbeiten, welche die Gattung Laminaria behandeln, - besonders der älteren, aber auch der neuesten, - wird man sich bald davon überzeugen, wie ganz entgegengesetzte Anschauungen hier sich geltend machen, und zwar nicht weniger in systematischen, als in biologischen Fragen. ${ }^{1}$ Unter den höheren Meeresalgen dürfte wohl kaum eine zweite Gattung sich aufweisen lassen, deren Wachsthumsverhältnisse so wenig bekannt wären, wie die der Laminarien, obwohl letztere, wenigstens in den arktischen Meeren, zu den grössten und häufigsten Arten zu rechnen sind. Es sind dieselben nur äusserst selten in natura studirt worden und doch entfalten grade dieșe Pflanzen eine so wechselvolle Vielgestaltigkeit, dass es in vielen Fällen kaum möglich erscheint, die variirenden Formen zu begrenzen. Besonders sind es die Formen der L. digitata (= L. flexicaulis), welche in dieser Beziehung die grösste Schwierigkeit darbieten. Nimmt man z. B. eines der riesengrossen Exemplare der typischen Form dieser Art vor sich, wie wir sie aus dem arktischen Norwegen, und speciell aus dem östlichen Finmarken, kennen (in welcher Gegend dieselbe die bedeutendsten Dimensionen annimmt), so würde man bei Vergleichung mit der Form, welche der südliche Theil der Küsten hervorbringt, leicht glauben können, es mit einer ganz ver-

1 "The limits of the genus (Laminaria) are well fixed, but the same can by no means be said of the species, with regard of which writers differ very much." F arl. New. Engl. Alg. Pag. 92. 
schiedenen Pflanze, oder mit einem neuen Typus, zu thun zu haben. Begleitet man aber die Form von Schritt zu Schritt und verfolgt das gradweise Einschwinden der Dimensionen, von einem mehrere Fuss langen und mehrere Zoll dicken Stengel an, mit einem Blatt von fast gleicher Länge, bis zu der zwerghaften, kaum fingerdicken Form der südöstlichen Küste, so bleibt kein Zweifel daran übrig, dass uns ïberall dieselbe Pflanze, nur in einer Mannigfaltigkeit von Variationen, entgegentritt. Uebrigens bedarf es keineswegs eines so grossen Sprunges über mehrere Breitegrade um scharfausgeprägte Gegensätze zu entdecken: Manche kleine Felseninsel und noch mehr, mancher Fjordenarm, kann bereits die frappantesten Beispiele für die Vielgestaltigkeit dieser Gewächse aufweisen. Liegt die Insel z. B. so, dass dieselbe auf der einen Seite der Einwirkung des offenen Meeres ausgesetzt, auf der andern Seite aber derselben entzogen ist, so darf man mit ziemlicher Sicherheit erwarten, an der Meeresseite nicht allein üppigentfaltete Exemplare von $L$. hyperborea ( $=L$. Cloustoni) zu finden, sondern auch die sonst kleinere und schwächere $L$. digitata ( $L$. flexicaulis), besonders die f. typica derselben, zeigt hier eine imponirende Grösse, während dieselbe Form auf der entgegengesetzten Inselseite nicht bloss in Bezug auf Gestalt und Dicke des Stammes, sondern auch in Bezug auf Länge, Form und Consistenz des Blattes, ein so ganz anderes Aussehen darbietet, dass man dieselbe für eine ganz neue Art, oder mindestens für eine neue Form ausgeben würde, wenn man nicht auch hier wieder Schritt für Schritt alle zwischenliegenden Uebergangsstadien nachweissen könnte. Ein noch abweichenderes Gepräge trägt $L$. digitata ( $L$. flexicaulis), wenn dieselbe in den immer mit Wasser gefiullten Felsklüften der litoralen Region sich angesiedelt hat. Hier fwird der Stengel kurz, schwach und sehr biegsam, das Blatt dagegen verhältnissmässig sehr lang. Wahrscheinlich ist diese ausserordentliche Geneigtheit, je nach der Localität die Formen zu wandeln, die wesentlichste Veranlassung dazu gewesen, dass man theils die unter $L$. digitata ( $L$. flexicautis) gehörenden Formen, und theils $L$. hyperborea ( $L$. 
Cloustoni) als dieselbe Art auffasste. ${ }^{1}$ Ein anderer Umstand der sich hierbei geltend gemacht hat, ist jedoch der, dass man die Arten und Formen gewöhnlich nach getrockneten Exemplaren beschrieben hat, ohne die Pflanze im frischen Zustand gesehen zu haben; unter den Meeresalgen giebt es aber nur wenig Gattchungen, die das Aussehen beim Trocknen so sehr verändern, als grade die Laminarien. ${ }^{2}$ Nur durch genaue Beobachtung derselben im lebenden Zustand, und durch eine sorgfältige Vergleichung der verschiedenen Entwickelungsstadien, sowohl der jüngeren, noch unentwickelten, als der älteren, vollentwickelten, so wie durch eine umsichtige Auffassung der biologischen Verhältnisse, wird man ein sicheres Resultat erzielen und eine natürlichere Begrenzung und Gruppirung erreichen können. Dies ist der Weg, den der Verfasser einzuschlegen versucht hat. $\mathrm{Ob}$ es dieser Arbeit gelingen wird, in dieser Beziehung ein wenig mehr Licht über die schwebenden Fragen zu verbreiten, muss der Erfolg zeigen.

Habe ich auch an dieser Stelle mich ausschliesslich nur mit den norwegischen Formen beschäftigen wollen, die ẗbrigens grade bei dieser Gattung Repräsentanten der meisten und der hervorragendsten Typen aufweisen, so versteht es sich jedoch von selbst, dass ich, soweit es die Umstände haben gestatten wollen, auch Sammlungen aus andern Ländern, zumal den Nachbarländern

1 Vergl. Rupr. Algenstämme Pag. 6, Harv. Ner. bor. Amer. Pag. 94, Farl. Alg. Un. States Pag. 351.

2 ,The difficulty arises partly from the fact, that the species lose some of their characteristic in drying, so that the study of herbarium specimens is unsatisfactory." Farl. New. Engl. Alg. Pag. 92.

Nimmt man zwei Herbariumexemplare von L: hyperborea (L. Cloustoni) und $L$. digitata ( $L$. flexicaulis), so wird man $z$ wischen diesen beiden Arten oft keinen merkbaren Unterschied in der Farbe oder der Consistenz und Glätte der Blätter nachweisen können, obwohl die Verschiedenheit bei frischen Exemplaren sehr hervortretend und ziemlich constant ist. Auf der andern Seite findet man aber ebenso häufig grosse Verschiedenheit an Herbarium-Exemplaren derselben Art. Letzteres hängt zum grössten Theil mit der Art und Weise zusammen, in welcher die Pflanzen getrocknet sind, ob sie z. B. erst an der Luft getrocknet, und darnach aufgeweicht und für das Herbarium präparirt worden sind, oder ob sie eine Zeit lang in Salz anfbewahrt würden u. s. w. Werden sie dem Sonnenlicht ausgesetzt, so werden sie in der Regei schwarz; ebenso wenn der Trockenprocess sehr langsam von Statten geht. 
durchmustert habe, um in solcher Weise die von mir gemachten Beobachtungen zu ergänzen. Durch das Wohlwollen des Intendanten, Professor Dr. V. B. Wittrock, ward mir die Gelegenheit geboten, die, auch an Laminarien, reichen Sammlungen des Reichsmuseums in Stockholm durchzugehen. Mit gleicher Bereitwilligkeit ist Herr Professor Dr. F. R. Kjellman in Upsala meinen Wunschen entgegen gekommen. Es ist mir eine angenehme Pflicht den beiden genannten Herıen hierfür, wie für so manchen anderen Rath und sonstige werthvolle Mittheilungen, durch welche dieselben jeder Zeit, und mit immer gleicher Zuvorkommenheit, meine Arbeit gefördert haben, meinen herzlichsten Dank auszusprechen. Nicht minder fühle ich mich Herrn Professor J. E. Areschoug verpflichtet, dessen grosse Sammlungen, besonders skandinavischer, Laminarien ich theilweis durchmustert habe. Als einen werthvollen Beitrag zur Kenntniss der Laminarien unsers Landes habe ich noch zu erwähnen die bedeutenden Sammlungen norwegischer Algen, welche vom verstorbenen Professol M. N. Blytt und besonders von Professor Dr. F. C. Schübeler angelegt worden sind und nun dem botanischen Museum der Universität angehören. Der Freundlichkeit des Herrn Conservator Storm verdanke ich endlich, dass mir die in der Sammlung der wissenschaftlichen Gesellschaft in Trondhjem aufbewahrten Ueberreste von Bischof J. E. Gunnerus' Algenherbarium zur I)urchsicht überlassen worden sind.

Im Folgenden werde ich den Namen $L$. hyperborea für die in meinem "Bidrag" als L. digitata oder L. Cloustoni Edm., Le Jol. bezeichnete Art, so wie den Namen $L$. digitata für die dortige L. Alexicaulis in Anwendung bringen. Ueber meine Gründe dafür werde ich weiter unten Rechenschaft ablegen.

\section{Das Haftorgan der Laminarien.}

Bei der Gattung Laminaria, wie dieselbe längs der norwegischen Kuste auftritt, lassen sich für die Haftorgane folgende drei, freilich nicht immer scharf differenziirte Formtypen aufstellen 
1. Die Haupzweige sehr kräftig, in vertikale regelmässige oder fast regelmässige Serien geordnet.

2. Die Zweige durchgehends weniger kräftig, mehr oder weniger horizontal auslaufend; weniger regelmässig alternirende Kränze, theils niedergedrückter, theils ziemlich kugelförmiger Umkreis.

3. Zweige fein, faserartig, unregelmässig.

Zum ersten Typus gehört die Art, welche auf Taf. 1, Fig. 1 dargestellt ist, - L. hyperborea -, und bei uns nur diesen einen Repräsentanten zählt. Dieser Typus zeichnet sich, wie bereits gesagt, dadurch aus, dass die Hauptzweige der Wurzel sehr kräftig sind und sich in vertikalen, mehr oder minder regelmässigen Serien geordnet zeigen. - Im jüngsten Stadium stellt das Haustorium, oder das unterste Ende des Stammes, eine kleine, schwachentwickelte, Scheibe dar, die vorläufig das Haftorgan der Pflanze ausmacht; sehr bald aber beginnt die Entwickelmng der Hapteren, ${ }^{1}$ und ehe noch das Blatt angefangen hat sich zu theilen, ja sogar, ehe das Gewächs die Länge von ein paar Centimetern erreicht hat, haben letztere Organe bei dieser Art eine relativ kräftige Entwicklung erreicht, und in einem etwas weiter fortgeschrittenen Alter zeigt die Wurzel eine kräftigere Entfaltung, als bei irgendwelcher andern arctischen Laminarienform im gleichen Alterstadium. Das ursprüngliche Haftorgan, - das Haustorium, - behauptet jedoch immernoch seine bisherige Function, doch nicht so lange, als bei den meisten der übrigen Arten. Haben aber die Hapteren sich soweit kräftig entfaltet, dass sie num ganz das Festhalten der Pflanze, übernehmen können, so hört auch die ursprïngliche Function des Haustoriums auf; dasselbe löst sich von der Unterlage ab, während gleichzeitig die Hapteren nach und nach den Stamm in die Höhe heben, bis derselbe zum Schluss allein auf letzteren ruht. ${ }^{2}$ Je nachdem

1 Cfr. Warm. Podost in Danske Vidensk. Selsk. Skr., Bot. Centralbl. und Bot. Not.

2 Dies hat für unsere Art bereits Schulz nachgewiesen: „Bei älteren Pflanzen stirbt die ursprüngliche Mittelwurzel ab und wird abgeworfen, so dass nur die Pyramidenspitze des durch die Stammverlängerung gebildeten Wurzelkopfes übrig bleibt." Schichtenbildung Pag. 71. 
nun das Individuum an Alter, und der Stamm an Dicke zunehmen, entwickeln sich immer neue Hapteren, der eine Cyclus über dem andern, und jeder einzelne Zweig entsendet ebenfalls solche, die alle, wie bereits angeführt wurde, in dem Streben sich vereinigen, den Stamm bis zı einem bestimmten Grad in die Höhe zu heben.Schulz führt an (l. c.), „dass jeder Wurzeletage eine Stengelschicht entspricht, indem jeder Wurzelursprung unmittelbar in eine Stengelschicht fortsetzt:" Dasselbe behauptet Le Jolis (Examen). Die Folge eines solchen Verhaltens würde natürlich sein, dass man unmittelbar aus der Anzahl der Wurzelcyklen auf die Anzahl der Schichtringe im Stengel, oder das Alter des Individuums, würde schliessen können, wenn man sonst die Bedeutung jener Schichtringe recht erkannt hätte. Eine derartige Beziehung besteht jedoch, so weit meine Beobachtungen reichen, nur bis zu einem gewissen Grad, und es sind fast ausschliesslich nur die jüngeren Exemplare, bei welchen die Zahl der Wurzelcyklen der Zahl der Schichtringe entspricht. Gleichzeitig mit dem Zunehmen der Länge zeigt sich auch ein Dickerwerden der Hapteren. Wenn das Individuum ein gewisses Alter erreicht hat, fällt die Bildung eines neuen Wurzelcyklus nicht mehr mit der Bildung einer einzelnen neuen Stengelschicht zusammen, sondern ein em Wurzelcyklus entsprechen oft nicht weniger als vier Schichtringe im Stamme. Dabei erhalten, wie ich mehrfach beobachtet habe, auch die Wurzelzweige, jedenfalls die hauptsächlichsten, ebenfalls ihre Schichtringe in Gleichheit mit dem Stamme. Die Anzahl der letzteren beträgt jedoch selten mehr, als drei; ist diese Zahl erreicht, so entwickelt sich ein neuer Wurzelcyklus u. s. w. Während so die neuen Schichtringe in den Hauptzweigen sich entwickeln und die Zweige selbst immer dicker werden, nehmen auch die bereits entwickelten Secundärzweige an Dicke zu und entsenden zum Theil neue Aeste. Fig. 2 auf Taf. 1 zeigt einen $2 \mathrm{Cm}$. über der Wurzel genommenen Querschnitt des Fig. 1 abgebildeten Exemplars. Derselbe trägt 20 deutliche Schichtringe zur Schau; die Wurzel dagegen weist nur 7 Astcykel aus. Hier würde man also erwarten, dass die Hauptzweige, oder wenigsten einige derselben, 3-4 Schichtringe nach- 
weisen müssten, und dies ist auch wirklich der Fall. - Die Hapteren sind bei diesen und ähnlichen Exemplaren sehr dick und kräftig. Thre Entwickelung entspricht jedoch nicht immer der Höhe der Pflanze und der Dicke des Stammes; man findet so bei Exemplaren, deren Stamm eine Länge von 2-3 Metern und eine entsprechende Dicke erreicht hat, verhältnissmässig recht schwach entwickelte Hapteren. Dies beruht zum Theil auf der physischen Beschaffenheit des. Bodens, sehr oft aber auch auf einer Reihe der verschiedenartigsten Umstände. Namentlich wird in Betracht kommen, ob das Gewächs der Brandung preisgegeben ist, und in Folge davon zu seiner Selbsterhaltung kräftiger Haftorgane bedarf. An Orten, die dem offnen Meer ausgesetzt sind, und an denen darum in der Regel ein starker Wellenschlag herrscht, entwickelt sich die Wurzel besonders kräftig, und grade derartige Localitäten sind es, an denen $L$. hyperborea am besten gedeiht und die bedeutendsten Dimensionen erlangt. An etwas mehr geschïtzten Punkten dagegen erhält dieselbe, so günstig die Verhältnisse für ihr Gedeihen sonst auch sein mögen, eine weit schwächer entwickelte Wurzel, und diese zeigt an letzteren Orten seltener eine so regelmässige Bildung, wie an den ersteren; ebenso werden die Hapteren feiner und ästiger, stehen weniger vertikal und zeigen sich nicht kräftig genug um die Pflanze, wie bei den typischen Exemplaren, in die Höhe zu heben. Auch das Haustorium behauptet unter solchen Umständen oft länger noch seine ursprüngliche Function, so dạss derartige Exemplare sich im Ganzen dem folgenden Formtypus nähern. Besonders hervortretend ist dies in Fjorden oder ziemlich geschlossenen Buchten mit ruhigerem Wasser. Hier aber scheint unsere Alge überhaupt auch nur eine kümmerliche Existenz zu fristen, da es bloss verkrüppelte Exemplare sind, welche man ausnahmsweis an solchen Orten antrifft.

Der zweite Formtypus zeichnet sich dadurch aus, dass bei ihm die Zweige mehr oder weniger horizontal auslaufen und nicht so regelmässig alternirende Kränze bilden, während gleichzeitig die einzelnen Zweige weniger kräftig, feiner und ästiger sind, als bei der vorigen Form, und auch das Haustorium längere 
Zeit seine ursprüngliche Function beibehält, ja in manchen Fällen dieselbe bis zum Lebensende der Pflanze fortführt. Zn dieser Form gehören $L$. digitata ( $L$. flexicaulis) und noch ein paar andere Arten.

Auf Taf. 4 und 5, Fig. 1, sieht man zwei Formen der L. digi= tata, wie dieselbe an der Küste des nördlichen Norwegens auftritt. Die Hapteren sind bei beiden ungefähr gleich kräftig entwickelt; während dieselben aber bei der ersten Form regelmässiger, etwas gröber und weniger verzweigt sind und in ziemlich horizontaler Richtung verlaufen, zeigen sie sich bei der andern sehr ästig, ziemlich unregelmässig und in einander verschlungen. Der Stamm ist hier fast bis zur selben Höhe erhoben, als bei $L$. hyperborea, und das ursprüngliche Haustorium hat sich schon in einem frühen Stadium von der Unterlage abgelöst. Fig. 7 auf Taf. 4 stellt die Wurzel eines andern Exemplares derselben Form dar. Hier sind die beiden oberen Kränze ganz regelmässig; während die (hier verdeckten) unteren und älteren unregelmässig auftreten. Diese Form nähert sich somit in manchem dem vorigen Formtypus; es bietet dieselbe aber doch, wie die Figur ausweist, ein ganz anderes Gesammtbild dar, als die typische $L$. hyperborea: bei grösserer Verästelung sind die einzelnen Zweige feiner und laufen schmaler aus.

Fig. 1 auf Taf. 3 zeigt uns ein Exemplar einer andern Form (f. valida). Dieselbe scheint sich nicht allein durch den aufrechten, nach unten zu verdickten, nach obenhin schmal auslaufenden Stengel auf den ersten Blick der $L$. hyperborea zu nähern, sondern man bemerkt auch, wie die Hapteren hier eine bestimmtere Tendenz verrathen, nach unten hin $\mathrm{zu}$ wachsen, und sich vertikal $\mathrm{zu}$ stellen, wenn auch nicht mit voll ansgeprägter Regelmässigkeit und Kraft. Ich will indessen bereits hier bemerken, dass dies keineswegs als allgemeine Eigenschaft unserer Form anzusehen ist. Dieselbe entspricht vielmehr in allen wesentlichen Stücken der $L$. digitata f. typica. Das hier abgebildete Exemplar vorgegenwärtigt darum auch nur die äusserste Grenze der Form, wie ich bei der speciellen Beschreibung der einzelnen Formen näher darlegen werde. Fig. 5 auf Taf. 3 zeigt die f. stenophylla, deren Hapteren in allem wesentlichen mit den be- 
reits erwähnten Formen von $L$. digitata übereinstimmen. Etwas grössere Abweichungen treten uns an der f. ensifolia entgegen (Taf. 5, Fig. 2 u. Taf. 6, Fig. 1). Während Fig. 1 auf Taf. 6 sich als ein Uebergang zu den vorigen Formen zu erkennen giebt, insofern das Haustorium auch hier sich abgelöst hat und die Hapteren die jenem ursprünglich zukommende Function übernommen haben, bemerkt man an dem Taf. 5, Fig. 2 abgebildeten Exemplar, dass mit dem ebenbesprochenen ungefähr gleiches Alter haben wird, wie das Haustorium sich hier noch nicht von der Unterlage getrennt hat und die Hapteren in horizontaler Richtung sich ausbreiten und mehr herabgedrückt sind. Noch deutlicher tritt dies bei Fig. 7, Taf. 6 hervor, wie überhaupt bei manchen anderen, sowohl jüngeren, als älteren Exemplaren unserer Form. Ich besitze Exemplare, die ungefähr das gleiche Alter haben müssen, wie das auf Taf. 6, Fig. 4 abgebildete, während doch die Hapteren immer noch in ihrer ersten Entwickelung stehen. ${ }^{1}$ Auf der andern Seite habe ich jedoch auch, wie bereits erwähnt, bei derartigen Pflanzen vollständige Uebergänge zu den bereits erwähnten Formen dieses Typus beobachten können (oder von letzteren zu ersteren), so dass die Verschiedenartigkeit der Haftorgane bei dieser Form höchsten eine schwach differenziurte Subform zu bedingen vermag. L. digitata f. ensifolia wächst gewöhnlich an ziemlich geschützten Orten, und ihr Stamm ist gewöhnlich ungefähr eben so biegsam, wie bei f. stenophylla, und die Haftorgane solcher biegsamen, oder mit einem mehr oder minder liegenden Stengel versehenen Formen sind immer relativ schwächer entwickelt, es sei denn, dass dieselben an besonders ausgesetzten Stellen gewachsen sind. An die letzt genannte Form schliesst sich der Hauptsache

1 Wenn J. G. Agardh (Grönl. Lam. Pag. 11) die Meinung ausspricht, dass der Fucus bifurcatus Gunn. auch nicht einmal dieser Gattung beigezählt werden darf, da die radix scutata, welche die Abbildung (Norske Planter Taf. VI Fig. 2) aufweist, jeden derartigen Gedanken, zum mindesten den an L. digitata, verbiete, so können wir uns demselben um so weniger anschliessen, als Gunnerus ohne Zweifel ein Exemplar von der Art des eben besprochenen, mit seinen sehr schwach entwickelten Hapteren, vor sich gehabt hat, bei welchem es dann leicht erklärlich ist, dass er der Wurzel nicht die volle Aufmerksamkeit schenkte. 
nach an die f. crassifolia, Taf. 6, Fig. 10, so wie auch an L. nigripes, in der Gestalt wie letztere an der finmarkischen Küste auftritt. Der dritte Formtypus characterisirt sich, durch in der Regel feime, sehr ästige, lange und spitz zulaufende Hapteren in fast immer unregelmässiger Vertheilung. Taf. 7, Fig. 1 u. 5, Taf. 8, Fig. 1 und Taf. 10, Fig. 1 zeigen diese Form bei ausgewachsenen Exemplaren von $L$. intermedia. Ab und zu trifft man jedoch auch Exemplare, deren Haftorgan sich demjenigen der vorigen Form, namentlich demjenigen von $L$. digitata f. ensifolia und f. crassifolia sehr bedeutend nähert oder gar so ziemlich gleich kommt, (vergl. Taf. 9, Fig. 2), wie ja auch bei jüngern Exemplaren jener Form sich mancherlei Uebereinstimmungen mit der jetztbesprochenen nachweisen lassen. Taf. 9, Fig. 1 zeigt uns ein Exemplar mit ziemlich regelmässigen Hapterenkränzen; der oberste ist durch einen Zwischenraum von ca. 1 Centimeter ganz von den beiclen unteren abgetrennt. Der Stammestheil, welcher diesen Zwischenraum bildet, zeigt eine Verminderung des Umfangs (ca. 0.5 Cm.), die der Dicke des neuen Schichtringes entspricht, von welcher der oberste Kranz ausgeht.

Zeigen nun auch die hier vorgeführten Formtypen in ihren ausgeprägtesten Gestalten eine bedeutende Verschiedenheit, so finden sich doch, wie mehrfach bemerkt, vielfache Uebergänge zwischen den Hauptgruppen. Dies hat seinen Grund vor allem in der physischen Beschaffenheit des Bodens, auf welchem die Pflanze steht; es mögen aber auch mancherlei andere Umstände dabei mitwirkend sein. Ich habe bereits darauf aufmerksam gemacht, dass die Hapterenkränze der L. hyperborea dort, wo diese Alge in Fjorden oder geschlossenen Buchten vorkommt, ihre Regelmässigkeit einbüssen, wie denn überhaupt die ganze Pflanze an derartigen Fundstellen nur schlecht gedeiht und ein verkrüppeltes Aussehen zeigt, wobei sowohl Stamm, als Blatt sehr weit von dem typischen Bilde abweichen. Etwas ähnliches findet Statt, wo unsere Pflanze auf loserem Grunde (kleineren Steinen u. drgl.) auftritt. Die Hapteren werden in solchem Fall ästiger, länger und weniger derb, und suchen Anhalt nicht bloss an dem einen Stein, auf welchem das 
Individuum ursprünglich sich festgesetzt hat, sondern, so weit es ihnen möglich ist, auch an andern benachbarten Gegenständen. Bei derartigem Meeresgrund findet man daher auch fast immer, dass die Wurzel eine grössere oder geringere Anzahl kleinerer Steine, Muscheln u. drgl. umschliesst. Dasselbe Verhalten wiederholt sich bei L. digitata, wie auch bei L. saccharina: die Hapteren werden verhältnissmässig um so feiner, je loser der Boden ist.

Das Vorkommen von Hapteren, die dem Stengelsystem angehören (den früher sogenannten Adventivwurzeln) bei verschiedenen Algen ist eine bereits länger bekannte Thatsache, doch habe ich nirgend eine Beobachtung derartiger Gebilde bei der Gattung Laminaria erwähnt gesehen. Man trifft indessen dergleichen bei den Formen dieser Gattung, die sich durch einen biegsamen Stamm auszeichnen und an Orten wachsen, wo eine heftige Strömung oder ungestüme Brandung sie sonst bald fortführen würde, weil die ursprïngliche oder Normalwurzel nicht im Stande sein würde, die Pflanze festzuhalten. Bei Inderöen in der TrondhjemsFjorde $\left(64^{0} 2^{\prime}\right.$ N. B.) fand ich im Sommer 1883 verschiedene Exemplare einer L. digitata-Form, welche zwischen der f. typica und der f. stenophylla in der Mitte steht, und sich durch zahlreiche, über den Stamm hinauf verbreitete, Hapteren auszeichnet. Diese Exemplare wuchsen in einem schmalen Sund, in welchem ein ausserordentlich reissender Strom herrscht, dessen Richtung nach Ebbe und Fluth wechselt, was aber der Stärke der Strömung keinen Abbruch thut. In dem tieferen Theil des Strandgebietes, welches durch die Ebbe trocken gelegt wurde (der litoralen Region), war diese Form recht allgemein; sowohl Stamm, als Blatt lagen für gewöhnlich ganz flach am Boden, aber die Normalwurzel, obschon ziemlich kräftig entwickelt, besass nicht Kraft genug, um das Gewächs dem reissenden Strom gegeniiber festzuhalten; deshalb hatten sich gleich oberhalb der Basis eine Anzahl Hapteren entwickelt (Taf. 4, Fig. 8), welche als weitere Stïtzen dienen mussten. Fig. 9 derselben Tafel zeigt den untern Stammestheil eines anderen Exemplars. Hier haben die Hapteren sich an den verschiedenen Seiten des Stammes entwickelt, weil bei der nach Ebbe und Fluth wechselnden Strom- 
richtung der Stamm der Pflanze vom Wasser bald nach der einen, bald nach der andern Seite mit fortgerissen wurde, ehe noch die Hapteren sich hatten anheften können. Als nun aber, wie es bei diesen Exemplar geschehen, die obersten Hapteren (a) zuerst einen Anhaltspunkt gefunden hatten, fingen anch die tieferliegenden $(b)$, (die ursprïnglich die entgegengesetzte Richtung eingehalten und unter der Beugung des Stengels sich auf der andern Seite des Pflanze anzuklammern versucht hatten,) ebenfalls an, sich in die Richtung jener bereits angehefteten Hapterenäste zurückznkrümmen, um sich, sobald sie die daza nothwendige Länge erreicht hatten anf derselben Seite, wie die ïbrigen anzuklammern. ${ }^{1}$ Bei einem andern Exemplar, dessen Stamm eine Länge von ca. $50 \mathrm{Cm}$. hatte, entspringen einige Hapteren noch aus der Mitte des Stamms.

\section{Der Stamm.}

Der Stamm der Laminarien ist bereits früher mehrfach von Autoren beschrieben worden, die sich mit dieser Gattung beschäftigt haben. Von mehreren Verfassern, die genaner auf diesen Gegenstand eingegangen sind, ist jedoch der Unterschied zwischen den beiden hervorragendsten Arten dieser Gattung, der L. hyperborea und der $L$. digitata, in doppelter Beziehung viel schärfer betont worden, als dies nach dem Auftreten derselben an der norwegischen Küste mir berechtigt scheint. Es handelt sich dabei einmal um die Gestalt, zum Theil auch um die Consistenz, des Stammes und dann besonders um dass Verhalten der Schichtringe. In enger Verbindung mit letzerem Umstand wird auch von einem durchgreifenden Unterschied in der Entwickelung des Blattes bei L. digitata gesprochen. Auf letzeren Punkt werde ich im nächsten Abschnitt genaner eingehen.

Die ersten, welche das gegenseitige Verhalten der beiden hier in Betracht kommenden Arten mit einiger Ausführlichkeit behandelt haben, sind zunächst Clouston (Anders. Guide) und etwas

1 Die Hapteren $a$ hatten sich an einem Stein angeheftet, der etwas höher lag, als der die Normalwurzel tragende. Dadurch hat der untere Theil des Stammes seine senkrechte Richtung erhalten. 
später Le Jolis in seiner Monographie über die Gattung Laminaria (Le Jol. Examen). Die eingehende Beschreibung, welche Le Jolis über den Bau u.s.w. des Stammes bei der ersterwähnten Art liefert, entspricht in allen wesentlichen Stücken den Verhältnissen, die man an den norwegischen Exemplaren beobachtet; ich hätte nur noch beizufügen, dass der Stamm nicht immer bis ganz zur Spitze hinauf rund sich zeigt, sondern dass es auch eine, im Uebrigen jedoch nur schwach differenziirte, Form giebt (f. compressa. Taf. 1, Fig. 9), bei welcher der Stamm etwas zusammengedrückt und, in seinem oberen Theil, etwas mehr gebogen sich darstellt, als bei den typischen Exemplaren. Auf diese Bemerkung möchte ich jedoch immerhin einiges Gewicht legen. Es geschieht nämlich mehrfach, dass Le Jolis Arten, die von älteren Verfassern beschrieben werden, einzig und allein aus dem Grunde unter $L$. digitata einordnet, weil die Beschreiber angeben, dass der Stamm bisweilen nach obenzu zusammengedrückt sei, obwohl der Rest der Beschreibung viel besser auf $L$. hyperborea, als auf $L$. digitata passt. In andern Fällen beruft er sich auf diesen Umstand wenigstens als Beweis dafür, dass die älteren Autoren beide Arten vollständig zusammengeworfen hätten. - Ganz anders aber verhält es sich mit dem, was Le Jolis über $L$. digitata (L. flexicaulis) berichtet. Hier stimmen seine Beschreibungen kaum in irgend welchem Punkt mit den Verhältnissen überein, wenigsten insofern solche an der nordischen Form zu beobachten sind; und man könnte sich gradezu zu der Annahme geneigt fühlen, dass seiner Beschreibung Exemplare einer ganz andern Art zu Grunde gelegen haben dürften. Seit ich jedoch Gelegenheit gehabt habe, - theils in dem von ihm herausgegebenen Exiccatwerk, theils in Herbarien,- - einige Exemplare seiner L. flexicaulis in Augenschein zu nehmen, muss ich es inzwischen für ziemlich ausgemacht ansehen, dass wenigsten einige dieser Exemplare dem auch an der norwegischen Küste vorkommenden Formtypus zuzuzählen sind. Der eigentliche Kernpunkt der Abweichung liegt, wie erwähnt, in seinen Angaben über die Entwickelung des Blattes und das Fehlen der Schichtringe in dem Stamm. Ich habe bereits in meinem "Bidrag" den Nachweis dafür geliefert, dass sich 
bei $L$. digitata (jedenfalls bei den grösseren Formen derselben) ebenso deutliche Schichtringe vorfinden, wie bei $L$. hyperborea, und dasselbe bestätigen auch Kjellman (Ishafsfl. Pag. 296) und Areschoug (Obs. Phyc.). Uebrigen scheint auch Le Jolis selbst bisweilen derartige Ringe gesehen zu haben, aber ohne denselben die gleiche Bedeutung beizulegen, wie bei L. hyperborea. ${ }^{1}$

Taf. 4, Fig. 2 zeigt einen Querschnitt, der $5 \mathrm{Cm}$. oberhalb der Basis des Fig. 1 dargestellten Exemplares der L. digitata f. typica genommen ist. Hier sieht man 6-7 Schichtringe, die jedoch nicht ganz deutlich sind und theilweis in einander verschwinden. Fig. 6. welche den Querschnitt eines andern Exemplars derselben Form vorstellt, zeigt indessen 9 ganz deutliche und distincte Schichtringe, die ebenso scharf begrenzt sind, wie bei $L$. hyperborea. Der Schnitt Taf. 3, Fig. 2 von L. digitata f. valida zeigt 5 Schichtringe, während Fig. 6 derselben Tafel, - die auf der nördlichen Küste rorkommende Form von L. digitata f. stenophylla darstellend, nur 2-3 undeutliche Ringe aufweist. Dasselbe gilt von Fig. 10, die einem von Inderöen stammenden Exemplar einer zwischen $\mathrm{f}$. typica und f. stenophylla stehenden Mittelform angehört; die Ringe sind hier sehr unregelmässig und schwer nachweisbar, während sie in Fig. 11, obwohl dieselbe die gleiche Form aus der gleichen Gegend darstellt, durchaus distinct und scharf begrenzt auftreten. Auf Hvitingsö (etwa $9^{\circ}$ N.B.) fand ich Exemplare der f. stenophylla, (die in dieser Gegend in ausgeprägtesten Gestalt auftreten duirfte) mit 6 Schichtringen, obwohl der Stamm an seinem untern Ende nur einen Diameter von etwa $1 \mathrm{Cm}$. besass. ${ }^{2}$ Ungefähr dasselbe Verhalten, wie die Taf. 3, Fig. 6 dargestellte f. stenophylla

1 $„ . .$. . cependant, dans certains individus on remarque à la base du stipe un anneau colloré qui semble indiquer la présence de deux couches concentriques: j'indiquerai plus loin la cause probable de cette rare exception." l.c. p. 18. „2. . . . mais ces anneaux sont peu distincts en comparaison des couches concentriques si bien charactérisée de l'autre expèce. De plus, cette exception, lorsq'elle se présente, n'a pas lieu à une époque déterminée de l'anné et paraît purement accidentelle." 1 . c. p. 27.

2 Der Stamm ist bei dieser Form fast immer unten am dünnsten und erreicht nie bedeutendere Dicke. 
zeigt auch die f. ensifolia (Taf. 5, Fig. 3 u. 4). Fig. 3 ist ein $2 \mathrm{Cm}$. über der Basis genommener Schnitt mit einigen sehr undeutlichen und unsichern Ringen, während der, der Mitte des Stammes angehörige, Schnitt Fig. 4 drei ziemlich distincte Ringe unterscheiden lässt. Wahrscheinlich erlangt jedoch $\mathrm{f}$. ensifolia (und gleichfalls $\mathrm{f}$. crassifolia) nicht das gleiche Alter, wie die übrigen Formen, da man bei jenen nicht die Anzahl von Schichtringen findet, wie bei diesen. Dasselbe gilt von $L$. intermedia und L.nigripes.

Wenn die Schichtringe bei $L$. digitata, und überhaupt bei den ohne äussere Korticalschicht (Rindenschicht) auftretenden Arten häufig minder distinct sich zeigen, als bei L. hyperborea, so ist dies gewiss grade durch den Umstand bedingt, dass erstere einer solchen Rindenschicht ermangeIn, und dass ihre Korticalschicht im Ganzen weniger entwickelt und weniger scharf von der Zwischenschicht abgegrenzt ist. Am deutlichsten zeigt sich dieses Verhältniss bei $L$. intermedia und $L$. digitata f. ensifolia, bei welchen nicht allein die Korticalschicht an und für sich schwach ausgefallen ist, sondern auch die Abgrenzung derselben nach der Mittelschicht hin nur wenig hervortritt, während gleichzeitig die Anordnung der Zellen in der Zwischenschicht nicht die scharf ausgeprägten Serien der übrigen Formen der L. digitata zeigt. Dabei ist auch das Endochrom heller. In Uebereinstimmung mit dem eben gesagten steht es, dass man bei jüngeren Exemplaren von $L$. hyperborea, bei denen die Rindenschicht sich noch nicht entwickelt hat, weniger deutliche Schichtringe antrifft, obschon man bei dieser Alge bereits im jüngeren Alter eine schärfere Abgrenzung zwischen Kortical- und Zwischenschicht beobachten kann. Ebenso erkennt bei letzterwähnter Art, besonders bei älteren Pflanzen, bereits das unbewaffnete Auge die scharf ausgeprägten radialen Zellenreihen der Zwischenschicht. Eine ausführlichere Beschreibung, wie die Schichtringe sich bilden, findet man übrigens bei Ruprecht (Algenstämme p. 62). Dieselbe stimmt mit meiner Auffassung dieser Verhältnisse überein, und bestätigt die Richtigkeit der obigen Angaben ".

1 „Kützing zeichnet einen Querdurchschnitt rom Stamm der L. digitata (= L. hyperborea) mit 3 concentrischen Ringen. (Phyc. gen. t. 31, fig. 3). Es scheint nach 
Die Schichtringe der Laminarien haben bereits früh die Aufmerksamkeit der Forscher erregt. Die meisten Verfasser sind darin einig getresen, denselben eine gleiche Bedeutung beizulegen, wie die, welche den Jahrringen der dicotyledonen Banmgewächse zukommt, und somit dieselben in directe Beziehung zum Alter der Alge zu setzen. Eine Ausnahme bildet $\mathrm{Schultz},{ }^{1}$ der ausspricht, dass diese Ringe schon darum nicht einen jährlichen Zuwachs bezeichnen können, weil dieselben (nach seiner Anffassung) sich bereits im Lauf eines Sommers bei nur einjährigen Arten bilden. Ebenso behauptet $\mathrm{Hooker}$ von der holzartigen Lessonia fuscescens, dass ihre Schichtringe nicht einen regelmässigen jährlichen Zuwachs darstellen können. ${ }^{2} \mathrm{Zu}$ ungefähr dem gleichen Resultat ist auch Ruprecht gelangt. Er sagt (l. c. p. 64): „Wenn daher diese concentrischen Ringe auch wirklich einen periodischen Znwachs bezeichnen, und in manchen Fällen sogar einen jährlichen bedeuten mögen, so sieht man doch aus den mitgetheilten Beispielen, wie unsicher eine Alterbestimmung nach diesem Merkmale ist. So fand ich im untersten Theil eines bereits korkartigen, also gewiss schon alten Stammes von Thalassiophyllum bloss 2 concentrische Ringe. Ein Riesenexemplar der Laminaria digitata $(=L$. hyperborea) von der Eismeerknste des Russischen Lapplands musste, seinen gesammten Merkmalen nach,

dieser Darstellung, dass die Ringe durch eine verschiedene Form des Zellgewebes gedeutet werden sollen. Ich konnte mich davon an meinen bisher untersuchten Exemplaren nicht überzeugen; fand vielmehr, dass die meisten Zellen der Rinde bis über die grossen Höhlen (fig. c, c bei Kützing) mit einem braunen körnigen Inbalte und zuweilen ganz gefüllt sind, darauf nach innen die farblosere Schicht $d$ folgt und der concentrische, mit blossen Auge sichtbare Ring $d^{\prime}$ durch ein abermaliges Auftreten des obigen braunkörnigen Zellinhaltes bewirkt wird.

Ich wäre daher geneigt, anzunehmen, dass durch neue Zellenbildung in der Peripherie des Stammes die dem Rindensysteme zunächst liegenden Partien mit gefärbten Zellinhalte nach und nach mehr einwärts zu stehen kommen und diese concentrischen Ringe bilden, während die abwechslend zwischen den Ringen liegende periodische Neubildung aus (beinahe) farblosen Zellen besteht" l. c. p. $63-64$.

1 Sehichtenbildung p. 72 .

2 "The latter (concentric rings) are probably the indices of the number of times, that a subdirison of the lamina has occured, supposing that all split at about the same epoch, rather than a register of the years the vegetable has existed". Hook. Crypt. Bot. p. 153.

Vid.-Selsk. Forh. 1884. No. 14. 
ziemlich alt sein; doch unterschied ich bloss einen deutlichen Ring, obwohl das obere Stammstïck (das untere von unbekannter Länge fehlte) über 2 Fuss lang, 8 Linien dick und bereits fistulös war". Weiterhin heisst es: „Besieht man ältere Individuen von $L$. digitata (L. hyperborea), so ist es nicht schwer, sich zu überzeugen, dass der perennirende Stamm von der Markschichte aus abzusterben beginnt, indem ein röhrenförmiger Raum in der ganzen Länge desselben ensteht. Diese Röhre, von welcher in jungen Exemplaren keine Spur vorhanden ist, wird mit dem Alter immer bedeutender". Auch Lamouroux giebt an, alte Individuen mit ganz hohlem Stamm gesehen zu haben. ${ }^{1}$ - Was nun zunächst jene von Ruprecht und Lamouroux untersuchten und hohl oder fistulös gefundenen Exemplare betrifft, so will es mir höchst wahrscheinlich vorkommen, dass dies solche gewesen sind, die schon lange im Meere umhergetrieben und darum abgestorben waren. Unter den vielen hundert von mir im frischen Zustand untersuchten Exemplaren, (theils während sie noch festgewachsen am Boden hafteten, theils unmittelbar nachdem sie abgelöst und an den Strand ausgeworfen waren,) habe ich kein einziges mit einem hohlen oder fistulösen Stamme angetroffen; ja jede Andeutung dazu hat gefehlt, ausgenommen bei solchen Pflanzen, die längere Zeit auf den Wellen umhergeworfen waren oder am Ufer gelegen hatten. Sonst war im Gegentheil auch bei den allerältesten Exemplaren der Stamm durch und durch hart und holzartig, mit Ausnahme des oberen jüngeren Theils, dem noch die Rindenschicht fehlte. $^{2}$ Es ist daher leichtverständlich, dass Ruprecht an den

1 Essai p. 41.

2 In diesem Zusammenhang erlaube ich mir eine kleine Bemerkung zu Lindman's vorzüglicher Arbeit über das Treibholz Norwegens (Lindm. Drifved, Pag. 97). Er berichtet (nach andern Angaben) über das Vorkommen von Laminaria longicruris De la Pyl. an den Küsten von Norwegen und Bohuslehn, und nimmt an, dass diese Gewächse durch Meeresströmungen aus ihren ursprünglichen Heimathsgebieten angetrieben sein dürften. Es scheint mir aber nicht nur möglich, sondern eigentlich fast wahrscheinlich zu sein, dass wenigstens ein Theil dieser für L. longicruris gehaltenen Stämme der $L$. hyperborea angehören. Längs der westlichen, und besonders der nördlichen Küsten Norwegens werden unter den Herbst- und Winterstürmen grosse Mengen letzterer Alge losgerissen und ans Land geworfen. Haben sie hier eine Zeit lang gelegen, so beginnt die etwas losere Markschicht sich aufzulösen, und dieser Zersetzungsprocess schreitet dann allmählig weiter gegen die Peri- 
obenerwähnten alten Exemplaren nur einen einzigen Ring entdecken kcnnte, besonders da der untere (vielleicht grösste) Theil des Stammes fehlte. Die Verschiedenheit der Anzahl den Schichtringe in den rerschiedenen Theilen des Stammes hat bereits Schultz (l. c.) eingehend erörtert. Schultz (l. c. Taf. II, Fig. 1) sowohl als auch Le Jolis ${ }^{1}$ sind aber dabei doch der Meinung, dass die inneren Schichtringe in longitudinaler Richtung die grösste Ausdehnung haben. und die äusseren stufenweis kürzer werden. Soweit ich habe sehen können, ist indessen das wahre Verhältniss grade umgekehrt. Dem widerspricht auch nicht, dass die äussere, noch im Wachsthum begriffene Schicht nicht selten in kürzerer oder längerer Distanz yon der Basis aufhört. - Was aber nun die Bedeutung der Schichtringe betrifft, so bin ich mit Ruprecht vollständig einverstanden in der Anschauung, dass diese Gebilde ja Wohl im Allgemeinen eine periodische Zunalıme bezeichnen dürften, dass sie aber speciell bei der Gattung Laminaria kaum jemals einen jährlichen Zuwachs andeuten, sicher jedoch niemals im jüngeren Stadium der Entwickelung. In der letzten Zeit habe ich eine Reihe hier einschlagender Experimente begonnen, die aber leider noch nicht zum Abschluss gekommen sind. Kann ich aber auch

pherie vor, so dass der Stamm zum Schluss ganz hohl wird. Dabei schrumpft die äusserste Schicht, wenn sie auch am längsten sich hält, bedeutend zusammen. Trifft nun eine Springlluth ein, so führt sie einen Theil der verwesenden Stämme wieder in ihr ursprüngliches Element zurück, um sie später, vielleicht an einen weit entfernten Küstenpunkte, wieder ans Ufer auszuwerfen. Derartige Stämme zeigen aber eine auffallende Aehnlichkeit mit denen der $L$. longicruris, zumal wenn man es mit besonders verschrumpften und knorrigen Exemplaren zu thun hat, und die Rindenschicht abgescheuert worden ist. Unter solchen Imständen ist eine Verwechslung sehr leicht und ohne mikroskopische Untersuchung kaum sicher zu vermeiden.

Auf Jäderen, wo L. hyperborea (und andere Laminarien) als Dünger verwendet wird, habe ich grosse Mengen hohler, verschrumpfter Stämme dieser Art angetroffen, die wohl an ein Jahr auf den Feldern gelegen hatten, ohne dass die Aussenschicht noch zerstört gewesen wäre.

1 , Tne coupe longitudinale nous fait voir que chaque zône correspond à un verticille de racines; la zône la plus centrale se continue du verticille le plus inférieur jusq'au sommet du stipe, et la zône la plus extérieure, correspondant au verticille supérieur, s'évanouit à une faible distance de la base du stipe". Le Jol. 1. c. p. 15 . 
meine Behauptung noch nicht als erwiesene Thatsache hinstellen, so werde ich doch einige Gründe anführen, die für eine derartige Annahme sprechen; behalte mir aber vor, bei einer späteren Gelegenheit eine genügendere Darlegung dieser Verhältnisse zu geben. ${ }^{1}$

Bei Berlevaag in Ost-Finmarken fand ich im Sommer 1883 eine grosse Anzahl fast gleichgrosser auf den Strand ausgeworfener Exemplare von $L$. hyperborea, welche, nach ihrem Aussehen zu schliessen, kein besonders hohes Alter erreicht haben konnten, obwohl der Stamm eine durchschnittliche Länge von 1 M. und am Unterende einen Durchmesser von $2.5 \mathrm{Cm}$. nachwies. Alle besassen jedoch eine Rindenschicht, diese erstreckte sich aber nicht höher, als bis etwa zur Mitte des Stammes, und war durchgehends weniger rauh, als gewöhnlich und mit einer verhältnissmässig nur geringen Anzahl von Epiphyten (Rhodymenia) besetzt. Bei der Durchschneidung des unteren Stammes zeigte die Mehrzahl dieser Exemplare bei einer flüchtigen Untersuchung eine Anzahl von 4-5 ziemlich breiter Schichtringe; bei genauerer Untersuchumg eines Querschnittes von zweckmässiger Dicke liessen sich jedoch 8-10 Ringe unterscheiden; es lag nämlich zwischen je zwei jener breiteren Ringe stets noch ein sehr schmaler, theilweis kaum erkennbarer, vorher ïbersehener Ring. ${ }^{2}$ Bei einzelnen Exemplaren konnte man jedoch 10 fast gleiche, distincte Ringe unterscheiden. An einem Querschnitt des Taf. 1, Fig. 8 dargestellten Exemplars von L. hyperborea, (dessen Stamm am Unterende einen Diameter von $0.8 \mathrm{Cm}$.

1 Bei Alaria könnten dagegen die Schichtringe möglicherweisé einen Jahreszuwachs bezeichnen. Es sind dieselben bei dieser Art sehr scharf und hervortretend. Hier hat man ausserdem noch einen andern Anbalt zur Bestimmung des Alters der Pflanze in den am oberen Theil des Stammes (dem Rhachistheil) sich findenden Narben nach den älteren, bereits abgefallenen Sporophyllen.

Es war ursprünglich meine Absicht gleichzeitig mit der Laminaria, die norwegischen Formen der Alaria zu behandeln. Durch einen unglücklichen Umstand, der den Verlust einer sehr grossen und ausgezeichneten Sammlung von Alarien aus dem nördlichen Küstengebiet Norwegens veranlasste, bin ich für jetzt an der Ausführung dieses Vorhabens gehindert worden. Eine ausgezeichnete Bearbeitung ist übrigens den norw. Alaria-Fornen neuerdings zu Theil geworden durch F. R. Kjellman in seiner Norra Ishafvets Algflora.

2 Viel hängt hierbei $a b$ von der Dicke des Schnittes und einem gewissen Grad von Beleuchtung. 
besitzt und der Rindenschicht ermangelt), zeigen sich drei Ringe. Die beiden, der Markschicht zunächst liegenden, gehen ein wenig in einander über, der dritte ist aber ziemlich hervortretend und distinct. Ausserdem gewahrt man aber noch dicht an der Corticalschicht einen sehr schmalen und undeutlichen Ring. Ein entsprechendes Verhältniss zeigt der Durchschnitt des Taf. 3, Fig. 4 abgebildeten Exemplars von $L$. digitata f. valida, dessen Stamm die gleiche Dicke hat, und welches überhaupt ungefähr dieselben Dimensionen und, wahrscheinlich auch, dasselbe Alter besitzen dürfte, wie obiges jüngere Exemplar von $L$. hyperborea. Bei älteren Exemplaren der letztgenannten Art zeigen dagegen sämmtliche Ringe im Allgemeinen den gleichen Grad von Deutlichkeit, nur pflegen die der Markschicht zunächst gelegenen nicht ganz so distinct zu sein, wie die andern, und ab und zu findet man auch unter den letzteren ein paar in einander verschwimmende.

Um nun aber über das Alter jener oben besprochenen Laminarienstämme sich ein Urtheil zu bilden, dürfte folgenden Notiz einen Anhalt gewähren, die ich Herrn Ingenienr And. Bergh, Besitzer uud Leiter der Jodfabrik in Christiansund verdanke, der mir freundlich mitgetheilt hat, was er im Lauf von 12 Jahren über das Nachwachsen der Laminarien (fast ausschliesslich L. hyperhorea) in Erfahrung gebracht hat, von welcher Alge er grosse Mengen, ihrer Asche wegen, theils selbst hat einsammeln lassen, theils von den Banern der Nachbarschaft angekauft hat. Die Einsammlung geschieht meistens in der Weise, dass man mittelst einer, an einer langen Stange befestigten, Sichel die Exemplare möglichst nahe an der Wurzel abschneidet, wodurch an einzelnen Orten der Meeresboden zeitweilig fast ganz von Laminarien gesäubert werden kann. Nach der einstimmigen Aussage jener Bauern, mit denen auch Herrn Berghs Beobachtungen, so weit er sich ihrer entsinnen kann, aufs beste harmoniren, müssen nun aber $4-5$ Jahre verstreichen, ehe man auf derartigen abgeernteten Stellen wieder eine neue Ernte vornehmen kann, d. h. ehe dort wieder angeblich vollkommen ausgewachsene Exemplare anzutreffen sind. Die Höhe der letzteren beträgt dann etwa 1 M. - Können nun auch diese Angaben selbst- 
verständlich nicht als unbedingt zuverlässig gelten, so dürften sie doch ausreichen, um in Verbindung mit den obenangeführten Beispielen, die Ansicht zu unterstützen, ja wohl beinahe zu beweisen, nach welcher die Schichtringe jedenfalls nicht einen jährlichen, eher vielleicht einen halbjährlichen, Zuwachs andeuten sollen.

Noch einen andern Umstand möchte ich an dieser Stelle hervorheben, auf den bei dieser Frage Rücksicht genommen werden müsste. Unter den jungen Exemplaren von L. hyperborea und L. digitata trifft man beinahe zu allen Jahreszeiten verschiedene, die sich im Stadium des Blattwechsels befinden, während dies bekanntlich bei älteren, vollentwickelten Exemplaren nicht vorkommt. Taf. 6, Fig. 3 zeigt z. B. ein junges im Schluss des März gefundenes Exemplar der $L$. digitata f. ensifolia, bei welchen das neue Blatt beinahe voll entfaltet ist; auf Taf. 3, Fig. 4 sieht man ein Exemplar der f. valida, und auf Taf. 10 einige junge Exemplare der L. intermedia f. cucullata, sämmtliche im Schluss des August gesammelt, in verschiedenen, mehr oder weniger fortgeschrittenen Stadien dess Blattwechsels. Ich habe auch sonst im August verschiedene Exemplare von L. hyperborea gesammelt, welche im Blattwechsel begriffen waren, bei denen aber das neue Blatt noch nicht mehr als ein Drittel der Länge des alten Blatts erreicht hatte. Aeltere und vollentwickelte Exemplare haben dagegen in der Regel schon im Mai den Blattwechsel vollzogen, und nur ausnahmsweise findet man noch im Juni Exemplare mit einem alten Blatt an der Spitze des so gut wie vollentwickelten neuen. Dergleichen Beobachtungen regen die Frage an, ob die hier bezeichneten Arten nicht vielleicht im jüngeren Stadium mehrmals (zweimal?) im Jahre die Blatter wechseln könnten, und erst dann, wenn sie ihre volle Entwickelung erlangt haben, zum einmaligen jährlichen Blattwechsel übergehen, und ob ein solches Verhalten nicht auch den Umstand erklären könnte, dass bei älteren Exemplaren die innern Ringe gewöhnlich ziemlich undeutlich sind und häufig paarweise verschwimmen, während die äusseren Ringe (d. h. bei alten Exemplaren mit 3-5 Cm. dickem Stamm ungefähr die ganze, nach aussen gelegene, Hälfte der- 
selben) ${ }^{1}$ sich distinct und scharf begränzt zeigen. Letztere Hypothese scheint mir freilich selbst immerhin ziemlich dreist, da ja jener spät im Jahre sich vollziehende Blattwechsel auch wohl als eine Anomalie aufgefasst werden kann; doch aber habe ich nicht umhin gekonnt, hier auf diese Beziehungen aufmerksam zu machen.

\section{Das Blatt.}

Nan hat bereits lange gewusst, dass verschiedene Laminarien, zum mindesten $L$. hyperboren und $L$. saccharina, periodisch die Blätter wechseln, sowie dass dieser Blattwechsel, jedenfalls bei den vollentwickelten Exemplaren ein jährlicher ist und im Verlauf der 4-6 Wintermonate eintritt, d. h. durchgehends vom Schluss des Norember oder Anfang des December bis etwa gegen Ende des Mrai. Nur einzelne der älteren Verfasser sprechen einen Zweifel aus, ob wirklich alle Individuen der $L$. digitata auct. ein solches Verhalten zeigen. ${ }^{2}$

Im scharfem Gegensatz mit dieser Anschaumn stehen, nach dem in Anderson's Guide ïber dieselben erstatteten Bericht, Cloustons Beobachtungen. Derselbe hebt nämlich hervor, dass, während L. hyperborea jährlich das Blatt wechselt, ein derartiger Vorgang nie bei $L$. digitata beobachtet worden sei. ${ }^{3}$ Zum selben Resultat

1 Selbstrerständlich ist diese Angabe der Dicke nur relativ und gilt nur für Exemplare, die am offnen Veer oder überhaupt an solchen Orten wachsen, an welchen die Pflanze die bedeutendsten Dimensionen erreicht. An geschützten Fundorten trifft man dagegen nicht selten vollentwiekelte Exemplare, mit nur $1 \mathrm{Cm}$. Stammdicke.

2 ,Bedeukt man die umständliche Art und Weise, mit welcher solche Beobachtungen angestellt werden müssen, so wird man dem, in den wesentlichsten Stücken verschiedener Beobachter Uebereinstimmenden ein böheres Gewicht beilegen, als den einzelnen obenerwähnten Bedenklichkeiten über die Allgemeinheit dieses Vorganges (Grev. Alg. Brit. \&c.), und ist mit Turner berechtigt, diese eigenthümliche Regeneration für alle Individuen jährlich eintretend als Norm festzuhalten, ohne sich durch vielleicht einzeln vorkommende Anomalien beirren zu lassen". Rupr. 1. c. p. 61.

3 "But the great distinction in this part, and the one which makes this plant so valuable, is that the Cuvy ( $=L$. hyperborea) annually throws off the old leaf, and acquires a new one, while this has been never observed in the Tangle (= L. digitata $)^{\text {"s }}$ 1. c. p. 771 . 
gelangt Le Jolis, wenn ich anders seine Meinung richtig aufgefasst habe. ${ }^{1}$ Doch bemerkt derselbe auch, dass er bisweilen bei der fraglichen Art einen Vegetationszustand angetroffen habe, der sich in etwas dem bei $L$. hyperborea gewöhnlichen nähere, insofern sich im Blatte eine schwache Contraction zeigte, aber ohne dass sich irgend ein merkbarer Unterschied, sei es in der Farbe, sei es in der Consistenz, bemerken liess, der mit dem bei $L$. hyperborea beobachteten sich vergleichen liesse. ${ }^{2}$

In "Bidrag" habe ich nachgewiesen, dass es wenigstens eine Form von $L$. digitata giebt (nämlich $\mathrm{f}$. ensifolia), bei welcher der Blattwechsel sich im wesentlichen analog mit den bei $L$. hyperborea beobachteten Vorgangen vollzieht, und habe es zugleich als höchst wahrscheinlich bezeichnet, dass die übrigen Formen, ja überhaupt die nahestehenden Arten, ein gleiches Verhalten darbieten düıften. Bald darauf behauptete anch J. E. Areschoug (Obs. Phyc.) die Gleichartigkeit der Entwickelungsverhältnisse für alle L. digitataFormen. Gegen das Ende des letztverflossenen Februar habe ich bei Fredriksvär'n $L$. digitata f. typica mit dem nenen, ungefähr halbentwickelten Blatte angetroffen, und zwar war bei weit aus den meisten Exemplaren die Grenze zwischen beiden Blättern ziemlich scharf. Exemplare, welche ich später von Berlevaag in Finmarken, Lödingen in Nordland und Strömmen in Inderöen erhalten habe, lassen vollends keinen Zweifel mehr daran übrig, dass nicht allein die ron mir besprochene eine Form, sondern sämmtliche an der norwegischen Küste auftretende Formen, den bezeichneten Entwickelungsgang einhalten. ${ }^{3} \quad$ Nun ist aber noch zu unitersuchen, in

1 ,Sa fronde ( $L$. digitata) se developpe d'une manière continue et indefinie, et pour ce motif, peut atteindre de grands dimensions". Le Jol. l. c. p. 28.

2 "Cependant on trouve quelquefois dans le $L$. flexicaulis ( $L$. digitata) un état de végétation, qui le rapproche du $L$ Cloustoni (L. hyperboreu): alors un certain arrêt a eu lieu dans la crojssance de la plante, et un léger rétrécissement s'est manifesté dans une partie de la fronde; mais ce rétrécissement est toujours peu marqué, et à cet endroit la fronde ne présent pas de différences sensibles dans sa couleur, sa consistance ni son aspect, comme cela arrive au contraire de chaque côté de l'isthme qui sépare les deux frondes du $L$. Cloustoni ( $L$. hyperborea)". Le Jol. l. c. p. 27.

3 Ich habe ausserdem in Le Jol. Exsice (No. 151) ein Exemplar von L. digitat 
welcher Beziehung die hier berichteten Thatsachen zı jenem obenermähnten Ausspruche Cloustons stehen. Die Art, auf welche die Bemerkungen Cloustons sich zunächst beziehen und von ihm Tangle genannt wird, ist später von Edmondston als die eigentliche $L$. digitata (L.) angesehen und aufgestellt worden, während er die andere (L. hyperborea) als $L$. Cloustoni benannte. Die erstere wurde dann ron Harvey (Phyc. Brit.) als eine Form seiner L. digitata (= L. hyperborea), f. stenophylla, anfgestellt, aber von Le Jolis als besonders benannte Form, wieder eingezogen und seiner $\mathbf{L}$. flexicaulis zugezählt. Einige Zeit darnach hat J. G. Agardh (Lamin. p. 18) dieselbe als eigene Art aufgestellt, doch ohne sich hierbei anf die ron Clouston angegebene abweichende Entwickelungsart zu berufen. Kjellman (Ishafsfl. p. 300) lässt sie in der von Agardh angegebenen Begrenzung als eigene Art stehen, bezieht sich aber dabei zugleich auf $\mathrm{Cloustons}$ Bemerkungen ïber ihre abweichende Entwickelung, sowie anch anf Le Jolis' Vermuthung iiber das zweijährige Wachsthum derselben. Hierzı ist jedoch zu bemerken, - wie Kjellman selbst dies auch später berührt, dass die $L$. flexicantis Le Jol. nicht bloss die L. digitata Edm. oder f. stenophylla Harv. umfasst, wie ja denn letztere (s. o.) von Le Jolis nicht einmal als benannte Form beibehalten wird, sondern auch alle ïbrigen Formen, die skandinavischen (von denen Le Jolis Exemplare gehabt haben will) miteinbegriffen. Es bleibt uns somit nur noch zu entscheiden, inwiefern Cloustons Tangle oder f. stenophylla, wirklich identisch ist mit der $\mathrm{n}$ orwegischen f. stenophylla, wie dieselbe nach der Harveyschen Beschreibung aufgenommen ist. $^{1}$ Um uns von der Identität beider Formen zu ïberzengen, scheint mir aber bereits Cloustons Beschreibung allein zu genïgen. Zieht man aber noch die von Harvey gelieferte nachträgliche Beschreibung und die in der Phyc. Brit. gegebene Abbildung mit in Betracht, so dürfte jeder Zweifel schwinden. Zum selben Resultat ist übrigens auch J. G. Agardh gekommen, da er, wie

(L. Alesicaulis) mit Resten des alten Blattes gesehen, ebenso in Hohenack. Alg. sice. (No. 27).

1 Pbyc. Brit. t. 338. 
ich mich davon im Herbarium des Reichsmuseums in Stockholm selbst habe überzeugen können, norwegische Exemplare unter diese Form einordnet. Damit aber dürfte es wohl auch zur Entscheidung gebracht sein, dass dje Cloustonschen Beobachtungen auf einer verkehrten Auffassung des Verhältnisses beruhen müssen. Dass eine solche leicht möglich ist, lässt sich nicht läugnen. Eine Menge meiner aus Lödingen und Berlevaag stammenden Exemplare von f. ensifolia und f. typica (an welche die f. stenophylla sich in manchen Beziehungen nahe anschliesst) zeigen die Grenze zwischen dem alten und nenen Blatt nur sehr undeutlich, so dass beide, bei nicht ganz genauer Betrachtung, leicht als dasselbe Blatt anfgefasst werden können, da die Contraction nur schwach, wenn auch immerhin nachweisbar ist. Letztere hat, meiner Meinung nach, Clouston übersehen und deshalb das Blatt seines Tangle im besprochenen Entwickelungsstadium als ein zuzammenhängendes Ganze angesehen, während dasselbe in Wirklichkeit aus dem sich bildenden neuen Blatt und dem sich aufösenden alten zusammengesetzt ist. In den Wintermonaten, in welchen der Blattwechsel vor sich geht, habe ich freilich die eigentliche f. stenophylla noch nicht beobachten können; aber früh im Sommer habe ich auch von ihr bei Hvitingsö Exemplare gefunden, die noch Reste des alten Blatt an sich trugen.

In gewissen Beziehungen scheint jedoch der Process des Blattwechsels bei unsern beiden Arten ( $L$. hyperborea und $L$. digitata) einige Verschiedenheit darzubieten. Während nämlich bei der $L$. hypcrborea das alte Blatt in den allermeisten Fällen seine Form und Grösse bis zur Vollentwickelung des neuen Blattes behält (vergl. Taf. 1, Fig. 1), zeigt die $L$. digitata dagegen recht häufig ein anders Verhalten. Sobald nämlich das neue Blatt in seiner Entwickelung soweit fortgeschritten ist, dass es die Länge des Basistheils des alten Blattes erreicht hat, pflegt letzteres (d. a. Blatt) sich immer weiter nach unten hin $\mathrm{zu}$ theilen, bis auch seine ursprünglich ungetheilte Basispartie sich in meist ebenso viel Zipfel zerspalten hat, als solche an der entsprechenden oberen Partie zu zählen sind (Taf. 4, Fig. 1, wo g. die Grenze bezeichnet). Mit dem Fortgang der Entwickelung schreitet nun auch die abwärtsgehende Theilung 
immer weiter fort, in der Weise, dass auch das neue Blatt allmählich in dieselbe hineingezogen wird, so dass es, ehe es noch seine halbe Grösse erlangt hat, doch dieselbe Zipfelanzahl zeigt, wie das alte Blatt, wobei aber denn auch jeder neugebildete Zipfel an seiner Spitze einen alten Zipfelrest trägt. Oft verbleibt indessen auch die Basispartie unversehrt, bis das neue Blatt ungefähr die Hälfte seiner Entwickelung erreicht hat. In solchem Falle beginnt die Theilung in der Mitte des neuen Blattes (ganz wie bei L. hyperborea) und setzt sich von dort aus nach beiden Richtungen hin fort, abwärts nach der eigenen Basis hin, und aufwärts der Basispartie des alten Blattes entgegen, in welchem Punkte die Spaltung dann schliesslich mit der Spaltung des alten Blattes zusammenfällt (Taf. 5, Fig. 1). Hierbei ist jedoch zu bemerken, dass das neue Blatt nicht immer in die gleiche Anzahl von Zipfeln zerfällt, die das alte aufweist; oft bleiben mehrere neugebildete Zipfel immer noch mit einem entsprechenden unzerspaltenen Theil der alten Blattbasis längere Zeit hindurch verbunden, bis endlich das neue Blatt seine vollkommene Entwickelung erreicht hat. In solchen Falle nähert sich also unsre Art wieder dem Verhalten, das bei $L$. hyperborea als Regel gilt. Eine andere Entwickelungsform, welche nochmehr der bei $L$. hyperborea bekannten sich nähert, zeigt Taf. 5, Fig. 2 ; und auf Taf. 3 zeigt Fig. 4 (f. valida) einen der $L$. hyperborea vollständig analogen Fall. Bei $L$. intermedia f. cucullata und f. ovata ist die Grenze zwischen dem alten und dem neuen Blatt sehr scharf und die Contraction ungefähr ebenso deutlich, wie bei $L$. saccharina. ${ }^{1}$ Ich selbst habe die beiden letzten Formen (sowie auch die f. longipes) nur im Sommer gefunden; - einige junge im August und September gesammelte, noch im Blattwechsel begriffne, Exemplare findet man auf Taf. 10, - dagegen enthalten die Herbarien, sowohl des Prof. J. E. Areschoug, als des Stockholmer Reichsmuseums, zahlreiche Exemplare in allen Stadien des

1 Wunderbarer Weise sollen auch diese beiden Formen ( $=$ f. latifolia Areseh.) sich nach Le Jolis in Bezug anf den Blattwechsel ebenso verhalten, wie $L$. digitata oder seine $L$. flexicaulis, unter welche er dieselben einordnet. Cfr. dresch. Obs. Phyc. p. 10. 
Blattwechsels, und es zeigen dieselben bezüglich dieselben Unterschiede zwischen alt und neu in Bezug auf Contraction, Farbe und Consistenz, wie $L$. saccharina.

Diese Unregelmässigkeiten im Blattwechsel der $L$. digitata dürften theilweis auf die localen Verhältnisse zurückzuführen sein. Ich habe freilich keine besonders grosse Anzahl im Blattwechsel begriffener Pflanzen gesehen, und nur ein einziges Mal unsre Art an Ort und Stelle in diesem Stadium untersucht, und darf mich daher nur mit einiger Vorsicht aussprechen; zieht man aber in Betracht, dass die Consistenz der $L$. digitata, im Vergleich mit L. hyperborea, durchgehends eine losere, weniger lederartige, ist, so liegt, besonders wenn die Pflanze an ausgesetzen Orten wächst, die Annahme nahe, dass nicht nur die frïhe Spaltung des neuen Blattes, sondern wohl auch die Spaltung der Basis des alten, auf rein äusseren Umständen beruhen kann. ${ }^{1}$ So fand ich bei sämmtlichen Exemplaren, die ich bei Fredriksvärn sammelte, - d. h. an einem Ort, wo die Pflanze der Brendung nur wenig ausgesetzt war, - die Grenze zwischen beiden Blättern, wie schon beinerkt, ungefähr ebenso scharf, und die Contraction ebenso stark, wie bei $L$. hyperborea, während dagegen Exemplare, die an ungewöhnlich stark exponirten Orten, z. B. Berlevaag, gewachsen waren, die grösste Abweichung zeigten. ${ }^{2}-$

1 Auch bei Phyllaria lässt sich etwas ähnlicbes bemerken. Obwohl dieselbe normaler Weise ein ungetheiltes Blatt besitzt, sieht man doch letzteres oft bis zur Basis herab gespalten, wenn die Pflanze dem brandenden Meere ausgesetzt gewesen ist. (Vergl. Farl. Alg. Un. St. p. 395).

2 Bei dieser Gelegenheit möchte ich auch auf die Zerspaltung des'Stammes aufmerksam machen, welche bisweilen bei $L$. digitata und $L$. saccharina vorkommt. $M$ an findet, zumal bei älteren Autoren, nicht selten derartige Exemplare mit gespaltenem Stamm und dem entsprechenden, doppelten Blatte als eine besondere Art, oder wenigstens Form, dargestellt. - In Finmarken habe ich mehrfach Exemplare (zumal jüngere) von $L$. digitata und $L$. saccharina gefunden, bei welchen der Stamm mehr oder weniger gespalten war, und jeder Theil sein besonderes Blatt trug; diese Theilung war aber keine natürliche, sondern durch zufällige äussere Umstände veranlasst. Dem ungeachtet können derartige Exemplare immer noch lebensfähig sein und in ihrer Entwickelung fortfahren. Dabei nehmen die beiden Blätter, die unmittelbar nach der Spaltung deutlich als Bruchstücke zu erkennen waren, allmähljch die Gestalt an, welche das unversehrte Blatt vor der Spaltung besass, d. h. die normale Blattform der Art, erreichen aber nie eine bedeutende Grösse. Bei $L$. hyperborea habe ich ziem- 
Der Unterschied der beiden einander ablösenden Blätter in Farbe, Dicke und Consistenz ist bei $L$. digitata freilich auch nicht so hervortretenden, wie bei L. hyperborea, - während $L$. intermedia in diesem Punkte sich ungefähr ebenso, wie $L$. saccharina, verhält; doch ist auch in diesem Stïcke einige Unregelmässigkeit $\mathrm{zu}$ bemerken. Ich besitzte mehrere Exemplare, bei welchen das alte Blatt in demselben Grade vom neuen absticht, wie bei L. hyperborea (vergl. Taf. 3, Fig. 4); aber auch andere, bei welchen der Unterschied, entwedel nach Farbe oder nach Dicke, nur unbeträchtlich ist. Bei Fig. 2 auf Taf. 5 ist z. B., wie man sieht, der Unterschied der Farbe ziemlich ausgeprägt, während die Dicke beider Blätter ungefähr die gleiche ist. Bei Fig. 1 derselbe Tafel, wie auch bei Fig. 1 auf Tafel 5, dagegen zeigt sich der Färbungsunterschied geringer, während in Bezug auf Consistenz und Dicke eine bedeutende Abweichung sich geltend macht, wie dies besonders hervortritt, wenn man Fig 3 und 4 auf Taf. 4 zusammenhält. Fig. 3 vergegenwärtigt einen Theil der Dicke des neuen Blattheils, Fig. 4 den entsprechenden des alten Blattes. Bedenkt man dabei noch, dass die Basispartie des Blattes immer dicker ist, als die Blattmitte, so wird man einsehen, dass hier ein recht beträchtlicher Unterschied stattfindet.

Die Auflösung des alten Blattes der $L$. digitata scheint in der Regel von der Spitze anzufangen und allmählig fortzuschreiten, so dass dasselbe, wenn das neue Blatt beinahe seine volle Entwickelung erreicht hat, nur noch einen Brüchtheil seiner ursprünglichen Länge besitzt (Vergl. Taf 5, Fig. 2 und Taf. 6, Fig. 3). Dasselbe zeigt sich auch oft bei $L$. intermedia $f$. cucullata und $f$. ovata, wie auch bei $L$. saccharina. Auch bei $L$. hyperborea lassen sich zweifelsohne nicht grade selten Fälle nachweisen, welche dem eben geschilderten, wie es scheint, normalen Verhalten der $L$. digitata ana$\log$ sind; in der Regel aber trifft man bei ersterer das alte Blatt noch ganz und unversehrt, oder doch nur wenig destruirt. So habe

lich oft Stämme von 1-1.5 M. Höhe angetroffen, die ein ungetheiltes Blatt von ca. $5 \mathrm{Cm}$. trugen. Letzteres hatte sich offenbar entwickelt, nachdem das ursprüngliche Blatt durch irgendwelchen Umstand abgerissen war. 
ich Exemplare gesehen, deren altes Blatt immer noch seine volle uivveränderte Grösse besass, obwohl das neue so gut wie vollständig entwickelt war und nur durch einen einzelnen Zipfel mit der Basispartie des alten in Verbindung stand."

Bei $L$. hyperborea zeigt das Blatt schon in einem sehr jungen Alter recht ausgeprägt die Blattform der vollentwickelten Exemplare. Dasselbe gilt, soweit meine Beobachtungen reichen, nur bezüglich eines etwas späteren Alters, auch von L. digitata f. valida, sowie von f. debilipes, und, mit einiger Einschränkung, von $L$. intermedia. Dagegen ist dies nicht mehr der Fall bei $L$. digitata f. typica und f. ensifolia, welche beide, und zumal die letztere, im Zustand voller Entwickelung eine herzförmige Basis haben, während dieselben im früheren Stadium, auch in nicht ganz jungem Alter, ziemlich abweichende Formen aufweisen. Taf. 6, Fig. 6-9 zeigen verschiedene junge Exemplare von f. ensifolia. Sie besitzen alle ein, im Verhältniss zur Breite, langes Blatt, und die Basis desselben ist, auch in einem noch weiter fortgeschrittenen Alter, keilförmig. Von einer gewissen Altersstufe an nimmt die Breite des Blattes sehr bedeutend zu, und lange, ehe das letzere seine volle Entwickelung erreicht hat, zeigt sich dasselbe schon ziemlich breit im Verhältniss zu seiner Länge. Ausnahmsweise findet man aber auch ältere Exemplare mit einer sich der Keilform nähernden Basis. Auch während des Blattwechsels macht sich dasselbe Verhältniss noch manchmal geltend, insofern man Exemplare findet, deren junges Blatt eine keilförmige Basis hat und dieselbe bis zu seiner vollständigen Entwickelung bewahrt; in der Regel tritt jedoch, unmittelbar zuvor, ehe das Blatt seine volle Länge erreicht, ein schnelles Wachsthum desselben in die Breite ein (Taf. 5, Fig. 2). - Auf Taf. 4, Fig. 5 sieht man ein junges Exemplar von $L$.

1 Auch bei Alaria findet man im Herbste bisweilen Reste des Blattes, die noch am Stamme festsitzen, und im Winter sogar noch dergleichen an der Spitze des neuentwickelten Blattes, obgleich das normale Verhälten bei dieser Art darin besteht, dass dieselbe ihr Blatt bereits im Anfang des Herbstes abwirft, (die Destruction desselben beginnt oft bereits früh im Sommer), wo dann der Stamm mit seinen Sporophyllen, bis in den Februar, nackt zurück bleibt, um welche Zeit das neue Blatt sich zu entwickeln beginnt. 
digitata f. typica. Seine Gestalt ist ungefähr dieselbe, wie bei einer jungen f. ensifolia; es ist jedoch gewöhnlich am oberen Ende weniger zugespitzt, als bei jener, und ebenso sind die Blattzipfel, wenn das Blatt sich zu theilen angefangen hat, nicht so stark gebogen, wie dort

Folgende Tabelle zeigt das Verhältniss bei einigen jüngeren Exemplaren ron f. ensifotia.

\begin{tabular}{|c|c|c|c|c|c|c|c|}
\hline \multirow{2}{*}{$\begin{array}{l}\text { Stamm- } \\
\text { İänge. }\end{array}$} & \multicolumn{2}{|c|}{$\begin{array}{c}\text { Des neuen } \\
\text { Blattes }\end{array}$} & \multirow{2}{*}{$\begin{array}{c}\text { Breite } \\
\text { der } \\
\text { Contrac- } \\
\text { tion. }\end{array}$} & \multicolumn{2}{|c|}{$\begin{array}{c}\text { Des alten } \\
\text { Blattes }\end{array}$} & \multicolumn{2}{|c|}{ Basisform des Blattes bei } \\
\hline & Länge. & Breite. & & Länge. & $\mid$ Breite. $^{1} \mid$ & neuen. & alten. \\
\hline 34 & 7 & 3 & 2.5 & 42 & 9 & keilförmig & herzförmig \\
\hline 19 & 10 & 2.5 & 2 & $2 \check{3}$ & 3 & ' & keilförmig \\
\hline 32 & 20 & 4.5 & 2.7 & 42 & 6 & $"$ & $"$ \\
\hline 31 & 12 & 9 & 5.5 & 30 & 16 & $\eta$ & herzförmig \\
\hline 40 & 16 & 19 & 8 & 16 & 15 & herzförmig & $\eta$ \\
\hline 28 & 17 & 7 & 6 & 33 & 22 & keilförmig & $"$ \\
\hline 42 & 30 & 8 & $3 . \overline{5}$ & 40 & 10 & $"$ & $"$ \\
\hline 14 & 17 & 5 & 3 & 36 & 18 & $\eta$ & " \\
\hline
\end{tabular}

Le Jolis giebt an, dass die Schleimlacunen (lacunæ muciferæ) im Blatte der $L$. digitata (seiner $L$. flexicaulis und daher auch $L$. intermedia mitinbegriffen) nicht so hervortretend sein sollen, wie bei $L$. hyperborea; auch sollen die Zwischenräume zwischen denselben weniger regelmässig und die Lacunen nicht von einer Reihe kleiner Zellen umgeben sein. ${ }^{2}$ - Auch in dieser Beziehung habe

1 Oder Summe der Zipfelbreite. Alles $\mathrm{Cm}$.

2 "Les canaux mucifères, qui manquent complètement dans le stipe de cette espèce ( $L$. digitata), se retrouvent dans la fronde comme dans celle du L. Cloustoni ( $L$. hyperborea); mais ils sont moins apparants que dans cetee dernière, moins régulièrement espacés et disposés par groupes ou séries an dessous de l'epiderme; ils y sont moins apparents que dans cette dernière, moin régulièrement espacés, et disposés par groupes ou séries audessous de l'épiderm; ils sont à peu près de même grandeur que les cellules du tissu environnant, et ne sont pas entourés d'un rang de petites cellules colorées." l. c. p. 20. 
ich den Unterschied nicht so gross gefunden, als er nach dem obigen sein sollte. Während ich bei einzelnen Exemplaren von $L$. hyperborea in beiden Zwischenschichten des Blattes eine sehr grosse Anzahl von Lacunen gefunden habe, die durch Intervalle von 50-100 $\mu$ von einander getrennt waren, habe ich wieder bei andern Exemplaren nur eine sehr geringe Anzahl von Lacumen entdecken können, und zwar lagen dieselben fast ausschliesslich auf derselben Seite, und fehlten beinahe ganz auf der andern; ausserdem konnte der Abstand von der Epidermis ein recht beträchtlicher sein (Taf. 1, Fig. 6). Durchgehends findet man die Lacunen jedoch ganz von Zellen umsäumt, welche sich in Bezug auf Gestalt und Grösse bedeutend von den iibrigen Zellen der Zwischschicht unterscheiden. Taf. 1, Fig. 4 u. 5 zeigen die betreffenden Verhältnisse in neuen und alten Blatt unserer Art. - Bei einzelnen Formen der $L$. digitata und bei $L$. intermedia trifft man jedoch häufig ebenso zahlreiche und ebenso grosse Lacunen, als bei L. hyperborea; nicht selten fehlt jedoch die Reihe von kleinen Zellen. Der Schnitt Taf. 10, Fig 18 zeigt eine Lacune, welche beinahe ganz, und eine andere, welche halb von derartigen Zellen umgeben ist. Viel hängt hierbei natïrlich vom Alter- und Entwickelungsstadium des Individuums ab (vergl. Taf. 1, Fig. 4 und 5). An exponirten Fundorten scheinen die Lacunen in der Regel kleiner und weniger zahlreich zil werden, als an geschützten.

Die Lacunen im Blatt der L. digitata können oft ganz fehlen. Man trifft dieselben z. B. entweder gar nicht, oder doch nur höchst selten, bei den norwegischen Exemplaren der f.valida (Taf. 3, Fig. 3), der f. stenophylla (Taf. 3, Fig. 7), und ebenso nicht bei der f. typica, wenn dieselbe an ausgesetzten Orten wächst (Taf. 4, Fig. 3 u. 4). Bei f. debilipes scheinen sie dagegen immer aufzutreten, während sie bei f. ensifolia bald sich zeigen, bald fehlen. Taf. 5, Fig. 2 zeigt uns ein gegen Ende März gesammeltes Exemplar mit Lacunen (Fig. 5), sowohl im nenen, als im alten Blatt; es sind aber dieselben sehr sparsam und zerstreut, und fehlen grösstentheils auf der einen Seite. Taf. 6, Fig. 1 stellt ein anderes Exemplar derselben Art dar, das in derselben Gegend gegen Ende November 
gefunden wurde. Hier sieht man keine Lacunen (Fig. 2); und dasselbe ist der Fall mit dem weitaus grössten Theil der in den Sommermonaten gesammelten Exemplare. Bei den aus Bohuslehn in Schweden stammenden Exemplaren, die ich zu untersuchen Gelegenheit hatte, habe ich immer Schleimlacunen im Blatte gefunden. $\mathrm{Ob}$ diese Exemplare aber vielleicht ausschliesslich der f. ensifolia (oder vielleicht auch der f. typica) angehört haben können, muss ich unentschieden lassen. Ebenso fand ich Lacunen an einem von Le Jolis bei Cherbourg gefundenen Exemplar, welches die Aufschrift L. flexicaulis Le Jol. trug, und der f. stenophylla angehören dürfte (oder derselben wenigstens sehr nahe steht); dagegen bemerkte ich keine derartigen Lacunen an dem von den Gebrüdern Crouan in den Alg. mar. Finist. unter No. 84 ausgetheilten Exemplar seiner $L$. brevipes, welches wohl am wahrscheinlichsten der f. ensifolia beizuzählen ist.

Ich habe oben bereits ausgesprochen, dass ich nur eine kleinere Anzahl fructificirender Exemplare, und zwar nur von einzelnen Formen, zu Gesicht bekommen habe. Was ich über diese Verhältnisse sagen könnte, wäre deshalb zu unsicher, um hier eine Stelle $\mathrm{zu}$ verdienen. Das Reproductionsverhältniss der Laminarien ist überhaupt ein im Ganzen sehr wenig gekanntes Gebiet. Wollte jemand sich die Aufgabe stellen, das hier herschende Dunkel aufzuhellen, so wäre dies eine ebenso verdienstvolle, als schwierige Arbeit. Gilt es schon von den Meeresalgen im Allgemeinen, dass es mit vielen Schwierigkeiten verbunden ist, denselben in ihrer Entwickelung zu folgen, so ist dies in noch höheren Grade bei den Laminarien zutreffend, da letztere nicht allein in einer Tiefe wachsen, aus welcher sie in der Regel bloss vermittelst des Schleppnetzes oder anderer Geräthschaften ans Licht gebracht werden, sondern auch, wegen ihrer kräftig entwickelten Haftorgane, sogar bei Anwendung der besten Instrumente, fast kaum ohne bedeutendere Verstümmelung in die Hände des Sammlers kommen. An der westlichen, und besonders an der nördlichen, norwegischen Küste stellen sich die Verhältnisse jedoch in dieser Beziehung etwas günstiger. Bekanntlich wird hier durch die täglich eintretende Ebbe 
ein Theil des Meeresbodens bis zu einer Tiefe von ungefähr $2 \mathrm{Me}-$ tern $^{1}$ dem Auge bloss gelegt, und dieser Theil des Meeresbodens (die litorale Region) beherbergt einen ganz erstaunlichen Reichthum an Algen, unter welchen die Laminarien an manchen Orten sogar einen hervortretenden Platz einnehmen. Doch trifft man nie, oder doch nur äusserst selten, und jedenfalls nur durch sehr kleine Individuen vertreten, die grösseren Arten und Formen, wie $L$. hyperborea, $L$. digitata f. typica und f. valida, wohl aber die f. ensifolia und kleine Repräsentanten der f. stenophylla. Letztere beide würden sich also doch, auch in Bezug auf ihre Entwickelung, hier studiren und verfolgen lassen.

Es ist ja gewiss, in mancher Beziehung, nur ein Umstand von ziemlich untergeordneter Bedeutung, ob man einer bestimmten Art diesen oder jenen der früher vorgeschlagenen Namen beilegt, doch ist man darüber einig gewesen, das Prioritätsrecht möglichst zu wahren. Schon aus diesem Grunde scheint es mir nicht besonders berechtigt, dass $\mathrm{L}$ e $\mathrm{J}$ ol is den Linnéschen Namen (Laminaria) digitata ganz verwirft. Wenn er aber als Motiv für dieses Vorfahren angiebt, einmal dass Linnés Beschreibung seines Fucus digitatus an grosser Unbestimmtheit leide, und ferner, dass auch die anderen Verfasser, mit Ausnahme von Clouston, entweder zwei wohl geschiedene Arten unter dieser Benennung zusammengeworfen haben, oder nur die eine dieser Arten beschrieben haben, (dadurch ja aber auch wieder die Vermuthung erwecken, dass sie ebenfalls die andere Art mit jener vereiniger wollen,) so kamn ich diese seine Ausführung, zumal was den letzten Punkt betrifft, noch weniger für voll beweisend anerkennen. - Im „Bidrag““ hatte ich den Vorschlag gemacht, den Linnéschen Namen L. digitata der in diesem Aufsatz als L. hyperborea ( $L$. Cloustoni) bezeichneten

1 Zur Zeit der Springfluthen und unter gewissen Windverhältnissen kann jedoch diese Zahl auf das doppelte steigen. 
Art beizulegen, und die andere als $L$. flexicaulis $^{1} \mathrm{zu}$ benennen. Besonders nach den von Linn é2 citirten Synonymen schien es mir nänlich am wahrscheinlichsten, dass erstere Art seiner Beschreibung zu Grunde gelegen habe. Wie die beiden letzten Synonyme ${ }^{3}$ zu verstehen sind, bleibt freilich ziemlich unsicher; dagegen lassen die beiden ersten: Fucus hyperboreus Gunn. Fl. Norv. I, p. 34 und Fucus scoparius Ström, Söndm. I, p. 92, keinen Zweifel mehr übrig in Bezug auf die Art, an welche wenigsten die beiden Forscher gedacht haben, welche jene Namen aufstellten. Dass aber auch Linné wahrscheinlich diese Art gemeint hat, ergiebt sich daraus, dass el dieselbe in seine Fl. Svec. nicht aufgenommen hat. ${ }^{4}$ - Hiergegen hat aber Kjellman ${ }^{5}$ die Einwendung gemacht, dass für ein so gewaltsames Vorgehen (wodurch ich nicht bloss den Namen $L$. Cloustoni mit $L$. digitata vertausche, sondern ausserdem noch die Pflanze, welche von den späteren skandinavischen Algologen J. G. Agardh, J. E. Areschoug u. s. w. - L. digitata genannt worden ist, zu einer L. flexicaulis umtaufe,) der Umstand kaum als genügende Rechtfertigung geltend gemacht werden könne, dass ältere Verfasser unter diesem Namen ( $L$. digitata) wirklich die L. Cloustoni Edm, Le Jol. (=L. hyperborea) beschrieben und angefiihrt haben, und in Verbindung damit die Befürchtung ausgesprochen, es werde ein derartiger Namenwechsel nur zu einer um so grösseren Verwirrung in der Nomenclatur Anlass geben. ${ }^{6}$ Diese Einwendungen kann ich jedoch um so viel weniger für berechtigt anerkennen, als grade die beiden ebengenannten skandinavischen

1 Es ist zu beachten, dass $L$. flexicaulis in der von Le Jolis gegebenen Begren* zung auch $L$. intermedia miteinbefasst.

2 . Iant. p. 134.

3 Bauhin. Pirax p. 364 und Raj. Synopsis p. 46.

$\$$ L. hyperborea ist in späterer Zeit freilich auch an der schwedischen Kiste (Bohuslen) gefunden, soll aber seltener sein, und nur in etwas grösserer Ticfe rorkommen.

5 1. c. p. 400 .

?. Ausserdem bemerkt Kjellman, dass L. digitala (L. flexicaulis) die gewöhnlichere sei; dies trifft aber nur zu an der schwedischen und an der südostlichen Küste Norwegens, so wie in den Fjorden, während an der West- und Nordküste $L$. hyperborea gewiss alle andern Laminarienarten an Zahl der Individuen über. wiegen wird. 
Algologen in ihren Beschreibungen (Areschoug, Phyc. Scand. p. 122; J. G. Agardh, Spec. Alg. I, p. 134) beide hier in Frage kommende Arten vereinigen, und Areschoug ausserdem in einem neulich erschienenen Werk (Obs. Phyc.) sogar soweit geht, dass er, in Einklang mit Le Jolis, den Linnéschen Namen L. digitata ganz abschaffen will, während J. G. Agardh in Lamin. (p. 24) unter dem Namen $L$. digitata die $L$. hyperborea ( $L$. Cloustoni) beschreibt, aber dabei doch die unzweifelhaft zu der andern Art gehörige Form, f. ensifolia Kütz., unter diesem Namen miteinbefasst; ebenso stellt der letztere noch eine neue Form auf, die f. integrifolia, welche zweifelsohne mit der f. latifolia Aresch. $(=L$. intermedia) identisch ist. ${ }^{1}$ - Wenn ich indessen mit $\mathrm{Kjellman}$ die Benennung $L$. digitata (L.) Edm. für die früher von mir $L$. flexicaulis (Le J ol.) genannte Art aufnehme und beizubehalten gedenke, so geschieht dies, weil ich es, wie bereits bemerkt, nur für eine Frage von untergeordneter Bedeutung ansehe, welcher von beiden Arten man den Linnéschen Namen beilegt, und weil dieser Name ganz in der Bedeutung beibehalten werden kann, die ihm von Edmondston beigelegt ist. ${ }^{2}$

Nach den für die Namengebung festgesetzten Regeln muss es gleichfalls als voll berechtigt angesehen werden einen Namen wieder aufzufrischen, der bereits zu Linnés Zeiten, sogar vor dem Erscheinen seiner Mantissa, derselben Pflanze beigelegt war, welche später von Edmondston und Le Jolis L. Cloustoni genannt wurde, nämlich den Namen $L$. hyperborea (Gunn.) ${ }^{3}$. Im „Bidrag“ habe ich nachgewiesen, dass diese Art identisch ist mit L. Cloustoni, und nach nochmaliger, gründlicher Prüfung der umsichtigen Characteristik unsrer Art, wie sie von Gunnerus gegeben wird,

1 Cfr. Kjellm. Spetsb. Thalloph. II, p. 26.

2 Denselben in der von Lamouroux (Essai p. 42) gegebenen Begrenzung beizubehalten, kann ich nicht für zweckmässig ansehen, da die dortige Beschreibung fast ganz auf $L$. hyperborea (L. Cloustoni) passt. Vergl. Le Jol. l.c. p. 41.

3 Ström (Söndm. I, p. 92) hat freilich einige Jahr zuvor eine Beschreibung dieser Art unter den Namen Fucus scoparius gegeben, auf welche auch Gunnerus an ein paar Stellen verweist, aber theils ist dieser Name nach Bauhinus angenommen, theils ist Strö ms vollständigere Beschreibung der Art (Beskr. p. 250) von einem späteren Datum, als Gunnerus' umfassende Arbeit. 
muss ich es als über allen Zweifel erhoben ansehen, dass seine Beschreibung der genannten Art gilt. Auch habe ich neulich unter den Resten seines Herbariums das Blatt des Originalexemplars vorgefunden, welches der Abbildung in Fl. Norv. I, t. 3 zu Grunde liegt, und dieses Blatt gehört einer L. Cloustoni. Es findet sich noch ein anderes Blatt mit der Aufschrift Fucus hyperboreus, welches derselben Art angehört, während die paar Exemplare von $L$. digitata ( $L$. flexicaulis), welche noch vorliegen, die Aufschrift Fucus bifurcatus tragen. Darnach darf es wohl als völlig erwiesen angesehen werden, nicht nur dass Gunnerus unter seinem Fucus hyperboreus nichts anders verstanden hat, als allein die $L$. Cloustoni, sondern alch, dass derselbe den Unterschied zwischen den beiden wohl geschiedenen Arten bereits richtig erkannt hat. Sollte er aber auch einzelne Exemplare der L. digitata zu diesem seinem Fucus hyperboreus mit dazu gerechnet haben, - wofür indessen kein Beweis vorliegt, - so könnte doch auch ein solcher Irrthum keinen hinreichenden Grund für die Verwerfung des von ihm eingefiihrten Namens abgeben, der einer klar und ausgeprägten Art entspricht, und nach dem Prioritätsrecht den Vorrang beanspruchen darf.

Aber auch abgesehen von dem eben ausgeführten, lässt es sich ohne Schwierigkeit nachweisen, dass die Le Jolis'sche Ansicht, nach welcher die $L$. hyperborea ( $\mathrm{G} u \mathrm{nn}$.) wesentlich seiner $L$. flexicaulis angehören soll, durchaus nicht von überzeugenden Gründen getragen wird. ${ }^{1}$ Wenn nämlich Gunnerus angiebt, dass sein Fucus hyperboreus bisweilen einen etwas zusammengedrückten Stamm zeigt, ${ }^{2}$

1 „Le Fucus hyperboreus de Gunner est très certainement notre L. flexicaulis; la déscription, fait avec soin, ne me laisse aucun doute à cet égard. En effet, Gunner dit que le stipe est un peu comprimé; que la plante, brun, à l'état frais, devient verte lorsqu'on la euit pour la donner aux bestiaux; enfin, que les habitants de la Norwège mangent le stipe de cette Laminaire: ce qui est très possible pour le $L$. Alexicaulis, mais nullement pour l'autre espèce. La planche III concorde bien avec la déscription et représente le L. flexicaulis, comme on peut le voir à la forme du stipe et à la dispositon des racines. Cependant Gunner avait vu aussi quelques échantillons du L. Cloustoni ornés de leur double fronde, et les avait décrits comme une variété prolifère." Le Jol. l. c. p. $34-35$.

2 Caulis est durus, subteres vel interdum aliquantum compressus. G u nn. 1. c. p. 34. 
so ist dies wirklich, längs dem nördlichen Theil der Küste, nicht so selten der Fall, wie ich dies noch weiter in der Beschreibung der entsprechenden Form, f. compressa, nachweisen werde; wird das Blatt für länger ausgegeben, als der Stamm (dem eine Länge von 6-8 Fuss beigelegt wird) und ersterem eine Breite von 2-4 Fuss zugeschrieben, ${ }^{1}$ so berichtet Gunnerus in solchen Angaben doch wohl nur, was ihm erzählt worden, so dass diesen Maassangaben kein besonderes Gewicht beizulegen ist; ${ }^{2}$ unter allen Umständen stimmt aber das angegebene Verhältniss eben so schlecht für sämmtliche Formen der $L$. digitata ( $L$. flexicaulis) als für $L$. Cloustoni. Wenn weiterhin bemerkt wird, dass die Pflanze in frischen Zustand etwas dunkel aussieht, aber gekocht eine grüne Farbe annimmt, ${ }^{3}$ so ist die erste dieser Angaben zu unbestimmt, um darauf einen Schluss bauen zu können; die zweite aber findet ihre Anwendung auf beide Arten in beinahe gleichem Grade. Die hiermit in Verbindung stehende Notiz, ${ }^{4}$ nach welcher Blatt und Stamm in Nordland als Viehfutter gekocht werden, haben für beide volle Richtigkeit, insofern beide Arten, zumal in Finmarken, im Winter als Surrogat für Heu gebraucht werden $;^{5}$ dagegen passt nur auf $L$. hyperborea ( $L$. Cloustoni), was von der Verwendung der betreffenden Alge als Feuerungsmaterial bemerkt wird. Dass letztere Art auch von Menschen gegessen werden solle, bezeichnet Gunnerus selbst bereits als ein blosses Gerücht. Indessen giebt auch Stephensen in seinen "Tangarter", in welchem man ebenfalls eine sehr gute Abbildung (l. c. t. 4) der L. hyperborea ( $L$. Cloustoni) findet, über diesen Punkt einige Mittheilungen, die wir hier in Uebersetzung folgen lassen wollen:

„Besonders in Zeiten von Hungersnoth lassen folgende Arten

1 Caulis ....... tres vel quatuor cubitos longus, crassitie baculi, Flons ... caule altior, 1 ad 2 cubitos lata. l. c.

2 Vergl. Ulva maxima und verschiedene andere Maassangaben in der Flor. Norv.

3 Tam frons s. folium, quam caulis, ubi recentia sunt, apparent subfusca, cocta autem magis viridescunt. 1. c.

4 Frons et caulis juniores cocti in Nordlandia dantur pecoribus; immo caulis coctus interdum etiam, ut fertur, ab hominibus editur. Caules siccati, præsertim in Lofoten et Vesteraalen, foco; putrefacti autem agris lætificandis inserviunt.

5 In Nordland benutzt man heutzu Tage meistens bloss Alaria. 
sich benutzen: a. Kerlingareyra ..... besteht aus einem Theil der Pflanze Fucus digitatus (L. hyperborea), norw. Stokketare, isländisch Hrossapaunglar genannt. . . . . Diese Tangart wird überall an der isländischen Meeresküste als Feuerungsmaterial benutzt. Hat man aber auch mehrfach den oberen Theil des Stengels bis herab zum Untertheil des ungetheilten Blattstück auf den Färöern und auf Island gespeisst, indem man daraus einen Brei, Fiörugrös oder Maurukiarne bereitete, so lässt sich doch diese Tangart nur in der Noth in solcher Weise anwenden."1 - In Bezug auf die von Gunnerus gegebene Abbildung der $L$. hyperborea (l. c. t. IV) habe ich bereits früher behauptet („Bidrag“), dass dieselbe sich auf eine $L$. Cloustoni beziehen müsse, und diese Behauptung findet ihre Bestätigung durch die in dem Gunnerusschen Herbarium aufgefundenen Exemplare. Fig. 2 ist eine nicht ganz gelungene Zeichung des Blattes, ausgeführt nach dem in Herbarium aufgefundene Originalexemplar, und Fig. 1 - die Abbildung des Stammes - ist jedenfalls auch nach einem getrockneten Exemplar gezeichnet. Der Abbildung der Wurzel darf man keinen Werth beilegen, da dieselbe weder der einen, noch der andern Art entspricht. Die von Gunnerus citirten norwegischen Namen: (Tare), Kurvetare oder Stokketare werden nur von dieser Art gebraucht, und grade im Bezug auf die richtige Wiedergabe der volksthümlichen Namen ist Gunnerus sehr gewissenhaft. ${ }^{2}$

Was nun die andere Art des Gnnnerus, jenen Fucus bifurcatus (l. c. p. 96 und Norske Planter p. 86) betrifft, so habe ich ebenfalls früher ausgesprochen, dass dieselbe mit $L$. digitata sich decken dürfte; und auch diese Vermuthung wird durch die im Herbarium gefundenen Exemplare zur Evidenz gebracht. Die Abbildung (Norske Planter t. VI, Fig. 2) ist ohne Zweifel nach einem jüngeren, getrockneten Exemplar der f. ensifolia ausgeführt, wie sich dies besonders aus der eigenthümlichen Form der Zipfel erkennen lässt, da letztere oft unter dem Trocknen die betreffende Gestalt annehmen. Hat unsre Alge auf der Abbildung eine radix

1 Vergl. Mohr. Isl. Naturh. p. 242.

2 Der erste der citirten Namen, Tare, ist allen Laminarien gemeinsam. 
scutata erhalten, so findet dies wohl seine Erklärung in dem Umstand, dass die Hapteren bei dieser Form im Ganzen wenig entwickelt sich zeigen, und zumal bei getrockneten Exemplaren häufig ziemlich undeutlich auftreten. Uebrigens hat Gunnerus bei fast allen seinen Abbildungen der Wurzel, bezüglich der correcten Wiedergabe dieses Pflanzentheils, nur sehr wenig Rücksicht geschenkt. 1

Von andern Verfassern, welche mehrere Arten unterschieden haben, möge hier noch De la Pylaie genannt werden, der nicht minder, als 4 Arten beschreibt. ${ }^{2}$ Seine Beschreibung ist jedoch ziemlich unvollständig, was Grevill $\mathrm{e}^{3}$ zu der Annahme veranlasst, dass sämmtliche vier ebenerwähnte Arten nichts weiter als Formen der L. digitata auct. vorstellen. Ebenso legt Le Jolis der genannten Arbeit einen nur geringen Werth bei. ${ }^{4}$ Indessen dïrften doch vielleicht ein paar jener Arten sich erkennen lassen. L. phycodendron gehört, wie auch Le Jolis zugiebt, unter L. Cloustoni (L. hyperborea). Die Beschreibung der L. ochroleuca scheint ebenso keinen Zweifel an ihrer Identität mit $L$. digitata f. typica zu gestatten. Als die auszeichnende Characteristik derselben wird hervorgehoben: ein hellerer, gelblicher Stamm, wie bei L. phycodendron, aber eine andere Consistenz, als bei letzterer; der Stamm fast gleichdick, glatt (non rugoso), nach dem Blatte hin etwas zusammengeschnïrt. Das Blatt am Grunde herzförmig und mit ziemlich

1 Fucus bifurcatus wurde, nur wenige Jahre nach dem Erscheinen der Fl. Norv., von Tonning (Rar. Norv.) als eine Form der L. digitata (L.) aufgestellt, und in Linnés Fl. Lapp. (ed. II) als eine eigene Art angenommen.- Wahlenberg vereinigt dieselbe in seiner Fl. Lapp. mit L. saccharina, was jedoch von Sommerfelt in den Suppl. Fl. Lapp. insoweit berichtigt wird, dass er dieselbe als eine Form der $L$. digitata auct. aufnimmt. So auch Lyngbye (Hydroph. Dan.). Areschoug rechnet dieselbe ebenfalls zur $L$. digitata auct.

2 Observ. p. 178.

3 Alg. Brit. p. 28.

4 Le Jolis scheint sehr geneigt, die Artsbeschreibungen älterer Verfasser zu reduciren. So übersieht er Lyngbye's $L$. digitata allein aus dem Grund, weil letzterer seiner Beschreibung die unrichtige Bemerkung beigefügt hat, dass „folium exsiccatum pulvere tenuissimo albo, qui saccharum sapit, hic illic obductum reperitur, omnino ad instar Laminariæ saccharinæ", wäbrend der Rest der Beschreibung im Uebrigen vollständig und ausschliesslich auf $L$. Cloustoni ( $L$. hyperborea) passt. 
breiten, langen und schmaler werdenden Zipfeln. Dies stimmt sehr gut mit den norwegischen Exemplaren der betreffenden Form, wie dieselbe zumal in Finmarken auftritt. L. leptopoda, welche von Le Jolis unter $L$. flexicaulis ( $L$. digitata) miteinbegriffen wird, ohne dass jedoch angegeben würde, zu welcher Form sie zu rechnen ist, ${ }^{1}$ soll bereits von Bonnemais on diesen ihren Namen erhalten haben. ${ }^{2}$ Es ist dieselbe möglicher Weise eine jüngere f. stenophylla, wenn gleich die Beschreibung nicht ganz übereinstimmt; aber einer andern Form lässt sie sich nicht wohl zuzählen, wènn sie nicht vielleicht eine dem nördlichen Frankreich eigenthümliche Form darstellen sollte. L. stenoloba (l. c. fig. K.) entspricht in allem wesentlichen der $L$. digitata f. stenophylla. Bonnemaison und Lamouroux haben nach Notaten in ihren nachgelassenen Herbarien jedenfalls zwei distincte Arten unterschieden (vergl. Le Jol. l. c.); ebenso $\mathrm{Cr}$ ou an in Alg. mar. Finist.

Nach dem hier angefiihrten wird man wohl unbedingt zugestehen müssen, dass $\mathrm{Cl}$ onston nicht der erste gewesen, der die von so vielen frïheren und späteren Algologen confundirten Arten von einandel geschieden hat, obwohl wir demselben das Verdienst nicht schmälern wollen, uns eine weit ausführlichere Beschreibung des Verhältniss der einen unserer Arten ( $L$. hyperborea) und einer Form der anderen ( $L$. digitata f. stenophylla) gegeben zu haben. Aber auch abgesehen hiervon befinden wir uns in unserm guten Recht und in vollen Einklang mit den für die Namengebung anerkannten Gesetzen, wenn wir den ersten Namen festhalten, der

1 Hier ebenso wenig, wie andern Stellen giebt Le Jolis an, welcher Form von L. Alexicaulis die von ihm untersuchten Exemplare beizüzählen sind; ebenso bezeichnet er nicht, welche Formen bei Cherbourg vorkommen. (Cfr. Liste Alg. Cherb.).

2 „Dans l'Herbier de M. Lenormand se trouve une forme de $L$. Alexicaulis provenant du Finistère et accompagnée de cette étiquette écrit par Bonnemaison en 1822: "Laminaria leptopoda Bonn. - Sous le nom de Lam. digitata on confond deux espèces; la présente caracterisée par son stipe plus allongé, brunâter, d'une diamètre égal dans toute sa longueur; l'autre épaissie à la base et s'ammincissant ensuite, d'une couleur pourpre noirâtre et reconnaissable par les couches épaisse et distinctes de son écorce." - A ce même échantillon est joint la note suivant de Bory: "Lamin. flabellum Bory, très différent du digitata; je l'ai en cent états toujours cuneiformes. "“ (l. c. p. 44). 
einer bestimmten und unanfechtbaren Art beigelegt worden ist. So viel über die Motive, von denen ich mich habe leiten lassen, wenn ich, wie bereits erwähnt, den Namen $L$. hyperborea (Gunn.) an Stelle von L. Cloustoni Edm., Le Jol. aufnehme.

Gen. Laminaria (Lamour.) J. G. Ag.

Lamin. p. 7; Lamour. Essai p. 40; char. mut.

\section{Digit a t .}

Laminaria hyperborea ( $\mathrm{G} u \mathrm{nn}$.) nob.

Fl. Norv. I, p. 34, tab. 3 et herb.

f. typica Foslie.

L. digitata f. typica Foslie, Bidr. p. 15.

Descr. Laminaria Cloustoni Le Jol. Examen p. 56.

$$
\text { Hafgygia } \quad \text { Aresch. Obs. Phyc. p. } 1 .
$$

Fig. Fucus scoparius Ström, Beskr. t. F., fig. 1.

$" \quad$ digitatus Fl. Dan. t. 392.
$" \quad$ Laminaria digitata Harv. Phyc. Brit. t. 223. ${ }^{1}$
$" \quad$ " $\quad$ hyperborea tab. nostra 1, fig. 1-8.

f. compressa novum nomen.

Deser. Laminaria digitata f. longifolia Foslie l. c. p. 19.

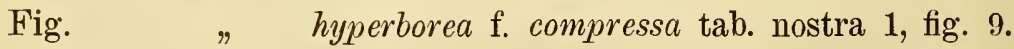

1 Fig. 2 bei Harv. ist kaum das Bild einer $L$. hyperborea. An der norwegischen Küste hat jedenfalls die Art bereits in diesem jungen Alter ein, im Verhältniss zu seiner Länge, viel breiteres Blatt, als hier die Figur angiebt. Dasselbe ist ausserdem bereits früh ein wenig gespalten. 
Syn. Fucus scoparius Ström, Söndm. p. 93.

" digitatus Mohr. Isl. Naturh. p. 342.

$" \quad$ Stephens. 1. c. p. 516.

$" \quad$ "Stackh. Ner. Brit. p. 5, t. 3 .

" $\quad$ Hornem. Plantel. p. 738; excl. syn. plur.

Phycodendron vel Fucus caule maximo lignescente Olafsen, Reise p. 234.

Laminaria phycodendron De la Pyl. Observ. p. 181.

99

$\cdot$

9

9

Hafgygia digitata Lyngb. Hydroph. Dan. p. 20; excl. var. et syn. plur.

" Harv. Man. p. 29, t. 4.

" J. G. Ag. Lamin. p. 24 ; excl. var. " Kütz. Phyc. gen. p. 346, t. 30-31. Phyc.germ. p. 275; Spec. Alg. p. 575; ubique excl. syn. et var.

Laminaria Cloustoni Edm. Fl. Shetl. p. 54, sec. Le Jol. l. c. p. 56 et Beilschm. in Flora p. 384 . $" \quad$ Le Jol. Liste. Alg. mar. Cherb. p. 92.

" $\quad$ Kjellm. Ishafsfl. p. 298.

Cuvy Cloust. in Anders. Guide p. 721. ${ }^{1}$

Zwischen der f. typica und f. compressa besteht, wie bereits erwähnt, keine scharfgezogene Grenze. Wenn ich im „Bidr." angeführt habe, dass bei letztgenannter Form das Blatt länger und durchgehends breiter sein sollte, als bei der ersten, so ist dies

1 In dieser Synonymenliste habe ich, mit ganz wenigen und unwesentlichen Ausnahmen, nur solche Namen aufgenommen, welche die vorligende Art, aber auch bloss diese, in ihrer Totalität umfassen. Von andern Synonymen, welche der Hauptsache aach dieselbe Art umfassen, will ich nennen:

Fucus digitatus W ahlenb. Fl. Lapp. p. 492

Laminaria digitata Lamour. Essai p. 22.

Die übrigen, welchc nach meiner Auffassung in ungefähr gleichem Grade sowohl

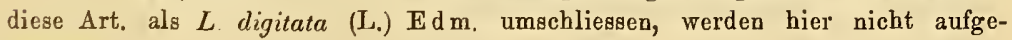
nommen. 
insoweit zu berichtigen, als auch in dieser Beziehung vollständige Uebergänge sich beobachten lassen. Man findet sogar häufig Exemplare der ersten Form, deren Blatt die gleiche, relativ bedeutende Länge zeigt, wie die letzte Form. Uebrigens existiren bei der f. typica zwei Blattformen, die eine mit einem im Verhältniss zur Höhe des Stammes kurzem Blatt, und die andere mit einem Blatt, dessen Länge drei Viertel der Höhe des Stammes erreichen, ja sogar übersteigen kann. Mit letzterer stimmt f. compressa in allen wesentlichen Stücken überein, abgesehen von dem einen, dass bei letzterer das obere Drittel des Stammes etwas zusammengedrïckt und ziemlich gebogen ist. Darnach sieht es aus, als ob statt der bisherigen zwei Formen, eigentlich drei derartige Formen für L. hyperborea aufszustellen sind; und es ist wohl möglich, dass eine fortgesetzte Untersuchung wirklich zu einem solchen Ergebniss führen wird; so weit aber meine Bekanntschaft mit den Verhältnissen reicht, dürften die Differenzen in der Blattlänge zum grössten Theil auf die localen Bedingungen, unter welchen die Pflanze auftritt, zurïckzufïhren sein. Gleich unterhalb der untersten Ebbemarke, an exponirten Stellen, begegnet man fast ausschliesslich nur Exemplaren mit einem, im Verhältnisse zur Stammhöhe sehr kurzen Blatt, und erst in grösseren Tiefen erscheint die andere der oben angedeuteten Formen, bei welcher das Blatt, sowohl nach Länge, als nach Breite, grössere Dimensionen nachweist. Ich habe friiher angegeben (1. c.), dass das Blatt bei f. compressa in mehr Zipfel zerspalten ist, und letztere darum auch etwas schmaler ausfallen, als bei der f. typica. Dies ist auch ohne Zweifel der häufigere Fall, doch habe ich bei meinen späteren Untersuchungen erkennen mïssen, dass auch in dieser Beziehung ein einigermassen constantes Verhalten sich nicht findet. Was nach solchen Einrälumungen als das eigentliche Charactermerkmal der f. compressa nach stehen bleibt, ist somit nur die eigenthümliche Form dess Stammes; aber grade in dieser Beziehung ist um so bestimmter hervorzuheben, dass man auch in grösseren Tiefen, an exponirten, sowie an einigermassen geschïtzen Orten, Exemplare mit einem nach oben mehr oder minder zusammengedrückten Stamm antrifft. 
Dieser Umstand scheint dafür zu sprechen, dass wir es hier, nicht bloss mit einer unbedeutenden, rein localen Abänderung der f.typica zu thun haben, sondern berechtigt sind, diese Variation als eine benannte Form aufzustellen. Taf. 1, Fig. 9 zeigt einen Durchschnitt des Stammes der f. compressa, der $10 \mathrm{Cm}$. unterhalb der Spitze des Stammes genommen ist.

Es ist bekannt, dass die Laminarien in den kälteren Meeren grössere Dimensionen annehmen, als in den temperirten, und dass grade die nördlichen, und zum Theil die westlichen, Küsten Norwegens die Gegend bezeichnen, in welcher, nicht bloss L. hyperborea, sondern auch die übrigen nordischen Arten der Gattung Laminaria, ihre grössten und üppigsten Formen entfalten. Je weiter man nach Süden herabsteigt, um so kleiner werden die Dimensionen, und unmittelbar im Osten von Jäderen erzielt die L. hyperborea einen im Vergleich zu den nördlichen und westlichen Formen nur zwerghaften Wuchs, bei welchem der schwache Stamm aber oft ein verhältnissmässig grosses Blatt trägt, so dass der Unterschied zwischen den Grenzformen unsrer Art, ebenso gross, wo nicht gar grösser noch, sich darstellt, als bei der $L$. digitata. An den skottischen und nordenglischen Küsten scheinen diese Verhältnisse wieder denen des arctischen Norwegens zu gleichen, doch zeigt sich auch hier dasselbe schnelle Einschwinden der Grösse nach Süden hin. An der französischen Küste dürfte $L$. hyperborea überhaupt keine grösseren Dimensionen aufweisen, als im südlichen und südostlichen Norwegen.

Die Hapteren dieser Art sind oben, Pag. 6-8, beschrieben. Taf. 1, Fig. 1 zeigt die gewöhnliche Form derselben bei grossen und kräftig entwickelten Individuen.

Der Stamm besitzt bei finmarkischen und nordländischen Exemplaren dieser Art im Allgemeinen eine Höhe von ungefähr 2 M. (so weit meine Erfahrungen reichen) und am Unterende einen Diameter von $3-5 \mathrm{Cm}$.; doch kann derselbe in beiden Beziehungen bedeutend grössere Dimensionen erlangen. Auf einer Tiefe von 3-4 Faden habe ich oft Exemplare gesehen, welche vile grössere Dimensionen zu besitzen schienen, aber schon in einer solchen Tiefe, 
und nochmehr in grösseren, kann eigentlich nur ein glücklicher Zufall dem Algologen diese Riesen unverstïmmelt in die Hände spielen. Die weit überwiegende Anzahl dieser Pflanzen, die ich zu untersuchen Gelegenheit fand, bestand aus solchen Exemplaren, welche die Stïrme von Zeit zu Zeit ans Land geworfen hatten und die in einer geringeren Tiefe gewachsen waren. Ich habe oft Versuche gemacht, Exemplare aus einer Tiefe von etwa 2 Faden und darüber aufzunehmen; doch fast immer vergeblich. Dürfte man es als wahrscheinlich annehmen, dass unsre Art in Tiefen die 2 Faden übersteigen ein stärkeres Wachsthum und überhaupt eine kräftigere Entwickelung besässen, als in der Ufernähe, so müsste man die durchschnittlichen Dimensionen höher ansetzen, als ich dies oben gethan habe. Dass man viel grössere Exemplare gefunden haben will, ist mir oft erzählt worden; eine genauere Massangabe zu erhalten, ist mir jedoch nur in einem einzigen Fall geglïckt. Ich verdanke diese Angabe dem Herrn Ingenieur And. Bergh in Christiansund. Derselbe hat nämlich im Jahre 1875 ein an den Strand ausgeworfenes Exemplar dieser Art, welches durch ungewöhnliche Grösse seine Aufmerksamkeit erregte, der Messung unterworfen, und fand die Länge des (blattlosen) Stammes volle 5 Meter. Dies ist das grösste Exemplar an unsern Küsten, von welchem man etwas zuverlässiges weiss. F. L. Ekman ${ }^{1}$ giebt folgende genäherte Masse für die grössten der von ihm bei Christiansund gesehenen Exemplare: Stamm 6-8 Ellen (3.8-5 M.) hoch, und am unteren Theil $2^{1} / 2-3$ Zoll $(6.5-7.8 \mathrm{Cm}$.) im Diameter dick. - Bei nordländischen, und zumal bei finmarkischen, Exemplaren, welche an exponirten Orten in geringeren Tiefen wachsen, ist der Basistheil des Stammes, im Verhältniss zum Obertheil, oft sehr dick. Taf. 1, Fig. 1 zeigt das Dickenverhältniss eines aus Ost-Finmarken stammenden Exemplars unsrer Art. Unter sïdlicheren Breiten, in mehr geschützten Gegenden, so wie in grösseren Tiefen sind die Unterschiede in der Dicke der verschiedenen Stammestheile weniger ausgeprägt. Man findet oft ältere Exemplare, deren Stamm bis

1 Skand. Hafsalg. p. 10. 
ungefähr zur Mitte hin fast dieselbe, doch nicht grosse, Dicke bewahrt.

Die grösste Anzahl von Schichtringen habe ich bei finmarkischen Exemplaren gefunden. Dieselbe betrug 20 Ringe, und der Durchmesser des Stammes am unteren Ende war dabei ca. 4.5 $\mathrm{Cm}$. Le Jolis bezeichnet 12 Ringe als die grösste Zahl, welche er bei französischen Exemplaren gezählt hat; doch fehlt eine Angabe der Stammdicke. Bei südnorwegischen Exemplaren sind, nach Schübeler, ${ }^{1} 8$ Ringe das Maximum.

Bei einer nicht geringen Anzahl der in Berlevaag gesammelten Exemplare fand ich keine Schleimlacunen, weder im Stamm, noch im Blatte. Die von mir mit der grössten Genauigkeit untersuchten Pflanzen waren theils noch im lebenden Zustand, theils frische, in Conservirungsflüssigkeit aufbewahrte, theils getrocknete Exemplare. Es schienen dieselben jedoch noch ziemlich jung zu seiin, obwohl der Stamm eine Höhe von 1 Meter und an der Basis einen Durchmesser von $2.5 \mathrm{Cm}$. besass; die Rindenschicht erstreckte sich nicht weiter aufwärts, als bis ungefähr gegen die Mitte des Stammes, und dieser war nicht so rauh, als gewöhnlich. Dieses Fehlen der Schleimlacunen muss aber gewiss bloss als eine Anomalie betrachtet werden. Doch will ich nicht unbemerkt lassen, dass L. hyperborea, dort, wo dieselbe an stark exponirten Orten wächst, relativ gross wird, ehe sie ihre volle Entwickelung erreicht hat; und es scheint fast als Regel angesehen werden zu dürfen, dass die Schleimlacunen erst dann erscheinen, wenn das Individuum sich der vollen Entwickelung nähert. So fehlen an dem Taf. 1, Fig. 8 dargestellten Exemplar sowohl die Schleimlacunen, als die Rindenschicht. Man findet jedoch derartige Lacunen auch auf kleineren Exemplaren, als das letzterwähnte, wenn dieselben an Stellen wachsen, an denen unsre Pflanze ibberhaupt keine bedeutenden Dimensionen zu erlangen pflegt.

Die Lage der Schleimlacunen wechselt bedeutend. Bei Exemplaren, welche an etwas geschützten Orten wachsen, und eine nur schwach entwickelte Rindenschicht besitzen, liegen sie meistens all der Grenze der Cortical- und Zwischenschicht, wie dies überhaupt

1 Pflazzenw. Norw. p. 91. 
bei Arten ohne Rindenschicht ein gewöhnlicher Fall ist. Je älter das Individuum wird, und je kräftiger die Rindenschicht sich entwickelt hat, um so näher drängen sich die Schleimlacunen an die Peripherie der letzteren, und sind dann oft recht schwer zu erkennen. Taf. 1, Fig. 3 zeigt die Lage der Lacunen bei einem Exemplar mit $1 \mathrm{Mm}$. dicker Rindenschicht.

Das Blatt der L. hyperborea f. typica hat bei Exemplaren, welche an exponirten Stellen gleich unterhalb der untersten Ebbe= grenze wachsen, obwohl der Stamm eine Höhe von etwa 1.5-2 Meter zeigen, doch nur eine Länge von ca. $40 \mathrm{Cm}$., wobei die Breite theils ebenso gross, theils etwas grösser ist. Bei der überwiegenden Anzahl von Exemplaren, welche ich an der Küste Finmarkens und Nordlands beobachtet habe, ist das ebenangegebene Verhältniss das gewöhnliche gewesen. Dasselbe gilt von den wenigen unversehrten Exemplaren, welche ich bei Christiansund und Jäderen zu erbeuten mich im Stande sah. Auf ein ähnliches Verhältniss führt auch die Angabe Ekmans in Bezug auf den ersten jener Fundorte; er sagt nämlich, dass er die grössten Stämme mit einem verhältnissmässig kleinen Blatt versehen angetroffen hat. In grösseren Tiefen wird dagegen, wie bereits bemerkt, das Blatt gewöhnlich etwas länger; doch habe ich nie Exemplare gefunden, bei denen die Blattlänge 1 Neter überstiegen hätte. In Finmarken fand ich verschiedene, wie ich annehmen möchte, ziemlich junge Exemplare mit einer Stammhöhe von ca. 1 Meter und einer Blattlänge von ungefähr $70 \mathrm{Cm}$. Es waren dieselben wahrscheinlich in grösseren Tiefen gewachsen. An geschützteren Orten bleibt das Verhältniss ungefähr dasselbe, wie in tiefem Wasser. Das Blatt erreicht häufig dieselbe Länge, wie der Stamm, und wird sogar nicht selten auch etwas länger; dafür erlangt aber auch der Stamm an dergleichen Localitäten ïberhaupt nie irgendwelche bedeutende Grösse, sondern ist immer kürzer, schwächer, und an der Basis verhältnissmässig weniger verdickt, als an andern Fundorten. Bei den grössten, unter den ebenerwähnten Bedingungen gesammelten, Exemplaren hatte der Stamm eine Höhe von nicht über $100 \mathrm{Cm}$., und das Blatt eine Länge von etwa $60 \mathrm{Cm}$. Oft habe ich aber auch Stämme 
von 30-50 Cm. mit einem ebenso langen, oder längeren Blatt angetroffen. 'An geschützten Orten zeigt sich das Blatt auch gern weniger zeltheilt, als gewöhnlich, was mit dem entsprechenden Verhältniss bei $L$. digitata f. typica im Einklang steht. Trifft man $L$. hyperborea in dem Inneren der Fjorden, was jedoch selten vorkommt. oder hat sie der Zufall an Orte mit ruhigem Wasser verschlagen, so zeigt sich das Blatt noch minder gespalten, aber gleichzeitig dicker und steifer, fast spröde, wie bei $L$. saccharina, wenn dieselbe in dem innersten Fjordengebiet auftritt, wo der Salzgehalt des Wassers ein kleinerer ist, als im offenen Meere. Ebenso werden auch die Zellen der Zwischenschicht, besonders im Blatte, ziemlich dickwandig.

In Bezug auf die Structur ist ebenfalls der Unterschied zwischen L. hyperborea und den anderen Arten etwas in die Augen fallend. Wie erwähnt, ist der Stamm der ersteren immer viel härter und steifer, die Consistenz fast holzartig und fester, als bei irgend einer andern Art; zumal da, wo unsre Pflanze am offenen Meere gewachsen ist. An gechïtzten Orten pflegen die ebengenannten Eigenschaften minder ausgeprägt aufzutreten; hier zeigen auch die Hapteren eine weniger regelmässige Anordnung. Derartigen Fundorten entstammende Exemplare sind es denn auch, die eine Verwechslung mit anderen Formen veranlassen können, obwohl man durch eine anatomische Untersuchung sich leicht darüber vergewissern kann, ob man unsere oder eine andere Art vor sich hat. Die Zellen der Zwischenschicht des Stammes sind nämlich bei $L$. hyperborea viel auffallender in radiale Reihen geordnet, als bei den übrigen Arten, und ebenso ist die Abgrenzung dieser Schicht gegen die Corticalschicht viel schärfer ausgeprägt. Bei älteren Exemplaren ist ausserdem der Stamm immer mit einer Rindenschicht bedeckt und mit deutlichen Schleimlacunen versehen, welche letztere grade bei $L$. digitata (L.) Edm., der Art mit welcher allein eine Verwechselung denkbar ist, nicht vorhanden sind. Doch kan es immerhin bei jungen Exemplaren nicht ganz leicht sein, dieselben von $L$. digitata f. valida im selben Altersstadium zu unterscheiden, wenn beide an sehr exponirten Stellen wachsen, weil unter 
diesen Umständen $L$. hyperborea schon eine bedeutende Grösse erreicht baben kann, ehe das Auftreten der Rindenschicht und der Schleimlacunen ihr den eigenthümlichen Charakter aufprägen; auch ist grade in diesem Alter der Unterschied in der Färbung weniger in die Auge fallend. In Bezug auf die Structur des Blattes besteht der Unterschied zwischen $L$. hyperborea und $L$. digitata darin, dass bei jener die Zellen der Zwischenschicht durchgehends etwas grösser und dickwandiger sich darstellen, als bei dieser. Taf. 1, Fig. 6 zeigt das, meiner Ansicht nach, gewöhnliche Verhältniss; während Fig. 4 u. 5 die kleinsten, und zwar nur als Ausnahme vorkommenden, Zellen darstellt.

An dem nördlichen Theil der norwegischen Küste vollzieht sich der Blattwechsel bei L. hyperborea im Allgemeinen in einem Zeitraum, der beiläufig von der Mitte des November oder dem Anfang des December an bis etwa gegen die Mitte des Mai reicht. Clouston führt dagegen an, ${ }^{1}$ dass diese Art bei Shetland das alte Blatt gegen den Schluss des März abwerfen soll. Ob aber auch die Entwickelung des neuen Blattes unter solchen Umständen entsprechend viel früher beginnt, ist mir unbekannt geblieben, da ich keine darauf bezügliche Angabe, weder bei Clouston, noch bei anderen Verfassern habe auffinden können. Bei finmarkischen Exemplaren, welche am Schluss des Februars gesammelt wurden, habe ich zum Theil das neue Blatt nur ca. $10 \mathrm{Cm}$. lang, und dabei ungetheilt und ziemlich schmal, angetroffen; und auch am Schluss des März zeigte es sich kaum weiter fortgeschritten, wie dies aus der Darstellung dieses Altersstadium in Fig. 1, Taf. 1, zu ersehen ist. Im Anfang des Juni habe ich einzelne Exemplare gesehen, die immer noch das alte Blatt an der Spitze des so gut wie vollkommen entwickelten neuen trugen. Ruprecht ${ }^{2}$ giebt die Notiz, dass im Ochotskischen Meer, "das an manchen Stellen erst im Anfang des Monats August (alten Styls) eisfrei wird, der Regenerations-Process der Blätter bei den meistens im Juli gesammelten Individuen noch nicht beendet ist." Darnach hat es den Anschein

1 l. c. p. 721 .

2 l. c. p. 65 . 
als ob der Blattwechsel in den kälteren Meeren später vor sich geht, als in den mehr temperirten.

Der Stamm der L. hyperborea ist fast immer mit einer kleineren oder grösseren Anzahl von Epiphyten bedeckt; besonder's bemerkt man: Thannidium, Polysiphonia urceolata, Euthora, Ptilotu, Rhodymenia und Delesseria; doch siedeln sich auch andere, ja sogar viel grössere Algen auf ihren Stämmen an; ich besitze z. B. mehrere ungefähr 1.5 M. hohe Exemplare, die mit Alarien, L. saccharina und $L$. digitata von einer Länge bis $2 \mathrm{M}$. besetzt sind.

Beschaffenheit und Neigungsverhältnisse des Bodens sind für das Gedeihen der $L$. hyperborea von der grössten Bedeutung; es kann dieselbe auch nur da sich kräftig entfalten, wo sie in besonderem Grade der Brandung und Einwirkung des offenen Meeres ausgesetzt ist. In offenen Buchten mit einer Tiefe von etwa 2-10 Faden und einem ebenen Felsgrund (oder Sandgrund, auf dem grössere Steinblöcke liegen) scheint sie am besten zu gedeihen. Hier ist die Anzahl der Individuen die grösseste und die Formentwickelung die üppigste. Selten wird man unsere Alge an Orten finden, wo der Boden sich stark abschüssig zeigt, mögen auch sonst die übrigen Bedingungen fuir ihr Gedeihen sich vorfinden. - Bekanntlich trifft man an den Küsten gewisse Localitäten, an welchen die gemeine Miesmuschel (Mytilus edulis) in grossen Mengen sich ansammelt und, in Gemeinschaft mit grösseren Balanen und anderen Schalthieren, weit ausgedehnte Colonien bildet. An solchen Punkten trifft man die L. Iyperborea nie, oder wenigstens sehr selten. Ob es die Anwesendheit der Muscheln, oder andere Umstände sind, die das Vorkommen unserer Pflanze an derartigen Localitäten verhindern, kann ich nicht entscheiden; möglicherweise gilt obige Regel auch nicht allgemein; doch habe ich nie eine Spur unserer Alge da gefunden, wo derartige Muschelbänke sich angesiedelt hatten; L. digitata dagegen ist an solchen Punkten recht häufig. ${ }^{1}$ Ein paar Beispiele mögen das gesagte illustriren. Neben der Einfahrt zum Hafen von Gjesvär in Finmarken liegen verschiedene kleinere

Natürlich sind hier nur solche Orte gemeint, wo Mytilus edulis wirkliche Colonien bildet. 
Skjärs oder Felsenriffe, von welchen einige während der Ebbe ein wenig über der Wasserfläche hervorragen, und zwischen diesen beträgt die Tiefe 1-5 Faden; hier herrscht ein ungewöhnlich starker Strom, zumal in der Zeit zwischen Ebbe und Fluth. Der Ort ist freilich nicht direkt dem Andrang des offenen Meeres ausgesetzt, aber doch viel weniger noch geschützt zu nennen, da die brandende See fast ununterbrochen über die Riffe heriiberspielt. Unter solchen Umständen scheint dieser Ort die besten Bedingungen für das Gedeihen der L. hyperborea darzubieten; aber doch wird man hier vergebens nach dieser Art aussehen, während dagegen I. digitata f. typica und f. valida in der sublitoralen, und f. ensifolia in der litoralen Region ganz gemein sind. Es ist aber auch der Meeresgrund hier überall mit Mytilus edulis und Balanen wie bekleidet. Derselbe Fall wiederholt sich bei Borgevär in Lofoten. Die Skjärs „Hölen" und "Hestskjäret" liegen in einem gegenseitigen Abstand von 300 M., beide der Einwirkung des offenen Meeres ausgesetzt; Tiefe und Neigung des Bodens sind an beiden Punkten die gleichen; bei dem einen jener Skjärs ist aber der Grund mit Mytilus-Colonien bedeckt, und hier ist denn auch $L$. digi$t_{\text {ata }}$ alleinherrschend und von $L$. hyperborea keine Spur zu finden, während dagegen bei dem andern Skjär, wo Mytilus und Balanen nur ausnahmsweis vorkommen, letztere Alge in grosser Menge gedeiht.

Die grösste Tiefe, in welcher man, nach zuverlässigen Beobachtungen, angewurzelte Exemplare von L. hyperborea gefunden hat, beträgt ca. 20 Faden, das Maximum der Frequenz scheint einer Tiefe von 2-10 Faden zu entsprechen. Unsere Alge ist somit ausgesprochnermassen eine sublitorale Planze. Auf der Insel „Stauren" bei Gjesvär in Finmarken fand ich jedoch an einer Stelle, wo fast unausgesetzt eine starke Brandung herrscht, im Sommer 1882 ein Exemplar von L. hyperborea f. typica und zwei von $L$. digitata f. valida bei der untersten Ebbegrenze in einem Felsenbecken. Dies ist der einzigste Fall, wo ich diese beiden Formen in der litoralen Region habe auftreten sehen. Alle drei Exemplare besassen runde, aufrechtstehende und gleich kräftig entwickelte 
Stämme; die Höhe betrug 20-27 Cm., und der Umfang am Unterende $7 \mathrm{Cm}$. Die Länge des Blattes war 30-40 Cm. L. hyperborea besass Rindenschicht und dentliche Schleimlacunen im Stamme und Blatt; $L$. digitata f. valida dagegen hatte keine Rindenschicht und war ganz glatt; ebenso fehlten ihr Schleimlacunen. Auch die Hapteren entsprachen der bei typischen Exemplaren beider Arten gewöhnlichen Formation. In getrocknetem Zustand zeigte dies Exemplar von $L$. hyperborea am Unterende einen Umfang von $4 \mathrm{Cm}$., $L$. digitata f. valida dagegen nur $2-3 \mathrm{Cm}{ }^{1}$

L. hyperhorea ist gewiss unter allen norwegischen Meeresalgen die häufigste Art; unter den Laminarien ist sie dies unbedingt. Längs der ganzen Küste vom östlichen Finmarken an bis an den südlichsten Theil von Jäderen tritt sie in einer auserordentlich grossen Individuenanzahl auf; insonderheit längs des äusseren Skjärgaards? Als Beleg hierfür kann bereits dienen, dass auf der Strecke zwischen Trondhjem und Bergen sich drei Jodfabriken befinden. welche jährlich aus einem sehr engbegrenzten Bezirk mehrere hundert Tons Asche beziehen, die ihrem Hauptheile nach von verbrannter $L$. hyperborea herrührt. In Finmarken habe ich mehrfach erstaunlich grosse durch die Herbst- und Winterstürme an den Strand ausgeworfene Haufen von Algen gesehen, die ebenfalls wesentlich aus dieser Art bestanden. ${ }^{3}$ Im Südosten von Egersund, d. h. von dem Punkte an, wo das Land sich wieder ostwärts umzubiegen beginnt. scheint diese Art dagegen weniger häufig sich vorzufinden, - eine Ausnahme dïrfte jedoch vielleicht Lister machen. An der südöstlichen Küstenstrecke, z. B. an den Hvalöern, tritt

1 Alle Formen von $L$. digitata schwinden beim Trocknen verhältnissmässig viel mehr ein, als L. hyperborea.

2 Vergl. Ström 1. c. und Krogh, Efterretninger p. 276.

Unter "Skjärgaard"s versteht man bekanntlich den Saum von Klippen und Felseninseln, der an den meisten Stellen der Küste vorgelagert ist.

3 In Jäderen hatte ein einiger Landmann im letztverflossenen Jahr ca. 2000 Fuder Laminarien zur Düngung seiner Felder verwendet, und dies war doch nur ein kleiner Bruchtheil der Masse die im Lauf des Winters allein auf seinem Eigenthum an den Strand geworfen war. Dass auch diese wesentlich aus $L$. hyperborea bestanden, bezeugte die grosse Menge unaufgelöster Stämme, welche ich im letzten Sommer dort noch auf den Felden liegen sah. 
diese Art gradezu sparsam auf, wie denn überhaupt die Laminarien in diesen Gegenden keine besonders hervortretende Rolle in der Vegetation des Meeresboden spielen, obgleich dieselben immer noch als häufig gelten müssen. Wie dies Verhältniss sich in den grösseren Tiefen gestalten mag, ist mir unbekannt geblieben, da ich nur ein Bruchstück des oberen oder obersten Gürtels unsrer sublitoralen Region habe untersuchen können. Denkbar wäre es wohl, dass $L$. hyperborea hier etwas grössere Tiefen aufsucht und dort auch zahlreicher auftritt, als man bisher gemeint. In das Innere der Fjorden dringt unser Alge selten tiefer hinein. Im Porsangerfjord in Finmarken habe ich sie jedoch ziemlich weit von der Mündung bei Russemark angetroffen, freilich aber auch in ziemlich verkrüppelten Zustand. Der östlichste Punkt in Finmarken, wo diese Art mit Sicherheit gefunden wurde, ist Kiberg bei Vardö $\left(70^{0} 4^{\prime}\right.$ N. B. $48^{0} 8^{\prime}$ Ö. L.), wahrscheinlich geht ihre Verbreitung noch weiter ostwärts, und möglicherweise bis nach Hjelmö im östlichen und Ekkerö im westlichen Theil des Varangerfjord.

L. hyperborea f. compressa habe ich bei Berlevaag und an ein paar anderen Stellen in Finmarken, vom Meere ausgeworfen, am Strande liegend gefunden. Ein etwas verschrumpftes Exemplar wurde bei Borgevär in Lofoten bei 2 Faden Tiefe eingesammelt. Es scheint diese Form dem Tiefwasser anzugehören.

Laminaria Gunneri no b.

L. hapteris valde ramosis, ramis irregulariter dispositis, ultimis sensim tenuioribus; stipite tereti (vel superne subcompresso?), lævi, subæquali vel ad basin incrassato, apicem versus sensim attenuato; lamina plante junioris integra, ovalioblonga, plantæ adultæ subintegra vel digitato-fissa, coriacea, impellucida, nigrescenti; lacunis muciferis stipitis sat irregulariter dispositis, plerumque magnis, mumerosis, laminæ distinctis. Tab. 2.

Im Jahre 1882 wurde ich in Berlevaag in Ost-Finmarken darauf aufmerksam gemacht, dass es eine, der Digitata-Gruppe angehörende, Laminaria gäbe, welche als giftig angesehen werde. 
An mehreren Stellen, zumal in Finmarken, benutzt man nämlich Alaria und Laminaria während des Winters als Surrogat für das Viehfutter. Von der letztgenannten Gattung kommen jedoch allein $L$. digitata und theilweis L. hyperborea zur Verwendung. Ueber die betreffende Alge wurde berichtet, dass sie für das Vieh, welches sie genossen, sich als sehr schädlich erweisen und eine eigenthümliche Krankheit, die der Trommelsucht gleiche, hervorrufen solle. Es wurden sogar Beispiele angeführt, in welchen der Genuss dieser Laminaria den Tod der Thiere veranlasst haben solle, und in Folge davon war man beim Einsammeln der an den Strand ausgeworfenen Algen äusserst vorsichtig darauf bedacht, eine Beimischung dieser Art zu verhüten. Man gab mir auch schon damals eine ziemlich genaue Beschreibung dieser eigenthümlichen Alge, und dieser Beschreibung nach müsste dieselbe, wie ich bereits in „Bidr." bemerkt habe, entweder der L. atrofulva J. G. Ag. angehören, oder eine neue Art vorstellen. Sowohl im obenerwähnten, als auch im folgenden Jahre suchte ich mehrere Tage vergebens nach derselben. Letztverflossenen Winter erhielt ich indessen eine Menge Laminarien von Berlevaag, unter diesen auch einige Exemplare dieser, wie es sich zeigte, neuen Art. Ich habe mir erlaubt dieselbe nach dem im vorigen Jahrhundert lebenden, verdienstvollen Forscher, Bischof J. E. Gunnerus zu benennen.

Es steht mir nicht das genügende Material zu Gebote, um zu entscheiden, ob L. Gunneri wirklich die ihr von der Landbevölkerung in Berlevaag zugeschriebenen giftigen Eigenschaften besitzt; es lässt sich nämlich auch annehmen, dass die auf Rechnung der Pflanze gebrachte Krankheit der Hausthiere auf die thierischen Parasiten zurückzuführen ist, welche auf allen Arten von Laminaria fast niemals fehlen; nur wäre es freilich auch unter dieser Voraussetzung immerhin auffallend, dass nur diese eine Art in jener Gegend sich schädlich erwiesen hat. Das wichtigste Kennzeichen; dessen die Strandbewohner sich bedienten, um unsere Alge von der L. rigitata zu unterscheiden, - der Art mit welcher sie sonst in den äusseren, habituellen Kennzeichen manches übereinstimmende aufweist, - war die schwärzliche Farbe, welche das Licht nicht 
durchscheinen lässt, im Gegensatz gegen sämmtliche übrige Arten, welche gegen das Licht gehalten, in höherem oder minderem Grade durchscheinend sich zeigen. Wollte man noch sicherer gehen, so legte man die fraglichen Exemplaren auf den Schnee, der dann, wenn man unsere Art vor sich hatte, eine eigenthümliche gelbgrüne Färbung annahm.

Unter den mir zugesendeten Pflanzen befinden sich einige Exemplare, welche der L. nigripes J. G. Ag. angehören, wie denn überhaupt unsere Art der letzteren ziemlich nahe zu stehen scheint. Da jedoch nur eins von den Exemplaren, die ich erhalten habe, in Conservirungsflüssigkeit aufbewahrt ist (das Originalexemplar der Abbildung Taf. 2), und ich auch nur einmal ein Exemplar von L. nigripes an Ort und Stelle in frischem Zustand gesehen habe kann ich zur Zeit das gegenseitige Verhältniss dieser beiden Arten nicht näher bestimmen. Dass dieselben aber als wirklich geschiedene Arten zu betrachten sind, scheint mir ausgemacht. Die Farbe ist immer viel dunkler, als bei $L$. nigripes, das Blatt dicker und die Consistenz fester. Von $L$. atrofulva scheint sie jedenfalls durch ihre grösseren Schleimlacunen sich wohl abzugrenzen. ${ }^{1}$

Die Hapteren sind fein und sehr verzweigt. Taf. 2, Fig. 1, zeigt die Gestalt derselben bei epiphytischen Individuen. Bei Exemplaren, die auf Steinen festgewachsen waren, sind sie indessen ebenfalls fein, und fast ebenso ästig. Sie bilden nie regelmässige Kränze.

Der Stamm ist fast immer an der Basis am dicksten und nimmt von dort an nach obenhin gleichmässig an Umfang ab. Taf. 2, Fig. 1 vergegenwärtigt zwei Exemplare mit Stämmen von fast gleichbleibender Dicke; bei den übrigen aber herrscht in diesem Verhältniss mehr Uebereinstimmung mit L. hyperborea. Ein Exemplar besitzt einen $10 \mathrm{Cm}$. langen, runden Stamm, der an der Basis einen Diameter von nahezu $2 \mathrm{Cm}$. zeigt, und nach obenhin bis zum Blatte gleichmässig sich verdünnt. Ob der Stamm am Oberende bisweilen zusammengedrückt sein dürfte, habe ich an den

1 Vergl. Kjellm. Ishafsfl. p. 294. 
getrockneten Exemplaren nicht mit Sicherheit beobachten können. Die Schleimlacunen (Taf. 2, Fig. 3 u. 4) sind meist sehr gross, aber ziemlich ungleichmässig in ihren Dimensionen, und bilden einen etwas unregelmässigen Kreis. Die Zellen der Zwischenschicht des Stammes sind gross, - oft grösser als bei L. hyperborea, - und bilden weniger regelmässige radiale Reihen. Auch in diesem Punkt scheint unsere Art sich von $L$. nigripes zu unterscheiden; so weit meine Erfahrung reicht, sind nämlich die Zellen der letzteren kleiner.

Das Blatt ist wenig gespalten, und die Zipfel breit. Die Breite des Blattes scheint selten die Länge desselben zu übersteigen, aber die Basis ist meistens herzförmig. Ein Exemplar zeigte 7 ziemlich schmale und tief gespaltene Zipfel, aber in anderen Beziehungen konnte ich bei demselben keine besondere Abweichung beobachten. Die Mittelschicht ist ziemlich fest, mehr oder minder scharf ron der Zwischenschicht abgesondert. Letztere wird von grossen, - ungefähr denen der L. hyperborea gleichen, - dickwandigen Zellen gebildet. Der Zelleninhalt ist sehr dunkel. Die Schleimlacunen sind gross und zahlreich, und mit einem Saum von Zellen umgeben, die in Form und Grösse beträchtlich von den iibrigen Zellen der Zwischenschicht abweichen (Taf. 2, Fig. 5 u. 6).

Folgende Maasse vergegenwärtigen die resp. Verhältnisse bei getrockneten Exemplaren dieser Art: ${ }^{1}$

$\begin{array}{cccc}\begin{array}{c}\text { Total- } \\ \text { länge. }\end{array} & \begin{array}{c}\text { Stamm- } \\ \text { länge. }\end{array} & \begin{array}{c}\text { Grösse } \\ \text { Länge. }\end{array} & \begin{array}{c}\text { Blattes. } \\ \text { Breite } 2\end{array} \\ 52 & 21 & 31 & 15 \\ 45 & 22 & 23 & 15 \\ 40 & 11 & 29 & 12 \\ 36 & 15 & 21 & 17 \\ 31 & 14 & 20 & 13 \\ 53 & 22 & 31 & 11\end{array}$

1 Es ist zu beachten, dass das Blatt der Laminarien der Digitata-Gruppe beim Trocknen nur wenig in der Längenrichtung einschwindet, in der Breite dagegen, zumal wenn sehr gespalten, oft bis ziemlich zur Hälfte.

2 Oder gesammelte Breite der Zipfel. 


$\begin{array}{cccc}\begin{array}{c}\text { Total- } \\ \text { länge. }\end{array} & \begin{array}{c}\text { Stamm- } \\ \text { länge. }\end{array} & \begin{array}{c}\text { Grösse des } \\ \text { Länge. }\end{array} & \begin{array}{c}\text { Blattes. } \\ \text { Breite. }\end{array} \\ 39 & 19 & 20 & 11 \\ 38 & 10 & 28 & 18 \\ 29 & 7 & 22 & 15 \\ 38 & 14 & 24 & 12\end{array}$

Beim Trocknen bedeckt sich diese Art, ähnlich wie L. hyperbovea, mit einer Auswitterung, die einen salzigen Geschmack zeigt*

Diese Art wächst theils auf anderen Algen, wie Alaria und kränkelnden Stämmen der L. hyperborea, theils auf Steinen. Nach den mir gemachten Angaben muss dieselbe bei Berlevaag ziemlich gemein sein; sie wird bei den Herbst- und Winterstïrmen, zusammen mit andern Laminarien, an den Strand ausgeworfen.

Laminaria nigripes J. G. Ag.

Spetsb. Alg. Till. p. 29.

Descr. Laminaria nigripes J. G. Ag. 1. c.

$\begin{array}{clll}" & " & & \text { J. G. Ag. Grönl. Lamin. och Fuc. p. } 17 . \\ \text { Fig. } & " & " & \text { Kjellm. Ishafsfl. p. } 295 . \\ & " & & \text { l. c. tab. 25, fig. 8-10. }\end{array}$

Von dieser durch J. G. Agardh und F. R. Kjellman an den angeführten Stellen ausfühllich beschriebenen Art habe ich nur ein frisches und einige wenige getrocknete Exemplare aus Berlevaag in Ost-Finmarken vor Augen gehabt.

Das Exemplar, welches ich an Ort und Stelle zu untersuchen Gelegenheit hatte, trug, sowohl was Anordnung der Hapteren, als Form des Stammes betrifft, eine frappante Aehnlichkeit mit $L$. digitata f. ensifolia. Das Blatt indessen war wenig getheilt und etwas dunkel; doch lange nicht so dunkel, wie bei L. Gunneri. Auch bei den übrigen (getrockneten) Exemplaren zeigen die Hapteren jene bedeutende Aehnlichkeit mit denjenigen der f. ensifolia. Sie haben nämlich fast dieselbe horizontale Ausbreitung, sind niedergedrückt und wenig verästelt. Bei einigen wenigen Individuen zeigten sich die Hapteren etwas mehr verzweigt, doch lange nicht so sehr, wie dies bei L. Gunneri der Fall zu sein pflegt. Auch bei den finmarkischen Exemplaren scheint der Stamm an der 
Basis am dünnsten, ${ }^{1}$ und in der Mitte zusammengedrückt zu sein. Ebenso treten auch zwei verschiedene Blattformen auf, deren eine am meisten der f. reniformis $\mathrm{Kjellm}$., und deren andere der $\mathbf{f}$. oblonga Kjellm. entspricht. Dagegen weicht die Structur des Blattes in Finmarken bedeutend ab von derjenigen der spitzbergischen Exemplare. Kjellman ist so gefällig gewesen, den Durchschnitt des Blattes eines der finmarkischen Exemplare zu untersuchen. Dasselbe (und so auch die übrigen,) zeigte eine losere, mehr schleimige Mittelschicht, als die spitzbergischen Artgenossen; die Mittelschicht war ausserdem weniger scharf von der Zwischenschicht abgegrenzt, und die letztere aus etwas kleineren, aber dickwandigen, Zellen gebildet. In diesen Punkte zeigen die finmarkischen Formen eine ziemlich grosse Uebereinstimmung mit $L$. Gunneri. Möglicherweise kann der Unterschied zwischen den finmarkischen und spitzbergischen Exemplaren darauf beruhen, dass erstere älter gewesen sind, als die von Kjellman untersuchten spitzbergische Exemplare, denn eine Verdickung des Blattes tritt mit dem zunehmenden Alter ein; aber ob eine so bedeutende Verdickung der Zellenwände, wie hier vorliegt, in solcher Weise erklärt werden darf, bleibt freilich recht zweifelhaft. Ich habe jedenfalls beim Vergleich von älteren und jüngeren Exemplaren von $L$. hyperborea oder $L$. digitata, nie, auch nur annähernd, einen so grossen Unterschied entdecken können, wie den, der zwischen finmarkischen und spitzbergischen Exemplaren von $L$. nigripes zu Tage tritt. Es wäre darum die Möglichkeit nicht ausgeschlossen, dass die finmarkische $L$. nigripes sogar eine andere Art vorstellen könnte, als die spitsbergische. Diese Vermuthung muss jedoch bis auf weiteres unentschieden bleiben.

In frischen Zustand ist $L$. nigripes, nach den äusseren, habituellen Merkmalen, nur schwer von $L$. digitata $\mathrm{zu}$ unterscheiden. Beim Trocknen überzieht dieselbe sich mit einer Auswitterung von salzigem Geschmack, während bei $L$. digitata dagegen diese Auswitteruug süsslich schmeckt.

2 Vergl. Kjellm. l. c. p. 297. 
Einige wenige, an den Strand ausgeworfene, Exemplare dieser Art hat man bei Berlevaag in Ost-Finmarken gefunden.

Laminaria digitata (L.) Edm.

Fl. Shetl. p. 54, sec. Le Jol. 1. c. et Beilschm. 1. c.; Fucus digitatus L. Mant. p. 134, Syst. Nat. ed. XII, p. 718.

f. valida Foslie.

Bidr. p. 27.

Descr. Laminaria flexicaulis f. valida Foslie 1. c.

Fig. $\quad " \quad$ digitata f. valida tab. nostra 3, fig. 1-4.

f. grandifolia nob.

L. forma lamina circa $120 \mathrm{~cm}$. longa, in lacinias pauciores, $10-20 \mathrm{~cm}$. latas, plus minusque profunde fissa; ceteris formæ typicæ persimilis.

f. complanata $\mathrm{Kj}$ e $1 \mathrm{~lm}$.

Kariska hafv. algveg. p. 26.

Descr. Laminaria digitata f. complanata Kjellm. l. c. et Algenveg. Murm. Meer. p. 38.

Fig. " Kjellm. Kariske hafv.algveg. t. 1, fig. 14-18.

f. typica nob.

Descr. Laminaria flexicaulis a. genuina Le Jol. 1. c. p. 57. Fig. $\quad " \quad$ digitata f. typica tab. nostræ 4-5, fig. 1.

f. stenophylla Harv.

Descr. Laminaria (digitata) var stenophylla Harv. Phyc. Brit. t. 338. " $\quad$ stenophylla J. G. Ag. Lamin. p. 18.

Fig. $\quad$ " (digitata) var stenophylla Harv. l. c.

" digitata f. stenophylla tab. nostra 3, fig. 5-9.

f. ensifolia Le Jol.

l. c. p. 57 .

Descr. Laminaria flexicaulis d. ensifolia Le Jol. 1. c. Fig. digitata f. ensifolia tab. nostra 5, fig. $2-5$ et 6 , fig. 1-9. 


\section{f. debilipes no b.}

L. forma hapteris paulum ramosis, plerumque depressis; stipite breviore, gracili, subæquali; lamina plantæ junioris integra, basi ovata, plantæ adultæ subintegra vel in lacinias latas, pauciores plus minusque profunde fissa, in parte media $1.5-3$ mm. crassa, coriacea, flavescenti-olivacea, basi cordata vel subcordata; lacunis muciferis in stipite nullis. in lamina distinctis. Tab. 6, fig. $10-11$.

Syn. Fucus bifurcatus Gunn. Fl. Norv. I, p. 96, Norske Planter p. 86 et herb.

$" \quad \quad \quad$ Tonning, Rar. Norv. p. 12.

" digitatus Turner, Hist. Fuc. III, p. 66 ; ex parte.

$" \quad \quad \quad \quad$ 3. furcatus Sommerf. Suppl. Fl. Lapp. p. 183.

Laminaria pseudo-digitata Lamour. mscr. in herb., sec. Le Jol. l. c.

$"$

$n$

$"$

"

9

,

Hafgygia

Laminaria leptopoda Bonnem. mscr. in herb., sec. Le Jol. l. c.

stenoloba De la Pyl. Observ. p. 178.

digitata J. G. Ag. Spetsb. Alg. Progr. p.

2; Bidr. p. 11; Till. p. 28.

Gobi, Algenfl. Weiss. Meer. p. 76. Kjellm., Vinteralgveg. p. 64; Spetsb. Thalloph. II, p. 25; Algenveg. Murm. Meer. p. 38; Kariska hafv. algveg. p. 25; ubique ex parte, sec. Kjellm. Ishafsfl. p. 300 .

" Schübeler in Heugl. Reise p. 317. " var stenophylla Kütz. Spec. Alg.

p. 577; excl. syn. Kleen, Alg. p. 33. 
Syn. Laminaria digitata Kjellm. Ishafsfl. p. 299; excl. f. latilaciniata, f. cucullata et f. ovata. " stenophylla Kjellm. l. c. p. 300.

" flexicaulis Le Jol. l. c.; excl. var. ovata et cucullata.

$\begin{array}{lll}" \quad & \quad \text { Nyl. et Sæl. Herb. Fenn. p. } \mathbf{7 3}{ }_{\curlyvee} \\ & \text { sec. Kjellm. l. c. } \\ \quad & \text { Foslie, Bidr. p. } 19 ; \text { excl. f. lati- } \\ & \text { laciniata. }\end{array}$

\section{Tangle Cloust. ". c.}

Exsicc. Laminaria digitata Hohenack. Alg. mar. sicc. No. 27.

$" \quad$ Aresch. Alg. scand. exsicc. No. 86.
$" \quad$ brevipes Crouan, Alg. mar. Finist.
No. 84.
$\quad$ Alexicaulis Le Jol. Alg. mar. Cherb.
$\quad$ No. 151.

Im „Bidr." nahm ich die L. Alexicaulis Le Jol. mit einer etwas modificirten Begrenzung auf. Was mich dazu veranlasst hat, jenen Namen mit dem hiergewählten, L. digitata (L.) Edm., zu vertauschen, habe ich bereits oben ausführlicher dargelegt. Während ich der $L$. flexicaulis eine etwas engere Begrenzung gab, die jedoch nur in ziemlich unwesentlichen Stücken von der Begrenzung abweicht, welche ich gegenwärtig der neubenannten Art zuertheile, vereinigte ich die beiden Le Jolis'schen Formen, f. cucullata und f. ovata, zu einer selbstständigen Art: $L$. cucullata (die mit $L$. intermedia identisch ist,) und nahm gleichzeitig unter L.flexicaulis eine neue Form, f. latilaciniata, auf; bemerkte aber dabei, dass letztere nicht unwesentliche Abweichungen von $L$. flexicaulis oder jetzigen L. digitata (L.) Edm. zeige, so dass fortgesetze Untersuchungen vielleicht ihre Selbstständigkeit darthun würden. Späterhin zeigte sie sich als eine von $L$. digitata (L.) $\mathrm{Edm}$. wirklich gesonderte Form; aber ob dieselbe als eine eigene Art aufzufassen sei, oder, wie hier geschehen, mit f. cucullata und f. ovata zusammengestellt 
werden müsste, blieb mir lange zweifelhaft. Hierüber wird das weitere unter $L$. intermedia beigebracht werdell.

Ich habe oben (p. 25) ausgesprochen, dass f. stenophylla in Bezug auf ihre Entwickelung, so weit ich dieselbe habe verfolgen können. sich nicht von den anderen Formen der $L$. digitata unterscheidet, und zugleich die Gründe angegeben, welche dafür sprechen, dass die schottische f. stenophylla wirklich mit der unter demselben Namen aufgenommenen norwegischen Form identisch ist. Nachdem jener erste Theil meiner Arbeit bereits den Händen des Setzers übergeben war, erhielt ich durch die Güte des Herrn Prof. Kjellman zwei Exemplare der f. stenophylla, die beide vom Grafen H. F. G. Strömfelt herstammen, und von denen das eine am 30 Mai 1883 bei Caithness, Thurso, Schottland, eingesammelt, das andere am 4 September desselben Jahres bei Eyrarbakki im südlichen Island, am Strande ausgeworfen, gefunden worden war. Beide Exemplare stimmen in allen wesentlichen Stücken mit den norwegischen Repräsentanten der f. stenophylla vollständig überein, sowohl was den äusseren Habitus, als was den anatomischen Bau der Pflanze betrifft. Die einzige Abweichung, welche ich habe entdecken können, besteht darin, dass jene Exemplare Schleimlacunen im Blatte besitzen, während solche der norwegischen f. stenophylla, wie dieselbe an dem südwestlichen Theil der Küste auftritt, ganz fehlen. An finmarkischen Exemplaren habe ich jedoch, wenn auch selten, Lacunen im Blatt gefunden; es kommen dieselben auch bei Pflanzen aus südlicheren Gegenden vor. Da nun aber die Schleimlacunen auch bei einer anderen Form unserer Art, der f. ensifolia, bald auftreten, bald fehlen, so dürfte diesem Umstand kaum weiteres Gewicht beizulegen sein. Damit fällt aber auch jeder Grund fort für die Aufnahme der f. stenophylla Harv. als selbstständiger Art. So wie dieselbe im äusseren Skjärgaard der südwestlichen Küste auftritt, erscheint dieselbe freilich sich in ziemlich ausgesprochener Weise von den übrigen Formen abzusondern; aber schon hier, und noch mehr in weiter nördlichen Gegenden, lassen sich doch Uebergänge nachweisen. Mehr berechtigt dürfte vielleicht die Aussonderung zweier anderer Formen der $L$. 
digitata sein, nämlich der f. ensifolia und f. debilipes. Von diesen führt nämlich die letztere bereits in sehr jungem Alter die Blattform der älteren Exemplare in ziemlich ausgeprägter Gestalt, und beide zeigen verschiedene Abweichungen von den übrigen Formen, nicht allein in Bezug auf die Gestalt des Stammes und wohl auch des Blattes, sondern auch in Bezug auf Gestalt und Anordnung der Hapteren, die bei diesen beiden Formen in ziemlich ausgeprägter Weise von den übrigen Formen sich unterscheiden, während die Hapteren der f. stenophylla mit denen der f. typica und f. valida durchgehends übereinstimmen. Wenn wir die besprochenen Formen aber desungeachtet als Formen von $L$. digitata stehen lassen, so hat dies seinen Grund darin, dass ich keine wirklich constanten Merkmale habe auffinden können. An der West- und Ostküste unterscheidet sich f. ensifolia meistentheils recht deutlich von den übrigen Formen; an der südöstlichen Küste dagegen lässt sie sich oft kaum von der f. typica unterscheiden, zumal da letztere selbst in dieser Gegend recht bedeutend von der nördlichen und eigentlichen Hauptform abweicht. Dagegen ist es zweifelhaft, inwiefern f. complanata als eine selbstständige Form beibehalten werden darf. In ihrer höchsten Entwickelung weicht dieselbe freilich nicht ganz unerheblich von der f. typica ab, aber das einzige charakteristische Kennzeichen, welches diese Form auszeichnet, nämlich die Verflachung des Stammes am oberen Ende, ist so wechselnd, dass eine Grenze darnach ummöglich sich ziehen lässt; denn die f. typica hat ebenfalls einen nach oben hin mehr oder minder zusammengedrückten Stamm, und diese Zusammendrückung geht auch wohl nach und nach in eine vollständige Verflachung über, wobei jedoch der Stamm nur in seltenen Fällen einigermassen breit wird, jedoch meistens ziemlich dick bleibt. Ich habe indessen oben eine andere Form, f. grandifolia, aufgestellt, welche sich auch nur durch ein einziges und vielleicht ebenso wechselndes Kennzeichen von der Hauptform absondert; die Variations- und Lebensverhältnisse dieser Pflanze sind mir jedoch überhaupt nur wenig bekannt. Ich nehme aber dennoch beide Formen auf, weil ich davon ausgehe, dass die Variationsrichtungen und Variationsgrenzen einer so wechselnden 
Art, wie der unsrigen, schärfer ins Licht treten und gewissermassen die Aufmerksamkeit mehr herausfordern, wenn man auch die weniger ausgeprägten Formen zu ihrem Recht kommen lässt, vorausgesetzt dass dieselben nicht bloss locale Abweichungen darstellen.

$L$. digitata $f$. valida macht sich besonders bemerklich durch ihren aufrechten und runden Stamm, der an der Basis am dicksten ist, und von da aus nach dem Blatte hin gleichmässig dünner wird. In dieser Beziehnng erinnert dieselbe etwas an $L$. hyperborea, so weit verschieden die beiden sonst auch sind.

Die Hapteren stimmen am meisten mit denen der f. typica überein, aber es sind dieselben durchgängig weniger verzweigt und bilden nur äusserst selten regelmässige Kränze; ab und zu ist ihre Richtung jedoch vertikaler, als bei f. typica (vergl. Taf. 3, Fig. 1). Im Verhältniss zur Höhe und Dicke des Stammes sind die Hapteren ziemlich schwach, aber doch sehr fest mit der Unterlage verbunden.

Der Stamm ist meistens ganz glatt und ziemlich dunkel, und selten mit Epiphyten bedeckt. Von solchen kommen vor: Rhodymenia und Thamnidum, bisweilen Delesseria (Ptilota habe ich auf dieser Form nie bemerkt). Am Unterende erreicht sie wohl einen Durchmẹsser von $3.5 \mathrm{Cm}$., gewöhnlich ist sie aber etwas dünner, und häufig findet man Exemplare, welche sich der f. typica auch darin nähern, dass ihr Stamm, an der Basis nicht merklich dicker erscheint, als in der Mitte. Die Höhe des Stammes steigt bei finmarkischen Exemplaren bis 1.5 M., gewöhnlich beträgt dieselbe ungefähr $1 \mathrm{Mr}$.

Das Blatt ist bei ältern und vollentwickelten Exemplaren fast immer kürzer, als der Stamm und übersteigt bei den Exemplaren, welche ich gesehen habe, selten eine Länge von $1 \mathrm{M}$., meistens ist es kürzer. Seine Basis ist gewöhnlich herzförmig, bisweilen abgerundet, oder breit keilförmig; es ist immer vielfach und ziemlich tief gespalten, die Zipfel sind 3-8 Cm. breit, gewöhn= lich 4-6; am Oberende sind dieselben theils etwas zugespitzt, theils ziemlich breit. In Bezug auf die Structur des Blattes lassen sich freilich auch bei dieser Form, ebenso wenig, als bei den übrigen

Vid.-Selsk. Forh. 1884. No, 14. 
Formen der $L$. digitata, constante Merkmale angeben; doch zeigt das Blatt im Vergleich mit der f. typica ein etwas festeres Element; die Zellen der Zwischenschicht sind meistentheils etwas kleiner, haben oft ihre grösste Länge in der radialen Richtung und erscheinen theilweis in mehr oder weniger regelmässige radiale Reihen geordnet, im Gegensatz zur f. typica, deren Zellen oft in longitudinale Reihen geordnet auftreten. Die Zwischenschicht ist sowohl bei dieser, wie bei den übrigen Formen, weniger scharf von der Mittelschicht abgegrenzt. Ich entsinne mich nicht, je Schleimlacunen bei dieser Form bemerkt zu haben (Taf. 3, Fig. 3).

Taf. 3, Fig. 1 u. 4 vergegenwärtigen, so weit meine Beobachtungen reichen, die Formextreme bei älteren und jüngeren Exemplaren. Wie oben bemerkt, wird das Blatt bei vollentwickelten Exemplaren nicht selten bedeutend länger, als dies bei Fig. 1 der Fall ist, während gleichzeitig die Zipfel nach der Spitze zu weniger breit sich zeigen. Junge Exemplare führen häufig die bereits recht deutlich ausgeprägte Blattform der älteren Pflanze; dadurch wird es oft ziemlich schwer, unsere Form von $L$. hyperborea im gleichen Alterstadium zu unterscheiden. Man findet jedoch auch Blätter mit keilförmiger Basis, die dann aber durchgehends breiter ist, als bei den anderen Formen, die zu einer Verwechselung Anlass geben könnten.

In welchem Zeitraum der Blattwechsel vor sich geht, ist mir unbekannt. In den Sommermonaten habe ich nie ältere oder ausgewachsene Exemplare im Blattwechsel angetroffen; bei jüngeren ist dies jedoch oft noch im Schluss des Augusts der Fall gewesen.

Der südlichste Punkt, an welchem f. valida gefunden wurde, war Borgevär in Lofoten (ungef. $68^{\circ} 15^{\prime}$ N. B.). Hier zeigte sie sich, ebenso wie an mehreren Stellen in Finmarken, ziemlich häufig; sie findet sich jedoch nur an Localitäten, welche der Einwirkung des offenen Meeres ausgesetzt sind, d. 'h. unter den selben Bedingungen, wie L. hyperborea; doch scheint sie solche Orte vorzuziehen, an welchen Mytitus edulis gemein ist. Sie gehört dem oberen oder obersten Gürtel der sublitoralen Region an, und findet sich am zahlreichsten unmittelbar unter der niedrigsten 
Ebbemarke. Bis in welche Tiefe dieselbe hinab steigt, habe ich nicht ermitteln können; die grösste Tiefe, aus welcher ich dieselbe aufgenommen habe, betrug etwa 3 Faden. Nur ein einziges Mal habe ich dieselbe in einem Felsenbecken im untersten Theil der litoralen Region, und zwar mit L. hyperborea zusammen, angetroffen (s. p. 52). Ebenso, wie L. hyperborea, lässt diese Alge sich nur sehr schwer unverletzt aufnehmen.

L. digitata f. grandifolia. Bei Berlevaag in Ost-Finmarken wurden einige Exemplare dieser eigenthümlichen Form an den Strande ausgeworfen gefunden. Es steht dieselbe auf der einen Seite der f. typica sehr nahe, erinnert aber auf der anderen Seite durch das breitzipflige, doch bei weitem nicht so dünne, Blatt etwas an $L$. intermedia $\mathrm{f}$. longipes.

Die Hapteren stimmen mit denen der f. typica überein, wie diese im östlichen Finmarken aufzutreten pflegt.

Der Stamm entspricht ebenfalls demjenigen der Hauptform, wie die letztere in Finmarken auftritt, und bereits durch dies Merkmal grenzt sich unsere Form wohl entschieden von $L$ 。 intermedia f. longipes ab. Bei dem einen der gefundenen Exemplare war der Stamm $120 \mathrm{Cm}$. lang, an der Basis dünner, als in der Mitte, von dort ab schmaler werdend, und in der Nähe des Blattes etwas zusammengedrückt; nach unten zu rauh, nach oben hin glatt und biegsam. Bei dem andern war der Stamm am Unterende von mehr gleichmässiger Dicke, stimmte aber sonst in der Hauptsache mit dem ebenbeschriebenen Exemplar überein.

Das B latt ist ca. $120 \mathrm{Cm}$. lang, d. h. ungefähr ebenso lang, als der Stamm; fast ebenso breit, als lang, aber in eine verhältnissmässig kleine Anzahl von Zipfeln gespalten. Letzte sind 10-20 Cm. breit, zum Theil auch breiter. Die Consistenz ist dieselbe, wie bei f. typica.

Es ist somit eigentlich nur die Form des Blattes, welche den Unterschied von f. typica begründet; aber in diesem Punkte zeigt sich auch eine recht bedeutende Abweichung. $\mathrm{Ob}$ vollständige Uebergänge sich nachweisen lassen, kann ich nicht angeben; eine 
genauere Beschreibung der Form muss darum auch bis auf weiteres unterbleiben.

L. digitata f. complanata. Diese Form ist, wie Kjellman am angeführten Orte hervorhebt, ausgezeichnet durch ihren, zumal in der oberen Hälfte, stark abgeflachten, verhältnissmässig breiten Stamm.

Die Hapteren stimmen in allem Wesentlichen mit denjenigen der f. typica überein.

Der Stamm erreicht im nordwestlichen Theil des Karischen Meeres und an der Westküste von Nowaja Semlja, nach Kjellman, eine Länge von 80 bis etwas über $100 \mathrm{Cm}$., und am Unterende einen Umfang von bis $8 \mathrm{Cm}$. Ueber den grössten Theil seiner Länge ist derselbe abgeflacht, und am Oberende bis $7.5 \mathrm{Cm}$. breit. An der finmarkischen Küste erreicht der Stamm, was Länge und was Dicke am Unterende betrifft, oft viel bedeutendere Dimensionen, wird aber am seinem Oberende nie so breit. Die grösste Breite, welche ich gesehen habe, betrug $4 \mathrm{Cm}$., bei $0.5 \mathrm{Cm}$. Dicke. Die gleiche Dicke giebt Kjellman an für die dünnsten Stämmen bei Nowaja Semlja. Bei finmarkischen Exemplaren ist übrigens auch der Stamm nur selten über den grösseren Theil seiner Länge hin abgeflacht; gewöhnlich ist dies nur bei der obersten Hälfte (oder Drittel) der Fall.

Das Blatt weicht in keinem Stücke von demjenigen der f. typica ab; wenigstens nicht an der finmarkischen Küste.

Die ganze Gestalt der Pflanze stimmt also in allem Wesentlichen mit der f. typica überein, abgesehen davon, dass der Stamm am Oberende ganz verflacht und sehr breit ist; besonders das erste kann freilich auch bei der f. typica "eintreffen, nur ist der Stamm hier, selbst in diesem Fall, nie besonders dünn; an dem sïdlicheren Theil der Küste habe ich sogar Exemplare der Hauptform ange= troffen, deren Stamm oben rinnenförmig gestaltet war, und in den Lofoten fand ich ein Exemplar derselben, bei welchem der Stamm bereits von der Basis an sich verflacht zeigte, doch war auch hier der obere Ende verhältnissmässig dick.

In der Umgrenzung, in welcher ich die f. complanata auffasse, 
findet dieselbe sich an der norwegischen Küste bloss in Ost-Finmarken. Ich habe sie nur als an der Strand ausgeworfen in Gesellschaft von f. typica gefunden. Sie wächst wahrscheinlich in einer Tiefe von 2-10 Faden.

L. digitata f. typica. Unter allen Formen der L. digitata ist diese dem meisten Wechsel unterworfen. Sie ist nicht, wie die meisten anderen Formen, an gewisse Localitäten gebunden, sondern gedeiht nicht nur an der finmarkischen Küste, - wo sie freilich ihre kräftigste Entfaltung erreicht, - sondern auch in südlicheren Gegenden der ganzen norwegischen Küste entlang, und zwar nicht allein am offenen Meer, in grösserer oder geringerer Tiefe, sondern auch an ziemlich geschützten Orten. Aus diesem Grunde ist dieselbe aber auch oft recht schwer zu erkennen, denn zwischen ihren nördlichen Formen, zumal den finmarkischen, und dem südlichen Habitus, den sie z. B. in der Umgegend von Mandal annimmt, besteht eine Verschiedenheit, die gewiss nicht kleiner ist, als diejenige, welche die Grenzformen der L. hyperborea von einander scheidet. So gross aber auch die Unterschiede sind, welche diese Form umschliesst; viel grösser noch ist indessen der Abstand zwischen den extremen Formen der gesammten Species $L$. digitata. Hier würde man gradezu nicht glauben, es mit Pflanzen derselben Art zu thun zu haben, wenn nicht grade die wandelbare f. typica das Verbindungsglied zwischen all diesen Formen abgäbe.

Die Hapteren sind oben (p. 10) ausführlicher beschrieben. Taf. 4, Fig. 1, und Taf. 5, Fig. 1 zeigen die gewöhnliche Gestalt derselben bei f. typica, wie dieselbe in Finmarken auftritt. Je weiter man aber nach dem Süden herabsteigt, desto mehr nähern sich diese Organe denjenigen der f. ensifolia, und am südöstlichen Theil der Küste wird diese Aehnlichkeit so gross, dass es oft kaum möglich erscheint, die beiden Formen in Bezug auf Form und Anordnung der Hapteren aus einander zu halten.

Der Sta mm erreicht in Finmarken gemeiniglich eine Länge von ca. 1 II., doch findet man auch häufig Exemplare, deren Stammlänge bis auf $2 \mathrm{M}$. steigt, wobei der unterste Durchmesser $4 \mathrm{Cm}$ • beträgt, und das Blatt eine Länge von über $1 \mathrm{M}$. aufweist. Der 
untere Theil des Stammes ist rund, bisweilen, und zwar am häufigsten, die ganze untere Hälfte entlang von gleichmässiger Dicke, bisweilen aber auch an der Basis etwas dïnner, als in der Mitte. Von der Mitte aus nach dem Blatte zu zeigt sich der Stamm immer mehr zusammengedrückt; eine Verdickung an der Basis ist selten zu bemerken. Oben, wo der Stamm ins Blatt übergeht, kann derselbe bis $3 \mathrm{Cm}$. breit werden, behält aber dabei doch eine Dicke von ca. $1 \mathrm{Cm}$. Seltener findet man Exemplare, bei welchen der Stamm bereits unterhalb der Mitte zusammengedrückt ist. Ein vereinzeltes Mal habe ich ein kleineres Exemplar mit bereits von der Basis an etwas verflachtem Stamm gefunden, aber auch solche zeigten sich am Oberende nicht sonderlich breit, sondern waren hier sogar im Verhältniss zum unteren Theil ziemlich dick. Bei Mandal fand ich ein paar Exemplare, bei denen der Stamm oben rinnenförmig gestaltet war; dieselben waren jedoch im Ganzen etwas verkrüppelt. Längs der südlichen Küsten erlangt der Stamm kaum die Hälfte der Dicke und Länge, die man in Finmarken beobachtet; aber in Bezug auf die Proportionen des Stammes findet keine beträchtliche Abweichung statt, es müsste den sein, dass man in jenem Theil der Küste häufig auf Exemplare stösst, deren Stamm oben und unten sich dünner zeigt, als in der Mitte; doch ist derselbe auch hier ein wenig zusammengedrïckt, selten aber soviel, wie bei f. ensifotia. Die Farbe ist bei den grösseren finmarkischen Exemplaren ziemlich hell, oft ebenso hell, wie bei $L$. hyperborea; unterwärts ist der Stamm rauh, oben glatt und biegsam; oft ist derselbe mit Epiphyten bekleidet, besonders mit Thamnidium, aber auch mit Rhodymenia und Ptilota. Die Consistenz ist bei den grösseren Exemplaren, welche dem Anprall der Brandung ausgesetzt sind, viel fester, als bei den an geschützten Orten gewachsenen.

Das Blatt ist bei Exemplaren mit einem Stamm von 1 M. Länge (oder mehr) gewöhnlich etwas kürzer, als der letztere, doch findet man auch Exemplare mit $1 \mathrm{M}$. langem Stamm und ebenso langem, ja sogar längerem Blatt; dies gehört aber zu den Seltenheiten. Exemplare mit kürzerem Stamm 
können dagegen ein Blatt tragen, das die Länge des Stammes bedeutend ïbertrifft. Das Blatt ist gewöhnlich vielfach und ziemlich tief gespalten, und die Breite der Zipfel 2-10 Cm., gewöhnlich 4-7. Die Basis ist herzförmig, bisweilen, aber seltener, keilförmig. Die Zellen der Zwischenschicht sind ziemlich gross; diese Schicht selbst nicht scharf von der Mittelschicht abgetrennt, und bei den finmarkischen Exemplaren in der Regel ohne Schleimlacunen, dagegen bei Exemplaren vom südlichen Theil der Küste fast immer mit Lacunen versehen. Im Ganzen ergiebt sich aus meinen Beobachtungen, dass die Schleimlacunen bei Exemplaren aus höheren Breiten sparsamer und kleiner sind, als bei solchen aus niederen Breiten; es stimmt dies uiberein mit dem, was Kjellman im Allgemeinen über dieses Verhältniss bei $L$. digitata angegeben hat. Taf. 4, Fig. 4 zeigt die durchschnittliche Grösse der Zellen der Zwischenschicht. Dieselben sind oft in ziemlich regelmässige longitudinale Reihen geordnet, liegen meistens ziemlich dicht an einander gedrängt und sind etwas dünnwandig.

Junge Individuen der f. typica, f. stenophylla und f. ensifolia lassen sich nur schwer von einander unterscheiden. Die erste hat gewöhnlich ein, im Verhältniss zur Länge, etwas breiteres und weniger zugespitztes Blatt, als f. stenophylla und f. ensifolia, aber ein einigermassen constantes Verhältniss habe ich nicht auffinden können. Taf. 4, Fig. 5 zeigt ein junges Individium der f. typica.

In welcher Jahreszeit der Blattwechsel bei f. typica sich vollzieht, ist mir unbekannt. Derselbe scheint jedoch etwas früher vollendet zu sein, als bei $L$. hyperborea, aber auch hier spielt der Unterschied der nördlichen und südlichen Fundorte eine ähnliche Rolle, wie bei der letztgenannten Art. Die beiden auf Taf. 4 und 5 abgebildeten Exemplare sind in Berlevaag in Ost-Finmarken $\left(70^{\prime} 7^{0}\right.$ N. B.) d. 20 Februar eingesammelt. Bei dem einen (Taf. 4, Fig. 1) ist der Blattwechsel noch nicht weit fortgeschritten, bei dem anderen aber (Taf. 5, Fig. 1) ist das neue Blatt bereits zur Hälfte entwickelt. Bei Fredriksvärn (ungef. $58^{\circ} 8^{\prime}$ N. B.) fand ich am Schluss desselben Monats mehrere Exemplare, bei welchen der Blattwechsel verhältnissmässig viel weiter fortgeschritten war. 
Bei Strömmen in Inderöen $\left(63^{0} 52^{\prime}\right.$ N. B.) fand ich im letzten Sommer eine Form, welche zwischen der f. typica und f. stenophylla in der Mitte steht, doch vielleicht der ersten etwas näher kommt. Mit f. stenophylla stimmt sie darin überein, dass der Stamm derselben sehr biegsam ist, ja bisweilen gradezu horizontal liegt und dabei auch in der Mitte noch mit Hapteren versehen ist. Letzteres beruhte indessen möglicherweise zum Theil auf den eigenthümlichen localen Verhältnissen, unter welchen unsre Pflanzen sich entwickelt hatte. Wie bereits oben, bei der Beschreibung der Haftorgane, ausgeführt wurde, herrschte nämlich am Fundorte ein ausserordentlich starker Strom, der es für Pflanzen, die nicht mit Stämmen von besonders fester Consistenz versehen waren, fast grade zu unmöglich machte, eine mehr oder minder aufrechte Stellung zu behaupten. Doch auch an solchen Orten, wo der Strom weniger reissend war, fanden sich Exemplare mit stark gebogenem Stamm. Ein solcher kommt jedoch, so weit meine Erfahrungen reichen, bei der f. typica nie vor, sondern bei ihr steht der untere, runde Stammtheil immer aufrecht. Ausserdem war das Blatt jener in Frage kommenden Exemplare, im Verhältniss zur Länge des Stammes länger, als dies bei f. typica der Fall zu sein pflegt, und näherte sich in diesem Punkt am meisten der f. stenophylla. Auf der anderen Seite aber zeigte unsere Pflanze ihre Verwandtschaft mit der f. typica wieder dadurch, dass der Stamm dicker war, mehr Schichtringe besass (Taf. 3, Fig. 11) und am Unterende sich gleichmässiger dick zeigte, als dies bei der f. stenophylla gewöhnlich ist. Sie war oft mit Epiphyten besetzt, sogar mit Rhodymenia, was bei, der f. stenophylla, so weit ich gesehen, nie vorkommt. Die Hapteren zeigten die meiste Aehnlichkeit mit denjenigen der f. typica. Am einigen Brückenbalken fand ich ebenfalls verschiedene Exemplare der hier besprochenen Form. Dieselben wuchsen in horizontaler Richtung, rechtwinklig zum Pfosten, an welchem sie sich angeheftet hatten, und wurden von der Strömung bald nach der einen, bald nach der andern Seite mitgerissen. Die Breite des Blattes ist im Allgemeinen etwas geringer, als bei der Hauptform; die Basis theils herzförmig, theils keilförmig, und die Zipfel theils 
schmal $(2-5 \mathrm{Cm}$.), theils sehr breit. - Folgende Tabelle zeigt die betreffenden Verhältnisse bei einigen diesen Exemplare.

$\begin{array}{ccc}\text { Totallänge. } & \text { Stammlänge. } & \text { Blattlänge. } \\ 153 & 45 & 108 \\ 172 & 47 & 125 \\ 220 & 75 & 145 \\ 245 & 84 & 161 \\ 143 & 39 & 104 \\ 146 & 55 & 91 \\ 95 & 38 & 57 \\ 150 & 42 & 108 \\ 152 & 37 & 115 \\ 231 & 103 & 128 \\ 144 & 22 & 122 \\ 129 & 45 & 84\end{array}$

An einer Stelle in der Ufernähe, wo die rïckströmende Bewegung des Wasser nur schwach war, wuchsen mehreren Individuen, welche noch stärker von der f. typica abwichen, als die ebenerwähnten. Hier fand ich z. B. ein Exemplar mit $21 \mathrm{Cm}$. langem Stamm, und $80 \mathrm{Cm}$. langem und $14 \mathrm{Cm}$. breitem, ungetheiltem Blatt mit keilförmiger Basis; und ein anderes, das bei $22 \mathrm{Cm}$. Stammlänge ein $102 \mathrm{Cm}$. langes Blatt mit breiter keilförmiger Basis und zwei seicht eingeschnittenen, 16 und $18 \mathrm{Cm}$. breiten Zipfeln trug. Die Hapteren waren bei den letztgenannten Exemplaren sehr schwach entwickelt, aber der Stamm zeigte sich ziemlich dick; der grösste Durchmesser des runden Theils betrug etwa $2.5 \mathrm{Cm}$. Ein Exemplar mit nur $5 \mathrm{Cm}$. langem Stamm trug ein ungetheiltes, 44 $\mathrm{Cm}$. langes und $17 \mathrm{Cm}$. breites Blatt mit fast herzförmiger Basis. Bei einem andern war der Stamm $34 \mathrm{Cm}$. lang und das Blatt von gleicher Länge; letzteres hatte aber seine grösste Breite $(30 \mathrm{Cm}$.) in der Nähe der Spitze, die sehr seicht eingeschnitten sich zeigte. Sämmtliche Exemplare waren jedoch über und über mit Flustra membranacea bekleidet; und gewiss hat dies hemmend auf die normale Entwickelung unsrer Pflanzen eingewirkt. 
An der norwegischen Eismeerküste elzielt die f. typica ihre grösste Entwickelung; das Maximum ihrer Frequenz erreicht sie nach meinen Beobachtungen im östlichen Theil Finmarkens. Es ist dieselbe eine sublitorale Alge, und gehört dem obersten Theil dieser Region an; in dem tieferen Theil derselben begegnet man ihr nur selten, und dann nur in kleinen Individuen. Auch in Nordland ist sie sehr allgemein. Längs dem südlichen Theil der Westküste ist sie wohl nicht mehr so häufig; doch bin ich mit der Verbreitung dieser, so wie der anderen $L$. digitata-Formen grade in diesen Gegenden minder vertraut; nur scheint sie mir jedenfalls an einzelnen Punkten, wie z. B. bei Hvitingsö zum Theil durch f. stenophylla ersetzt, die hier sehr stark vertreten ist. Am südöstlichen Theil der Küste ist sie auch gemein, jedenfalls bei Mandal und Fredriksvärn, doch erreicht sie hier keine bedeutende Grösse.

$L$. digitata f. stenophylla. So wie diese Form an den exponirten Punkten der westlichen Küste sich darstellt, entspricht sie recht gut der Harvey'schen Abbildung in Phyc. Brit. t. 338, nur in den Hapteren zeigt sich eine Abweichung; doch dürften letztere in der Figur weniger correct wiedergegeben sein.

Die Hapteren stimmen im Wesentlichsten mit denjenigen der f. typica nach Form und Anordnung überein, doch sind sie gewöhnlich schwächer und weniger ästig, als bei jener. Taf. 3, Fig. 5 zeigt die Gestaltung der Hapteren bei finmarkischen und nordlandischen Exemplaren. Weiter im Süden nähert sich dieselbe mehr der bei f. ensifolia gewöhnlichen; die Hapteren zeigen sich nämlich mehr niedergedrückt, doch selten so sehr, wie bei jener Form. Obwohl die [Haftorgane der f. stenophylla, sowohl im Verhältniss zu denjenigen der anderen Formen (f. ensifolia und f. debilipes ausgenommen), als auch im Vergleich mit den übrigen Dimensionen der Pflanze selbst, durchgängig schwach erscheinen, - ein Eindruck der sich besonders bei den Exemplaren geltend macht, die an sehr exponirten Orten wachsen, - ist die Pflanze doch recht fest mit ihrer Unterlage verbunden.

Der Stamm ist ebenfalls durchgehends schwach im Vergleich mit der Grösse der ganzen Pflanze. Am Unterende ist er rund 
und etwas dünner, als in der Mitte, wo er gewöhnlich eine leichte Compression aufweist, und von wo aus er sich bis zum Blatte hin mehr oder minder verdünnt. Er ist sehr biegsam, glatt, von dunkler und glänzender Farbe, und, so weit ich bemerkt, nie mit Epiphyten besetzt.

Das Blatt ist, im Verhältniss zum Stamme, lang, vielfach und tief gespalten; die Basis ist keilförmig. Taf. 3, Fig. 5 zeigt ein Exemplar aus Finmarken mit etwas breiterem Blatt, dessen Basis ebenfalls breiter ist, als bei den gewöhnlichen südwestlichen Formen. Schleimlacunen kommen bei norwegischen Exemplaren dieser Form nur selten vor.

Wie bereits mehrfach bemerkt, ist die f. stenophylla nicht grade sehr scharf von gewissen Formen der f. typica geschieden, und ausser der unter letzterer beschriebenen Uebergangsform, habe ich nicht selten Exemplare angetroffen, die in ungefähr gleichem Grad an den charakteristischen Merkmalen beider Formen theilnahmen.

Folgende Zahlenwerthe vergegenwärtigen die betreffenden Verhältnisse bei einigen auf Hvitingsö $\left(59^{0} 1^{\prime}\right.$ N. B. $)$ eingesammelten Exemplaren.

\begin{tabular}{rrrrrl} 
Total- & Stamm- & \multicolumn{2}{c}{ Blatt- } & \multicolumn{2}{c}{ Zipfel- $_{\text {Bänge. }}$} \\
Länge. & \multicolumn{2}{c}{ Länge. } & Breite. & Zahl. & Breite. \\
182 & 77 & 105 & 34 & 7 & $2-6$ \\
155 & 48 & 107 & 45 & 16 & $1.5-5$ \\
215 & 75 & 140 & 69 & 9 & $1-9$ \\
182 & 66 & 116 & 11 & 6 & $1.2-2$ \\
198 & 52 & 146 & 26 & 6 & $2-5$ \\
271 & 108 & 163 & 49 & 11 & $2-8$ \\
213 & 73 & 140 & 24 & 11 & $1.5-5.5$ \\
166 & 63 & 103 & 34 & 9 & $1.5-6$ \\
206 & 81 & 125 & 16 & 8 & $0.7-4.5$ \\
206 & 48 & 158 & 23 & 8 & $0.5-2.5$ \\
152 & 52 & 80 & 23 & 8 & $1-4$ \\
284 & 118 & 166 & 18 & 9 & $0.7-3.5$
\end{tabular}

1 Oder gesammelte Breite der Zipfel. 
Der Stamm hatte bei diesen Exemplaren an der Basis einen Umfang von 3.2-4.3 $\mathrm{Cm}$. Man trifft auch Exemplare mit etwas breiteren Zipfeln; ebenfalls kann der Stamm etwas dicker werden. Nicht unbeträchtlich grössere Individuen waren in einer Tiefe von 1-2 Faden zu sehen, aber wegen ungünstiger Witterungsverhältnisse gelang es nicht, eines derselben aufzunehmen. Bei den Orkneyinseln soll unsere Form nach Clouston eine Länge von 12-20 Fuss erreichen können.

Junge Exemplare der f. stenophylla lassen sich nur sehr schwer von der gleichaltrigen f. ensifolia unterscheiden. Sie besitzen beide ein, im Verhältniss zur Breite, sehr langes und 'stark zugespitztes Blatt. Bei ersterer ist dasselbe jedoch etwas dunkler; auch scheinen die Zellen der Zwischenschicht etwas kleiner zu sein, als bei der letzteren. Wie bei f. typica berührt, lassen sich beide auch nur mühsam von dieser unterschieden.

Wenn der Blattwechsel bei dieser Form sich vollzieht, kann ich nicht angeben. Bei Hvitingsö fand ich im Anfang des Sommers ein paar Exemplare, welche Reste des alten Blattes trugen.

Die Form ist sublitoral und gehört dem obersten Gürtel dieser Region an, kommt aber doch auch mehrfach in der tiefsten Zone der litoralen Region vor; ab und zu trifft man sie sogar in den Felsenbecken derselben Region. In eingeschlossenen Fjorden und ruhigen Buchten, oder allgemein, an geschützten Orten ist sie nicht zu finden. Je mehr der Fundort der Einwirkung des offenen Meeres ausgesetzt ist, desto besser gedeiht unsre Form und desto grössere Dimensionen nimmt sie an. Das Maximum der Frequenz erreicht sie, wie ich glaube, am südlichen Theil des Westküste. An der südostlichen Küstenstrecke habe ich sie nicht beobachtet; doch findet sie sich wahrscheinlich anch hier, da sie bei Bohuslen in Schweden vorkommen soll. In Areschollgs Alg. scand. exsicc. wird nämlich unter No. 86 ein Exemplar mitgetheilt, welches nach meinem Ermessen der f. stenophylla beizuzählen ist. Dasselbe hat Sshleimlacunen im Blatte und unterscheidet sich ausserdem durch hellere Färbung von der norwegischen sïdwestlichen Form. ${ }^{1}$

1 Natürlich beziehe ich mich bloss auf das Exemplar, welches im botanischen Museum der hiesigen Universität sich vorfindet. 
L. digitata f. ensifolia. Ich habe keine Mittel zur Verfügung gehabt, durch welche ich mich davon hätte überzeugen können, in wieweit meine Auffassung dieser Form mit derjenigen Le Jolis sich deckt; aber nach der Beschreibung, welche dieser Algolog von der f. ensifolia giebt, scheint es mir ziemlich ausser Zweifel gestellt, dass unsre norwegische Form mit der von ihm beschriebenen identisch ist. Taf. 5, Fig. 2, und Taf. 6, Fig. 1 zeigen die typische Form der f. ensifolia bei vollentwickelten Exemplaren.

Die Hapteren sind bereits oben (p. 11) genauer beschrieben worden.

Der Stamm ist gewöhnlich kürzer, als das Blatt, biegsam, unterwärts rund und dünn, in der Mitte zusammengedrückt, im Querschnitt fast elliptisch (Taf. 5, Fig. 4), wobei der längste Diameter bis $3 \mathrm{Cm}$. erreicht; nach dem Blatt hin dünner, aber auch hier mehr oder weniger zusammengedrückt; selten ist er am Oberende ebenso breit, oder gar breiter, als in der Mitte. Er ist glatt und etwas glänzend, aber die Farbe hell olivenartig oder doch beträchtlich heller, als bei der f. stenophylla; er ist nie mit Epiphyten bekleidet, und die Consistenz ist weniger fast, als bei den ïbrigen Formen. Bei jungen Individuen ist der Stamm fast gleichdick und fadenförmig.

Das Blatt ist theils breiter, als lang; theils, und am häufigsten, jedoch von grösserer Länge, als Breite. Die Basis ist bei ältern und vollentwickelten Exemplaren herzförmig. Das Blatt ist selten mehrfach gespalten; die Zipfel sind bisweilen nach der Spitze hin lang zugespitzt; bisweilen haben sie aber ihre grösste Breite nicht fern von der Spitze und sind dann ziemlich stumpf. Bei jungen Individuen ist das Blatt immer mehrere Mahl länger als breit, zugespitzt und mit schmaler keilförmiger Basis versehen (Taf. 6, Fig. 4-9). Die Zellen der Zwischenschicht stimmen im Wesentlichen mit denjenigen der f. typica überein, sie sind oft in longitudinale Reihen geordnet, nicht scharf von der Mittelschicht abgegrenzt; durchgehends hat aber das Blatt ein etwas loseres Element und dünnere Zellenwände, als die Hauptform. An norwegischen Exemplaren fehlen dem Blatte meistens die Schleim- 
lacunen, und wo sie vorhanden sind, zeigen dieselben sich sehr sparsam und von ziemlich ungleichmässiger Grösse (Taf. 5, Fig. 5, १und Taf. 6, Fig. 2).

Der Blattwechsel scheint bei dieser Form etwas früher stattzufinden, als bei den übrigen. Ich habe z. B. ältere, bei Bohuslen gesammelte Exemplare gesehen, welche bereits im Anfang des November den Blattwechsel begonnen hatten, und in Nordland habe ich im Anfang des März mehrere Exemplare mit dem vollentwickelten neuen Blatt angetroffen. Wie oben erwähnt, babe ich junge Individuen auch von dieser Art während der Sommermonate in mehr oder minder fortgeschrittenen Stadien des Blattwechsels beobachtet; aber nie ältere und vollentwickelte Pflanzen.

In einer etwas eingeschlossenen Bucht im südlichen Theil von Jäderen fand ich im letztverflossenen Sommer eine Form, welche bezüglich des Blattes bedeutend von der f. ensifolia differirte, aber übrigens mit typischen Exemplaren der letzteren übereinstimmte. Das Blatt war nämlich oft viel weniger getheilt und zugleich dünner, als gewöhnlich, und erinnerte an gewisse Formen von $L$. intermedia; es fehlten ihm aber die Schleimlacunen. In Bezug auf die Structur zeigt dasselbe sonst die meiste Uebereinstimmung mit dem Blatte der f. ensifolia. - Folgende Masse zeigen die Verhältnisse bei einigen dieser Exemplare.

\begin{tabular}{ccrccc} 
Total- & Stamm- & \multicolumn{2}{c}{ Blatt- } & \multicolumn{2}{c}{ Zipfel- } \\
länge. & $\begin{array}{c}\text { Länge. } \\
\text { Länge. }\end{array}$ & Breite. & Zahl. & Breite. \\
145 & 73 & 72 & 110 & 3 & $30-45$ \\
150 & 34 & 116 & 67 & 3 & $11-30$ \\
107 & 25 & 82 & 53 & 3 & $10-22$ \\
170 & 52 & 118 & 66 & 3 & $5-37$ \\
156 & 48 & 108 & 51 & 4 & $6-18$ \\
144 & 41 & 103 & 61 & 5 & $6-14$ \\
157 & 51 & 106 & 73 & 9 & $4-14$ \\
164 & 60 & 104 & 41 & 3 & $5-18$ \\
164 & 62 & 102 & 67 & 6 & $7-15$ \\
135 & 33 & 102 & 75 & 7 & $4-16$
\end{tabular}

1 Oder gesammelte Breite der Zipfel. 
CHRISTIANIA VIDENSK.-SELSK. FORHANDL. 1884 . No. 14.

\begin{tabular}{ccccrr} 
Total- & Stamm- & \multicolumn{2}{c}{ Blatt- } & \multicolumn{2}{c}{ Zipfel- } \\
länge. & länge. & \multicolumn{2}{c}{ Länge. } & Breite. & \multicolumn{2}{c}{ Zahl. } & Breite. \\
150 & 48 & 102 & 52 & 3 & $12-26$. \\
158 & 42 & 116 & 74 & 11 & $4-12$ \\
148 & 51 & 97 & 31 & 4 & $5-10$ \\
103 & 42 & 61 & 87 & 6 & $6-24$
\end{tabular}

Eine andere Form, die sich ebenfalls sehr weit von der typischen f. ensifolia entfernt, findet man in den Felsenbecken der litoralen Region in Nordland und Finmarken. Dieselbe hat einen sehr schwachen, kurzen, fast gleichmässig dicken Stamm und ein verhältnissmässig sehr langes, aber ziemlich schmales Blatt. Die Basis des letzteren ist herzförmig. Inwieweit diese Form wirklich der f. ensifolia unterzuordnen ist, muss ich einstweilen dahingestellt lassen; möglicherweise kann sie mit mehr Recht der f. typica beizuzählen sein; vor der Hand aber fehlen mir auch für letztere Annahme die ausreichenden Beweisgründe, da ich die Form nicht an Ort und Stelle in frischem Zustand genauer habe untersuchen können. - Folgende Masse zeigen die Dimensionsverhältnisse bei einigen derartigen Exemplaren.

$\begin{array}{cccc}\text { Totallänge. } & \text { Stammlänge. } & \text { Blattlänge. } & \text { Blattbreite. } \\ 143 & 18 & 125 & 20 \\ 109 & 9 & 100 & 15 \\ 66 & 6 & 60 & 21 \\ 192 & 32 & 160 & 22 \\ 119 & 14 & 105 & 32 \\ 99 & 9 & 90 & 18 \\ 94 & 14 & 80 & 35 \\ 117 & 7 & 110 & 30 \\ 71 & 6 & 65 & 26 \\ 135 & 5 & 130 & 50\end{array}$

L. digitata f. ensifolia ist eine litorale Pflanze, die aber auch in dem allerobersten Theil der sublitoralen Region vorkommt. Längs des südöstlichen Theils der Küste, an welcher der Unterschied zwischen Ebbe und Fluth höchst unbedeutend ausfallt, gedeiht sie in einer Tiefe von 1-2 Faden; es ist dies ein Abschnitt 
des Meeresbodens, der ziemlich genau der litoralen Region der westlichen und nördlichen Küste Norwegens entsprechen dürfte. ${ }^{1}$ Am besten gedeiht diese Form an etwas geschützten Fundorten, und dringt sogar ziemlich tief in das Innere der Fjorden hinein, kommt aber auch am offenen Meere vor. Sie ist überall ziemlich gemein.

L. digitata f. debilipes schliesst sich ziemlich nahe an die ebenbehandelte Form an; unterscheidet sich aber von derselben besonders durch ihren schwächeren Stamm und ihr sehr dickes Blatt.

Die Hapteren stimmen in der Regel mit denjenigen der f. ensifolia überein; sie sind meist schwach, niedergedrückt und wenig verzweigt.

Der Stamm ist kurz, schwach und sehr biegsam, fast überall gleich dick. Bisweilen zeigt er sich jedoch in der Mitte etwas dicker und zusammengedrückt, und unsere For'm nähert sich dadurch der f. ensifolia.

Das Blatt ist in der Mitte $1.5-3 \mathrm{Cm}$. dick und ziemlich steif; vollentwickelt zeigt es sich gewöhnlich länger, als breit; bisweilen ist es fast ungetheilt, bisweilen in wenige, aber meist breite und kurze Zipfel gespalten. Es ist nie so glatt, wie bei f. ensifolia, und seine Farbe etwas heller, als bei jener. Bezüglich der Structur besteht der Unterschied von f. ensifolia in einem etwas dichteren Element; auch sind die Zellen der Zwischenschicht hier etwas kleiner, als dort. Die Schleimlacunen, welche nie fehlen, sind gross und zahlreich (Taf. 6, Fig. 11).

Junge Individuen lassen sich, meinen Erfahrungen gemäss, immer leicht von den gleichaltrigen übrigen Formen unterscheiden. Das Blatt zeigt sich bereits in diesem Alterstadium verhältnissmässig dick; die Basis ist entweder eirund, oder fast herzförmig; an der Spitze zeigt sich das Blatt theils ganz abgestumpft und ein wenig eingerissen, theils schwach zugespitzt, aber im Verhältniss zur Länge immer breiter, als bei f. ensifolia in diesem Alter.

Ich habe diese Form bisher bloss bei Gjesvär und Christan-

1 Vergl. Kjell m. Algenreg. und Algenform. p. 5. 
sund angetroffen. An ersterem Orte trat sie sehr distinct auf und zeigte eine auffallende Abweichung von den übrigen Formen der $L$. digitata, besonders in Anbetracht des dünnen und schwachen Stammes, so wie des relativ ungemein dicken Blattes. Bei Christiansund zeigte sie bisweilen eine grössere Annäherung an f. ensifolia; ich fand z. B. eine paar Exemplare, deren Stamm etwas dickel war, als gewöhnlich, und in der Mitte eine Zusammendrückung, nach Art der f. ensifolia, aufwies; auch zeigte derselbe die gleiche Verdünnung am Ober- und Unterende, und das Blatt dieselbe Theilung, die wir an der f. ensifolia kennen.

Folgende Masse vergegenwärtigen die Dimensionsverhältnisse einiger dieser bei Gjesvär und Christiansund eingesammelten Exemplare.

\begin{tabular}{lccr} 
Total- & Stamm- & \multicolumn{2}{c}{ Blatt- } \\
länge. & länge. & $\begin{array}{c}\text { länge. } \\
\text { breite. }\end{array}$ \\
33 & 2 & 31 & 10 \\
20.5 & 9.5 & 11 & 6 \\
45 & 6 & 39 & 18 \\
34.5 & 3.5 & 31 & 20 \\
48 & 7 & 41 & 34 \\
84 & 28 & 56 & 20 \\
61.5 & 10.5 & 51 & 28 \\
61 & 8 & 53 & 27
\end{tabular}

Die Form ist litoral, und wächst auf Klippen in dem unteren Theil der litoralen Region, zeigt sich aber auch in Felsenbecken, sowie im allerobersten Saum der sublitoralen Region. An beiden oben ıngegebenen Fundstätten zeigte sie sich local und sparsam. Sie scheint etwas ausgesetzte Stellen vorzuziehen.

Laminaria intermedia $\mathrm{n} o \mathrm{~b}$.

L. hapteris plerumque valde ramosis, ramis irregulariter dispositis, ultimis sensim tenuioribus; stipite flexili, inferne tereti, mox compresso vel superne complanato, basi subconstricto; lamina plantæ junioris integra, ovali-oblonga vel ovata, 
plantæ adultæ integra vel in lacinias latas pauciores fissa, basi cordata, cucullata, interdum plana, sæpe bullata, coriaceomembranacea, flavescenti-olivacea; lacunis muciferis in stipite nullis, in lamina distinctis, sat magnis.

\section{f. longipes nob.}

L. forma stipite longiore usque $0.5-1 \mathrm{~m}$.; lamina subintegra vel in lacinias panciores, $10-30 \mathrm{~cm}$. latas, plus minusque profunde fissa. Tab. $7-8$.

f. cucullata (L e Jol.) Foslie.

Descr. Laminaria flexicaulis c. cucullata. Le Jol. 1. c. p. 59.

$\begin{array}{cll} & " & \text { cucullata f. typica Foslie 1. c. p. } 25 . \\ \text { Fig. } & " & \text { intermedia f. cucullata tab. nostræ 9-10, fig. 1-16. }\end{array}$

f. ovata (Le Jol.) Foslie.

Descr. Laminaria flexicaulis b. ovata Le Jol. 1. c.

" $\quad$ cucullata f. ovata Foslie 1. c. p. 27.

Fig. $\quad " \quad$ intermedia f. ovata tab. nostra 10, fig. 17-18.

Exsicc. $\quad$ digitata $b$. Aresch. Alg. scand. exsicc. No. 167.

Syn. Laminaria digitata b. latifolia Aresch in Linn; non C. Ag.

$" \quad$ " $\quad \begin{aligned} & \text { Aresch. Phyc. Scand. p. } \\ & 122 \text {; excl. syn. }\end{aligned}$
$" \quad$ flexicaulis f. latilaciniata Foslie 1. c. p. 21.
subf. latifc?ia Aresch. Obs. p. 10.
" cordata J. G. Ag. Nov. p. 26?
digitata b. integrifolia J. G. Ag. Lamin. p. 24?

Wie alle Laminarien zeigt auch diese Art eine bedeutende Neigung zum Variiren. Durch f. longipes nähert sie sich in einzelnen Beziehungen der $L$. digitata, auf der andern Seite aber ist sie durch die f. ovata mit $L$. saccharina verbunden. Unsere Art bildet somit ein Verbindungsglied zwischen den Gruppen Digitate und Saccharince.

Wie bereits unter $L$. digitata bemerkt wurde, ist f. longipes 
(f. latilaciniata) im "Bidr." ursprünglich als eine Form jener Art aufgestellt, und f. cucullata mit f. ovata zu einer besonderen Art, L. cucullata, zusammengeschmolzen worden. Damals hatte ich die zwei letztgenannten Formen nur an einer vereinzelten Fundstätte in West-Finmarken, und einige wenige Exemplare der f. longipes in einer ganz anderen und weit abgelegenen Gegend zu Gesicht bekommen. Unter meinen Reisen in den letzten beiden Sommern bin ich nun nicht bloss in der Auffassung bestärkt worden, dass f. cucullata und f. ovata als eine von $L$. digitata (L.) Edm. thatsächlich geschiedene Art anzusehen sind, sondern ich habe auch diese beiden Formen die ganze Küste entlang, von Ost-Finmarken an bis zu den Hvalöern, an der südöstlichen Landesgrenze, verfolgen können, und, trotz der vielen Hunderte von Exemplaren, die ich in Händen gehabt habe, ist doch anch nicht ein einziges Mal ein Zweifel daran bei mir aufgestiegen, dass dieselben $n \mathrm{icht}$ der $L$. digitata sich unterordnen lassen. Die dritte der obenerwähnten Formen, f. longipes, zeigt freilich, wie auch im "Bidr." angedeutet wurde, ein ziemlich distinctes Auftreten; doch aber meinte ich damals dieselbe bloss als eine Localitätsänderung der $L$. digitata ansehen zu müssen. Es fehlte mir damals am genügenden Material zur Beurtheilung ihres Charakters und ihres rechten Platzes im System, besonders was ihr Verhaltens der f. cucullata gegenüber betrifft. Später habe ich unsere Pflanze an ein paar andern Orten in Finmarken angetroffen; und es gelang mir hier, zumal an einem dieser Fundorte, bei Gjesvär in der Nähe des Nordcaps aus einer Tiefe von 2-3 Faden einige Exemplare zu erbeuten, welche sich der f. cucullata nahe anschlossen. In dieser Gegend traf ich ausserdem an einer andern Stelle, wo fo cucullata häufig vorkam, einige Exemplare letzterer Form, welche in die f. longipes übergingen. Ferner fand ich im letztverflossenen Sommer im Christiania-Fjord einige Exemplare, welche die f. longipes mit der f. cucullata verbinden. - Obwohl es also einleuchten muss, dass die f. longipes viel enger mit der $L$. intermedia f. cucullata verbunden ist, als mit der $L$. digitata, tritt dieselbe doch in den meisten Fällen ziemlich distinct auf, und es ist darum auch nicht unmöglich, dass 
sich im Lauf der Zeit herausstellen kann, dass dieselbe eigentlich eine selbständige Art vorstellt. Nach dem gegenwärtigen Standpunkt unserer Kenntniss der betreffenden Verhältnisse ist es jedoch das natürlichste sämmtliche drei als Formen dergleichen Art anzusehen. In jungem Alter zeigt denn auch f. longipes eine grosse Uebereinstimmung mit der f. cucullata auf derselben Altersstufe und eine bedeutende Abweichung von sämmtlichen Formen der L. digitata. Taf. 7, Fig. 6 zeigt ein junges Individuum von Berlevaag in Ost-Finmarken, wo diese Form weniger distinct auftritt und sich in etwas der $L$. digitata nähert. Auf Taf. 8, Fig. 6 sieht man ein Individuum von ungefähr gleichem Alter aus Russemark in WestFinmarken, welches in allem wesentlichen mit dem letzterwähnten aus Berlevaag übereinstimmt; Fig. 5, Taf. 9, sowie Fig. 3, Taf. 10 stellen endlich Individuen der f. cucillata von ungefähr ebenfalls dem gleichen Alter vor; zwischen allen diesen Darstellungen ist die Aehnlichkeit nicht zu verkennen.

Unter den mehrfach genannten Formen ist es allein die f. ovata, welche auf eine Verbindung zwischen $\boldsymbol{E}$. intermedia und L. saccharina hindeutet, und auch hier lässt sich eine solche nur in Bezug auf die äusseren habituellen Charaktere nachweisen, und ist obendrein, selbst in dieser Beschränkung, ziemlich selten. Bei Christiansund fand ich jedoch in einer Tiefe von ca. 5 Faden ein paar Exemplare von f. ovata, welche eine grosse äussere Aehnlichkeit mit $L$. saccharina f. latissima aufwiesen. Die Farbe dieser Exemplare war bedeutend dunkler, als gewöhnlich, und erst durch die anatomische Untersuchung liessen sie sich mit Sicherheit bestimmen. In letzterer Beziehung ist der Unterschied jedoch bedeutend. L. saccharina hat nämlich immer ein verhältnissmässig viel loseres Element und grössere Zellen in der Zwischenschicht. In Finmarken wachsen f. cucullata und f. ovata gewöhnlich zusammen mit L. snccharina f. oblonga; lassen sich jedoch auch in sehr jungem Alter mit Leichtigkeit von letzterer unterscheiden.

In Bezug auf die Structur lässt sich kaum ein nennenwerther Unterschied zwischen $L$. intermedia und $L$. digitata angeben; doch sind die Zellen der Zwischenschicht bei der ersteren gewöhnlich 
etwas kleiner, und das Blatt derselben ist immer mit Schleimlacunen versehen (und zwar in der Regel mit ziemlich grossen). Die Zellen der Zwischenschicht sind oft, wie bei L. digitata f. typica und f. ensifolia, in ziemlich regelmässige longitudinale Reihen geordnet.

Die Farbe der $L$. intermedia ist fast immer heller, als diejenige der $L$. digitata f. typica. Die Pflanze ist selten besonders glatt, doch fast nie mit Epiphyten bekleidet. Dagegen ist das Blatt immer (oder fast immer) mit einer Annelide, Spirorbis, besetzt, während ich diese nie auf der $L$. digitata gesehen habe. Sogar bei den Exemplaren der f. longipes, welche sich der L. digitata am meisten näherm, habe ich das Blatt mehr oder weniger mit dieser Annelide besetzt gefunden. Dieselbe kommt auch sehr häufig auf $L$. saccharina vor.

L. intermedia f. longipes. Dies ist die grösste der drei Formen und zeichnet sich besonders durch ihr grosses Blatt und durch den ziemlich langen und sehr biegsamen Stamm aus.

Die Hapteren sind fein und stark verzweigt, ohne bestimmte Ordnung (Vergl. Taf. 7, Fig. 1 u. Taf. 8, Fig. 1). Bereits durch dieses Merkmaal lässt sich diese Form meist von den Formen der $L$. digitata unterscheiden, mit welchen sie verwechselt werden kann. $\mathrm{Ab}$ und $\mathrm{zu}$ trifft man freilich auch Exemplare, deren Hapteren gröber sind, und eine geringere Verdünnung und Verästelung zeigen, so dass ihre Formation sich derjenigen der Hapteren bei $L$. digitata f. typica bedeutend nähert.

Die hier als Regel angegebene Beschaffenheit der Haftorgane, d. h. ihre Feinheit und ihre starke Verästelung, - scheint nicht damit zusammen zu hängen, dass unsere Alge gewöhnlich an ziemlich geschützten Stellen (übrigens auf losem sowohl, als auf festem Boden) wächst; wie denn überhaupt die physische Beschaffenheit des Bodens, und wohl auch die andern äusseren Verhältnisse bei unserer Form keinen so grossen Einfluss auf die Formation der Hapteren üben dürften, wie dies bei $L$. hyperborea der Fall ist (vergl. p. 11). Es sind nämlich diese Organe bei der $L$. intermedia auch dort, wo dieselbe auf Felsenboden und am ziemlich exponirten Or- 
ten sich angesiedelt hat, durchgehends fast ebenso fein und ebenso ästig, wie da, wo unsere Alge auf loser Unterlage und in Fjorden oder sonstigen geschützten Gewässern ihren Standort gefunden hat. Die auf Taf. 7, Fig. 1 i. 5 dargestellten Exemplare sind so z. B. auf Felsboden an einem ziemlich ausgesetzten Punkt bei Berlevaag in Ost-Finmarken gewachsen, während das Exemplar Taf. 8, Fig. 1 bei Russemark in Porsanger (West-Finmarken) d. h. an einem Orte gefunden ist, an welchem die Pflanze nur selten einem bedeutenderen Wellenschlag ausgesetzt war, und an welchem der Meeresgrund mit Send und kleinen Steinen bedeckt ist.

Der Stamm ist bei dieser Form oft ziemlich dick, aber desungeachtet sehr biegsam, bisweilen fast liegend. $\mathrm{Er}$ ist immer dünner an der Basis, als in der Mitte. Letztere ist entweder rund, wie das Unterende (Taf. 7, Fig. 1-3) oder zusammengedrückt (Taf. 8, Fig 1). Von der Mitte bis zum Blatte ist der Stamm immer mehr oder weniger zusammengedrückt. Der obere Stammtheil ist bisweilen auch ziemlich abgeflacht und bis volle $4 \mathrm{Cm}$. breit; gewöhnlich jedoch dünner und schmaler, als die Mitte des Stammes (Taf. 7, Fig. 1; Taf. 8, Fig. 1).

Das Blatt ist gewöhnlich, im Verhältniss zur Länge und Dicke des Stammes, sehr gross. Selten ist dasselbe mehrfach und tief gespalten. Taf. 7, Fig. 1 zeigt die Formextreme in dieser Richtung. Die Zipfel sind breit, gewöhnlich 10-30 Cm. Bisweilen zeigt sich das Blatt aber auch so gut wie ganz unzertheilt, nierenförmig und in seiner unteren Hälfte ausgebauscht, mit einer Concavität, die bis auf $20 \mathrm{Cm}$. steigen kann; letztere ist bisweilen uneben und sehr bauschig (Taf. 8, Fig. 1), bisweilen aber auch ganz eben und etwas glatt, doch niemals so glatt, wie bei den grösseren Digitata-Formen. Ferner ist das Blatt fast immer ziemlich dünn, theils sehr geschmeidig, theils ein wenig steif und spröde; letzteres bei Pflanzen, die tief im Inneren der Fjorden gewachsen sind. Die Epidermiszellen sind gewöhnlich sehr klein (Taf. 7, Fig. 4; Taf. 8, Fig. 3). Die Zellen der Zwischenschicht sind auch etwas kleiner, als diejenigen der $L$. digitata f. typica, obwohl sie sonst mit letzteren recht grosse Uebereinstimmung zeigen. Schleim- 
lacunen sind immer im Blatte $\mathrm{zu}$ erkennen; ihre Zahl ist gross, aber in Bezug auf ihre Dimensionen macht sich bisweilen bedeutende Ungleichartigkeit geltend.

Die Zeit der Blattwechsels bei dieser Form habe ich nicht bestimmen können. Ich habe nur einige junge in den Sommermonaten gesammelte Exemplare zur Ansicht bekommen. Taf. 7, Fig. 6 zeigt eines derselben, das im Anfang des August gefunden wurde, und noch Reste des alten Blattes trägt.

Folgende Masse zeigen die Dimensionsverhältnisse bei einigen finmarkischen Exemplaren dieser Form.

\begin{tabular}{rcrr} 
Total- & Stamm- & \multicolumn{2}{c}{ Blatt- } \\
länge. & länge. & länge. & breite. \\
136 & 34 & 102 & 80 \\
168 & 76 & 92 & 124 \\
110 & 60 & 50 & 40 \\
100 & 40 & 60 & 40 \\
157 & 55 & 102 & 130 \\
132 & 70 & 62 & 80 \\
133 & 75 & 58 & 104 \\
147 & 72 & 75 & 160 \\
116 & 66 & 50 & 88 \\
150 & 74 & 76 & 93 \\
186 & 82 & 104 & 98 \\
140 & 82 & 58 & 72 \\
117 & 54 & 63 & 47 \\
148 & 70 & 78 & 68 \\
108 & 56 & 52 & 67 \\
85 & 15 & 70 & 70
\end{tabular}

Die Form ist sublitoral und gehört dem obersten Theil dieser Region an. Ich habe dieselbe nicht in Tiefen gefunden, die $3 \mathrm{Fa}$ den übersteigen. Sie gedeiht am besten an etwas geschützten Orten, und geht ziemlich weit in die Fjorden hinein. In Finmarken findet sie sich local und ziemlich gemein bei Berlevaag und Russemark; bei Gjesvär traf ich einige wenige Exemplare. Längs der Westküste habe ich dieselbe nicht entdeckt, doch kommt sie wahr- 
scheinlich auch hier vor. Längs des südöstlichen Theils der Küste scheint sie sparsam zu sein. Hier habe ich nur einige Exemplare im Innern des Christiania-Fjords gefunden.

L. intermedia f. cucullata. In der Gestalt, in welcher diese Form längs der norwegischen Küste auftritt, zeichnet sie sich besonders aus durch ihren dünnen und langen Stamm und ihr relativ grosses, fast ungetheiltes Blatt.

Die Hapteren stimmen mit denjenigen der soeben beschriebenen Form überein. Uebrigens trifft man hie und da Exemplare mit ziemlich regelmässigen Hapteren (Taf. 9, Fig. 2), aber auch diese sind doch immer verhältnissmässig länger und werden bedeutend dünner, als die Hapteren der L. digitata.

Der Stamm ist in der Regel viel kürzer, als das Blatt, dabei dünn und schwach. Unterwärts ist derselbe rund, bisweilen an der Basis dünner, als in der Mitte, und dann hier gewöhnlich ein wenig zusammengedrïckt, bisweilen aber auch überall fast gleich dick. Von der Mitte aus nach dem Blatte hin wird er in der Regel schmaler, ist jedoch bisweilen am Oberende breiter und mehr zusammengedrückt, als in der Mitte.

Das Blatt ist bald länger, bald kürzer, als breit; die Basis herzförmig. Bei vollentwickelten Exemplaren ist es mehr oder weniger concav. Im jüngeren Alter der Pflanze ist das Blatt in der Regel eirund oder oval und fast plan; später aber beginnt es rascher in die Breite zu wachsen, und gleichzeitig nimmt die Concavität zu. Bei vollentwickelten Exemplaren habe ich eine Concavität bis zu $25 \mathrm{Cm}$. beobachtet. Selten sieht man das Blatt in eine verhältnissmässig grössere Anzahl von Zipfel gespalten, und letztere sind sehr breit und kurz. Am sïdöstlichen Theil der Küste habe ich nur ausnahmsweise Exemplare mit gespaltenem Blatt angetroffen; von solchen sah ich auch nur einige wenige unter den der grossen Zahl von Exemplaren, die ich ans Bohuslen in Schweden in Händen gehabt habe. Wenn die Pflanze in ganz eingeschlossenen Sunden oder Buchten wächst, wird das Blatt oft ein wenig spröde. Die Zellen der Zwischenschicht gleichen denjenigen 
der vorigen Form. Die Schleimlacunen sind zahlreich und ziemlich gross (Taf. 9, Fig. 4).

Folgende Masse erläutern das Verhältniss zwischen der Länge des Stammes und der Länge und Breite des Blattes bei finmarkischen Exemplaren.

\begin{tabular}{cccc} 
Total- & Stamm- & \multicolumn{2}{c}{ Blatt- } \\
länge. & länge. & länge. & breite. \\
52 & 2 & 50 & 30 \\
71 & 11 & 60 & 70 \\
61.5 & 1.5 & 60 & 40 \\
52.5 & 2.5 & 50 & 55 \\
73 & 3 & 70 & 55 \\
41 & 1 & 40 & 55 \\
55 & 5 & 50 & 45 \\
63 & 8 & 55 & 80 \\
54.5 & 1.5 & 53 & 42 \\
56 & 4 & 52 & 85 \\
30.5 & 0.5 & 30 & 22 \\
22.5 & 4.5 & 18 & 12 \\
84 & 26 & 58 & 54 \\
111 & 35 & 76 & 64 \\
78 & 17 & 61 & 86 \\
79 & 6 & 73 & 94
\end{tabular}

An der südöstlichen Küstenstrecke, sowie in Bohuslen in Schweden, wird unsere Form gewöhnlich etwas grösser.

Nach den im Reichsmuseum in Stockholm anf bewahrten Exemplaren zu schliessen, scheint der Blattwechsel bei älteren oder vollentwickelten Exemplaren ungefähr in der Zeit zwischen dem Anfang des Decembers und dem Schluss des April vor sich zu gehen; doch habe ich anch im März gesammelte Exemplare gesehen, bei welchen das neue Blatt fast voll entwickelt erschien, aber auch wieder im Mai gefundene Exemplare, die immer noch Ueberreste des alten Blattes an sich trugen. In Finmarken habe ich im Juni, Juli und August zahlreiche junge, im Blattwechsel begriffene Ex- 
emplare angetroffen; nie aber ältere Individuen in gleichem Verhältnisse (Taf. 10, Fig. 3, 5, 6, 8, 9 u. 10).

Unsere Form ist sublitoral und gehört dem oberen Theil dieser Region; es kommt dieselbe aber auch im tiefsten Theil der litoralen Region vor. Bei Havösund und Gjesvär in West-Finmarken war dieselbe local und ziemlich gemein. Bei Christiansund erhielt ich ein paar Exemplare aus einer Tiefe von ca. 5 Faden. Längs des südöstlichen Theils der Küste scheint dieselbe gemein zu sein. An exponirten Orten scheint sie selten vorzukommen.

$L$. intermedia f. ovata. Diese unterscheidet sich von der vorigen Form durch ihr planes Blatt, dessen Gestalt im Umfang bald eirund, bald beinahe nierenförmig, bald aber auch ei-lanzettlich sich darstellt. Sonst stimmt dieselbe mit der f. cucullata überein, und die Uebergänge von der einen zur andern sind vollständig. In Finmarken tritt dieselbe nur in Gesellschaft mit f. cucullata auf; ist aber selten.

\section{Saccharinæ.}

Laminaria saccharina (L.) Lamour.

Essai p. 42; Fucus saccharinus L. Spec. Plant. II, p. 1161.

f. linearis $\mathrm{J}$. G. Ag.

Lamin. p. 12.

Descr. Laminaria saccharina a. linearis J. G. Ag. 1. c.

f. prima J. G. Ag. Spec. Alg.I, p. 132.

Fig. Fucus saccharinus Fl. Dan. t. 416.

f. oblonga J. G. A g.

l. c. p. 12.

Descr. Laminaria saccharina b. oblonga J. G. Ag. l. c.

f. membranacea J. G. Ag.

l. c. p. 13.

Descr Laminaria saccharina c. membranacea J. G. Ag. l. c. 
f. longissima ( $(\mathrm{unn}$.) nob.

Descr. Ulva longissima Gunn. Fl. Norv. II, p. 128, t. 7.

" Laminaria saccharina f. grandifolia Kjellm. Ishafsfl. p. 287.

f. borealis nob.

Descr. Laminaria saccharina f. latissima Kjellm. l. c.; non Lyngb.

f. Agardhii (Kjellm.) nob.

Descr. Laminaria caperata J. G. Ag. Lamin. p. 13.

Fig. " Agardhii Kjellm. Spetsb. Thalloph. II, p. 18. $" \quad$ Kjellm. l. c. t. 1, fig. 2-3.

Syn. Ulva maxima Gunn. l. c. p. 47, t. 7. Fucus saccharinus Gunn. l. c. I, p. 52; excl. syn. plur.

Fl. Dan. t. 2197.

$"$. Th. Dan, t. 2197.

$\begin{array}{lll}" & \quad & \text { Fl. Dan. t. } 2197 . \\ " & \quad & \text { Tonning, Rar. Norv. p. } 12 . \\ " & \quad & \text { Hammer, Fl. Norv. p. } 139 . \\ " & \quad & \text { Retz. Fl. Scand. p. } 299 . \\ & \quad & \text { Wahlenb. Fl. Lapp. p. } 493 .\end{array}$

Laminaria Phyllitis C. Ag. Syn. Alg. p. 18; excl. syn. " saccharina C. Ag. Spec. Alg. I, p. 117; Syn. Alg. p. 17.

$" \quad$ " Lyngb. Hydroph. Dan. p. 21.

" $\quad$ Hornem. Plantel. II, p. 739.

$" \quad$ Aresch. Phyc. Scand. p. 121.

$" \quad$ Kleen, Nordl. Alg. p. 32.

" caperata Kleen l. c.

" saccharina var. septentrionalis Rostaf. in Gobi, Algenfl. Weiss. Meer. p. 78. Kjellm. Ishafsfl. p. 286.

" australis Aresch. Obs. Phyc. p. 13. Agardhii Kjellm. Spetsb. Thalloph. II, p. 18; Algenveg. Murm. Meer. p. 37; Kariska hafv. algveg. p. 24; Ishafsfl. p. 292. 
Syn. Laminaria caperata Gobi, Algenfl. Weiss. Meer. p. 76.

\section{"}

"
Kjellm. Vinteralgveg. p. 64.

saccharina borealis Aresch. Obs. Phyc. p. 14.

In seiner "Ishafsfl." nimmt F. R. Kjellman unter L. saccharina die beiden von J.G. Agardh beschriebenen Formen auf, d.h. f. linearis und f. oblonga, und beschreibt daneben zwei nene Formen: f. latissima und f. grandifolia. Der erste dieser Namen, f. latissima, ist bereits von Lyngbye für eine Saccharina-Form benutzt, und es muss diese Lyngbye'sche Form, so weit ich zu urtheilen vermag, dieselbe Form sein, von welcher Kjellman in der "Ishafsfl." erzählt, dass sie in Bohuslen vorkommt und der nordischen f. latissima Kjellm. entspricht. Lyng by e selbst identificirt seine f. latissima mit der L. maxima (Gunn.), führt aber dabei an, dass er dieselbe in der Tiefe der Fjorde von Odense in Dänemark gefunden habe, und ebenso berichtet Hornemann, dass dieselbe Form von Suhr im Hafen bei Sonderburg, in der Geltingbucht, bei Fehmarn und bei Neustadt beobachtet sei. Da unter solchen Umständen die f. latissima Lyngb. kaum ganz identisch mit der nordischen f. latissima Kjellm. sein kann, erlaube ich mir letzteren Namen mit f. borealis zu vertauschen. Mit dieser ist dann wohl L. maxima ( $\mathrm{Gunn}$.), vielleicht anch L. latifolia C. Ag. identisch. Von der ersten, der L. maxima Gunn., nimmt $J$. G. Agardh ${ }^{1}$ an, dass sie der hocharctischen $L$. caperata J. G. Ag. (=L. Agardhii Kjell m.) angehört; schon Kjellman ${ }^{2}$ bezeichnet indessen diese Vermuthung als minder wahrscheinlich. Ich bin mit Kjellman darin einig, das L. maxima (Gunn.) nicht unter die L. Agardhii eingeordnet werden darf; dagegen sehe ich es aber für ziemlich ausgemacht an, dass dieselbe mit der f. borealis identisch ist. In der knappen Beschreibung des Gunnerus finde ich nichts, das einer solchen Annahme widersprechen könnte. Freilich trifft man nur selten Exemplare, deren Breite die Länge übertrifft; und obwohl wir es hier mit derjenigen Form von $L$. saccharina zu thun haben, deren Blatt die relativ grösste Breite erlangt,

\footnotetext{
1 Grönl. Lamin. och Fuc. p. 15.

2 Spetsb. Thalloph, p. 24.
} 
habe ich doch nie ein Exemplar gesehen, dessen Blatt eine Breite von 1 Faden (und mehr als das), und dabei nur eine Länge von 2 Ellen, gehabt hätte. Hierbei ist jedoch zu bemerken, dass Gunnerus solche Exemplare auch nicht selbst gesehen haben will, sondern nur nach dem, was andere ihm berichtet haben, von solchen redet. Den Massangaben ist daher kaum besonderes Gewicht beizulegen. Die Abbildung (l. c. t. IIJ, fig. 5) erinnert mehrfach an gewisse Formen der f. borealis. Dass indessen die Figur eine Wiedergabe von $L$. maxima in natürlicher Grösse nach einem jüngeren Exemplar vorstellen soll, ist freilich schwer zu annehmen; es ist aber in Betracht zu ziehen, dass die Zeichnung gewiss nach einem getrockneten Exemplar ausgeführt worden ist.

Bleibt aber auch noch ein Zweifel darüber, welche Pflanze unter der $L$. maxima des Gunnerus zu verstehen ist, so ist dies nicht mehr der Fall bei der von ihm beschriebene Alge, welche er Ulva longissima nennt. Unter diese glaube ich nämlich ohne irgend welches Bedenken jene, ebenfalls an der westlichen und nördlichen Küste vorkommende Saccharina-Form einordnen zu dürfen, die mit der von $\mathrm{Kjellm}$ an beschriebenen f. grandifolia identisch ist. Ich habe mir daher, wie oben geschehen, die Freiheit genommen, letzteren Namen mit der Bezeichnung f. longissima (Gunn.) zu vertauschen.

In Uebereinstimmung mit J. E. Areschoug ${ }^{1}$ betrachte ich L. Agardhii Kjellm. als eine Form der L. saccharina. Ich begründe dies in folgender Weise. In seiner "Spitsb. Thalloph." (p. 24) gesteht Kjellman selbst ein, wie schwierig es ist, irgend welche bestimmte Grenze zwischen der $L$. saccharina und der dort von ihm beschriebenen $L$. Agardhii abzustecken. In ähnlicher Weise spricht er sich in seiner "Algenveg. des Murmanschen Meeres“ aus. Es heisst nämlich (p. 37): „Ich betrachte daher jede im südöstlichsten Theil des Murmanschen Meeres, am sïdlichen Nowaja Semlja und der Insel Wajgatsch, vorkommende Laminaria, die zur Saccharina-Gruppe dieser Gattung gehört, als L. Agardhii; doch gebe ich ausdrücklich an, dass sie im südlichen Theile des 
Gebietes unter Formen auftritt, die sich der $L$. saccharina so sehr nähern, dass sie, wenn sie in einer Gegend angetroffen würden, wo diese Art die vorherrschende wäre, mit der grössten Befugniss zu ihr gerechnet werden könnte." Als weiteren Beitrag zu der in den obenerwähnten Arbeiten von ihm und J. G. Agardh (letzterer unter $L$. caperata) gegebenen Beschreibung der L. Agardhii, berichtet $\mathrm{Kj}$ ellman in seiner "Ishafsfl.", dass er eine Menge von Exemplaren der betreffenden Art untersucht habe, ohne je Schleimlacunen im Blatte aufzufinden. Dieses Fehlen der Schleimlacunen würde somit, nach dem obigen, das einzige sichere Kennzeichen zur Unterscheidung der fraglichen Art von L. saccharina abgeben. Ich habe jedoch zahlreiche Exemplare der $L$. saccharina untersucht, und dabei nicht so selten solche getroffen, bei welchen die Lacunen entweder ganz fehlten oder, falls sie existirten, doch wenigstens sehr klein waren und sich kaum nachweisen liessen. So fand ich bei den Hvalöern ein Exemplar ohne, und ein anderes mit kleinen, zerstreuten Lacunen; bei Jäderen ein vereinzeltes Exemplar der f. oblonga, ebenfalls olne Lacunen; auch in Nordland und in Finmarken habe ich Exemplare der übrigen Formen angetroffen, bei welchen ich die in Frage stehenden Lacunen nicht nachweisen konnte. Bei Mehavn in Ost-Finmarken erhielt ich aus einer Tiefe von 10-15 Faden drei Exemplare, welche nach ihrem äusseren, habituellen Charakter sich ebenso leicht unter die $L$. Agardhii, als unter L. saccharina f. longissima einordnen liessen. Das eine derselben schien mir sogar am natürlichsten als eine f. borealis aufgefasst werden zu können. Sie waren ohne Rugä; die Consistenz fast membranös; das eine derselben zeigte sich schwach bauschig, die beiden anderen dagegen so ziemlich eben, aber mit einem ziemlich stark wellenförmigen Rand versehen. Folgende Zahlen vergegenwärtigen die Massverhältnisse bei diesen 3 Exemplaren.

\begin{tabular}{rccc} 
Total- & Stamm- & \multicolumn{2}{c}{ Blatt- } \\
länge. & länge. & länge. & breite. \\
170 & 50 & 120 & 54 \\
91 & 37 & 54 & 38 \\
163 & 102 & 61 & 62
\end{tabular}


Irgend welchen eigentlichen Unterscheid zwischen diesen drei Exemplaren nachzuweisen, war ganz unmöglich, abgesehen von dem Umstand, dass zwei derselben Schleimlacunen im Blatte besassen, das dritte aber nicht. Derartigen Beobachtungen gegenüber wird man dem für die L. Agardhii angegebenen Charakter, - dem Fehlen der Schleimlacunen, - kaum eine grössere Bedeutung beilegen dürfen. Daher habe ich es gewagt, die L. Agardhii als eine Form der $L$. saccharina aufzunehmen.

L. saccharina f. linearis. Bei den meisten finmarkischen Exemplaren dieser Form sind auf dem Blatte drei Felder unterscheidbar: ein Mittelfeld, das eine schmales, ebenes oder bauschiges, durch die ganze Länge des Blattes sich durchziehendes Band darstellt, ein Zwischenfeld, das sich stark rugös zeigt, und ein Randfeld, welches ziemlich dünn und mehr oder weniger wellig erscheint. Bei der grossen Mehrzahl ist das Mittelfeld scharf vom Zwischenfeld abgegrenzt; bei anderen ist jedoch die Grenze nicht so bestimmt, und fast das ganze Blatt rugös; und wieder bei anderen ist keine Spur von Mittelband zu entdecken, sondern das ganze Blatt zeigt sich stark rugös und bisweilen mit ganz flachem Rande. Letztere Blattform bezeichnet einen Uebergang zur f. oblonga.

Folgende Masse zeigen das Verhalten bei einigen finmarkischen Exemplaren.

\begin{tabular}{rcrr} 
Total- & $\begin{array}{c}\text { Stamm- } \\
\text { länge. }\end{array}$ & \multicolumn{2}{c}{ Rlatt- } \\
länge. & breite. \\
226 & 36 & 190 & 22 \\
175 & 31 & 144 & 8 \\
214 & 33 & 181 & 20 \\
219 & 31 & 188 & 12 \\
334 & 26 & 308 & 12 \\
153 & 27 & 126 & 10 \\
323 & 41 & 282 & 26 \\
78 & 27 & 51 & 6 \\
88 & 24 & 64 & 5 \\
72 & 2 & 70 & 5 \\
51 & 3 & 48 & 4
\end{tabular}


Das Maximum ihrer Frequenz scheint unsere Form in OstFinmarken zu erreichen. Hier habe ich zum mindesten grosse Mengen vom Meere ausgeworfen, am Ufer liegen sehen. Zugleich scheinen auch die Dimensionen der Pflanze hier die bedeutendsten zu sein.

$L$. saccharina f. oblonga. Diese unterscheidet sich von der vorigen Form durch ihr, im Verhältniss zur Länge, etwas breiteres, weniger rugöses, und oft etwas dünnes Blatt.

Folgende Ziffern illustriren das Verhalten bei Exemplaren vom nördlichen Theil der Küste.

\begin{tabular}{cccc} 
Total- & Stamm- & \multicolumn{2}{c}{ Blatt- } \\
länge. & länge. & länge. & breite. \\
83 & 32 & 51 & 26 \\
56 & 15 & 41 & 20 \\
90 & 48 & 42 & 25 \\
51 & 6 & 45 & 23 \\
109 & 28 & 81 & 26
\end{tabular}

L. saccharina f. membranacea. Von dieser sïdlichen Form, die der nördlichen f. longissima entspricht, habe ich nur ein paar Exemplare vom südöstlichen Theil der Küste vor Augen gehabt. Die Charaktere, welche sie von der folgenden Form abgrenzen sollen, scheinen sehr unbestimmt zu sein.

L. saccharina f. longissima. Im Allgemeinen scheidet sich diese Form scharf von den beiden vor angegangenen, der $\mathrm{f}$. linearis und der f. oblonga; in Nordland und Finmarken habe ich jedoch auch Uebergänge beobachtet. Nach Kjellmans Bemerkung soll sich unsere Form auch im Bezug auf die Structur durch ein viel weitläufigeres und mehr dünnwandiges Element von den beiden vorgenannten unterscheiden. Auch dies stimmt im ganzen mit meinen Beobachtungen, doch habe ich ein eigentlich constantes Verhalten nicht nachweisen können.

Bei Inderöen im Trondhjems-Fjord fand ich eine Form, welche sich im wesentlichen der f. longissima anschliesst, aber von derselben dadurch abweicht, dass sie sich viel dunkler gefärbt zeigt, und dass ihr Blatt ziemlich dick und ganz eben ist, gar nicht bauschig oder rugös erscheint, wohl aber einen stark welligen 
Rand besitzt. Ein ähnliches Exemplar erhielt ich bei Sellevig (Stordöen) aus einer Tiefe von 10 Faden.

Folgende Masse zeigen die Dimensionsverhältnisse bei der f. longissima.

\begin{tabular}{rrrc} 
Total- & Stamm- & \multicolumn{2}{c}{ Blatt- } \\
länge. & länge. & 206 & 35 \\
288 & 82 & 70 & 14 \\
74 & 4 & 258 & 46 \\
344 & 86 & 262 & 52 \\
366 & 104 & 78 & 15 \\
151 & 73 & 192 & 19 \\
233 & 41 & 215 & 21 \\
227 & 12 & 148 & 10 \\
171 & 23 & 162 & 19 \\
211 & 49 & 204 & 24 \\
260 & 56 & &
\end{tabular}

Diese Form gehört, ebenso wie f. borealis, dem tieferen Theil der sublitoralen Region, wird aber doch auch bisweilen schon in einer Tiefe von bloss 2 Faden angetroffen, z. B. bei Russemark im Porsanger-Fjord.

L. saccharina f. borealis. Diese unterscheidet sich, wie bereits Kjellman hervorhebt, eigentlich nur durch die Form des Blattes von f. longissima.

Folgende Masse veranschaulichen das Verhalten bei einigen finmarkischen Exemplaren der Form.

\begin{tabular}{rccc} 
Total- & Stamm- & \multicolumn{2}{c}{ Blatt- } \\
länge. & länge. & 78 & breite. \\
160 & 82 & 36 & 34 \\
72 & 36 & 66 & 38 \\
104 & 38 & 83 & 45 \\
135 & 52 & 51 & 31 \\
99 & 48 & 44 & 27 \\
68 & 24 & 43 & 38 \\
124 & 81 & 48 & 52 \\
82 & 34 & &
\end{tabular}


Wenn ich nach den Bruchstiicken von Blättern urtheilen darf, die ich ab und zu aus Tiefen von mehren Faden emporgeholt habe, scheint diese Form recht bedeutende Dimensionen erlangen zu können. In der Mitte des Juni fand ich bei Lödingen in Nordland, in einer Tiefe von nur 4 Faden, ein noch im Blattwechsel begriffenes Exemplar. Der Stamm hatte eine Länge von $70 \mathrm{Cm}$; das neue Blatt war $150 \mathrm{Cm}$. lang und $115 \mathrm{Cm}$. breit; das alte, etwas destruirte, Blatt war $120 \mathrm{Cm}$. lang.

L. saccharina f. Agardhii. Wie bereits ausgeführt, kann ich diese Alge bloss als eine von der f. longissima nicht grade sehr scharf differentiirte, hocharctische Form der vorliegenden Art ansehen. Man trifft dieselbe zerstreut und sparsam in Ost-Finmarken in einer Tiefe von 10-25 Faden.

Laminaria Phyllitis (Stackh.) J. G. A g.

Spec. Alg. I, p. 131; Fucus Phyllitis Stackh. Ner. Brit. p. 33, t. 9.

Descr. Laminaria Phyllitis J. G. Ag. 1. c.

Nach J. G. Agardhs Angabe soll diese Art auch an den norwegischen Küsten vorkommen. Ebenso berichtet Lyngbye, dass dieselbe in der Nähe von Arendal gefunden sein soll. Ich betrachte es als zweifelhaft, ob diese Art sich wirklich in den norwegischen Gewässern findet. Ich selbst habe sie nie angetroffen, und die aus Norwegen stammenden Exemplare, die ich unter diesem Namen in verschiedenen Herbarien gesehen habe, sind, so weit ich zu urtheilen im Stande bin, nur junge Exemplare von f. membranacea oder f. longissima gewesen. 


\section{Literatur-Verzeichniss.}

Agardh, C. A. Synopsis Algarum Scandinaviæ. Lundæ 1817.(C. Ag. Syn. Alg.)

" Species Algarum. Gryphiswaldiæ 1821-1828.(C. Ag. Spec. Alg.)

Agardh, J. G. Novitiæ Floræ Sueciæ ex Algarum familiæ. Lundæ 1836. - (J. G. Ag. Nov.)

Sepcies, genera et ordines Algarum. Vol. I. Lundæ 1848. - (J. G. Ag. Spec. Alg.)

Om Spetsbergens Alger. (Akademisches Program.) Lund 1862. - (J. G. Ag. Spetsb. Alg. Progr.)

De Laminarieis symbolas offert. - Lunds Universitets Årsskrift. Tome 4. Lund 1867. (J. G. Ag. Lamin.)

Bidrag till kännedomen af Spetsbergens Alger. -Kongl. Svenska Vetenskaps-Akademiens Hand= lingar. Band 7, No. 8. Stockholm 1868. - (J. G. Ag. Spetsb. Alg. Bidr.)

" Bidrag till kännedomen af Spetsbergens Alger. Tilläg till föregående afhandling. - Kongl. Svenska Vetenskaps-Akademiens Handlingar. Band 7, No. 8. Stockholm 1868. - (J. G. Ag. Spetsb. Alg. Till.)

" Bidrag till kännedomen af Grönlands Laminarieer och Fucaceer. - Kongl. Svenska VetenskapsAkademiens Handlingar. Band 10, No. 8. Stockholm 1872, - (J. G. Ag. Grönl. Lamin. och Fuc.) 
Areschoug, J. E. Algarum (Phycearum) minus rite cognitarum pugillus secundus. - Linnæa, von Schlechtendal. Tome 17. Halle 1843. - (Aresch. Pugill.)

n

Enumeratio phycearum, quæ in maribus Scandinaviæ crescunt. - Nova Acta regiæ Societatis scientiarum Upsaliensis. Vol. 13, Upsaliæ 1847 et Vol. 14, Upsaliæ 1850. - (Aresch. Phyc. Scand.)

" Algæ Scandinavicæ exsiccatæ. Ser. nov. Fasc. 1-9. Upsaliæ 1861-1879. - (Aresch. Alg. Scand. exsicc.)

Observationes Phycologicæ. Part. 4. - Nova Acta regiæ Societatis scientiarum Upsaliensis. Ser. 3. Upsaliæ 1883. - (Aresch. Obs. Phyc.) Bauhinus, Caspar. Pinax theatri botanici. Basileæ Helvet 1621. - (Bauhin. Pinax.)

Beilschmied. Flora der shetländischen Inseln von Thomas. Edmondston; im Auszuge durch Dr. Beilschmied. - Flora oder allgemeine botanische Zeitung. XXX Jahrg. Regensburg 1847. (Beilschm. in Flora.)

Botaniska Notiser. Lund 1883. - (Bot. Not.)

Clouston, Charles, Algæ. Guide to the Highlands and Islands of Scotland, by G. \& P. Anderson. London 1834. - (Clouston in Anders. Guide.)

Crouan, P. L. et H. M. Algues marines du Finistère classées. Brest 1852. -- (Crouan, Alg. mar. Finist.)

De la Pylaie, M. Quelques observations sur les productions de l'ile de Terre Neuve et sur quelques Algues de la côte de France, appartement au genre Laminaire. - Annales des Sciences Naturelles Ser. 1, Tome 4. Paris 1824. -- (De la Pyl. Observ.)

Edmondston, Thomas. A Flora of Shetland; comprehending a 
List of the Shetland Islands, with remarks on their Topography, Geology, and Climate, etc. Aberdeen 1845. - (Edm. Flor. Shetl.)

Ekman, F. L. Bidrag till kännedomen om Skandinaviens Hafsalger. (Akademische Dissertation). Stockholm 1857. - (Ekm. Skand. Hafsalg.)

Esper, E. J. C. Icones Fucorum; Abbildungen der Tange, mit beygefügten systematischen Kennzeichen, etc. Nürnberg 1800. - (Esper, Ic. Fuc.)

Farlow, W. G. List of the marine Algæ of the United States, with nots of new and imperfectly known species. - Proceedings of the American Academy of Arts and Sciens. New Series. Vol. 2. Boston 1875. - (Farl. Alg. Unit. States.) Marine Algæ of New England and adjacent Coast. - Report of the United States Fish Commission for 1879. Washington 1881. (Farl. New. Engl. Alg.)

Flora Danica. Vol. 2, Hafniæ 1767 und Vol. 3, Hafniæ 1770. - (Fl. Dan.)

Foslie, M. Bidrag til kundskaben om de til gruppen Digitatæ hørende Laminarier. - Christiania Videnskabs-Selskabs Forhandlinger 1883. No. 2. (Foslie, Bidr.)

Gmelin, S. G. Historia Fucorum. Petropoli 1768. - (Gmel. Hist. Fuc.)

Gobi, Chr. Die Algenflora des Weissen Meeres und der demselben zunächstliegenden Theile des nördlichen Eismeeres. - Memoires de l’Academie impériale des Sciences de St. Pétersbourg. Ser. 7. Tome 26, No. 1. 1878. - (Gobi, Algenfl. Weiss. Meer.)

Greville, R. K. Algæ Britannicæ. Edinburgh 1830.- (Grev. Alg. Brit.) 
Gunnerus, J. E. Flora Norwegica. Vol. 1, Nidrosiæ 1766. Vol. 2, Hafniæ 1772. - (Gunn. Fl. Norv.)

" Om nogle norske Planter. - Det Kongelige Norske Videnskabers Selskabs Skrifter. Del 4. Kjobenhavn 1767. - (Gunn. Norske Planter.) Hammer, Chr. Floræ Norvegicæ prodromus. Forlober af Norske Flora eller Planterige. Kjøbenhavn 1794. - (Hammer, Fl. Norv.).

Harvey, W. H. A Manual of the British Algæ. Ed. 2. London 1848. - (Harv. Manual.)

" Nereis Boreali-Americana. - Smithsonian Contributions to knowledge. Washington 1852. -(Harv. Ner. Amer.)

" Phycologia Britannica or a History of British Sea-Weeds. London 1846-1851. - (Harv. Phyc. Brit.)

Hohenacker, R. F. Algæ marinæ siccatæ. Eine Sammlung europäischer und ausländischer Meeralgen in getrockneten Exemplaren. Zweite Lieferung. Esslingen bei Stuttgart 1852. - (Hohenack. Alg. mar. sicc.)

Hooker, J. Dalton. Cryptogamical Botany of the Antarctic Voyage. London 1845. - (Hooker, Crypt. Bot.)

Hornemann, J. W. Dansk өkonomisk Plantelære. Del 2. Kjøbenhavn 1837. - (Hornem. Plantel.)

Kjellman, F. R. Förberedande Anmärkningar om algvegetationen i Mosselbay enligt iakttagelser under vinterdraggningar, anstälda af Svenska polarexpeditionen 1872-1873. - Öfversigt af Kongl. Vetenskaps-Akademiens Förhandlingar 1875, No. 5. Stockholm. - (Kjellm. Vinteralgveg.) " Om Spetsbergens marina klorofyllförande Thallophyter. I. - Bihang till Kongl. Svenska Vetenskaps-Akademiens Handlingar. Band 
3, No. 7. Stockholm 1875. - (Kjellm. Spetsb. Thalloph.)

Kjellman, F. R. Ueber die Algenvegetation des Murmanschen Meeres an der Westküiste von Nowaja Semlja und Wajgatsch. - Nova Acta regiæ Societatis scientiarum Upsaliensis. Ser 3. Upsaliæ 1877. - (Kjellm. Algenveg. Murm. Meer.) Bidrag till kännedomen af Kariska hafvets Algvegetation. -- Öfversigt af Kongl. Vetenskaps-Akademiens Förhandlingar 1877, No. 2. Stockholm. -- (Kjellm. Kariska hafvets Algveg.) Ueber Algenregionen und Algenformationen in östlichen Skager Rack nebst einigen Bemerkungen über das Verhältniss der bohuslän' schen Meeres-Algenvegetation zu der norwegischen. - Bihang till Kongl. Svenska Vetenskaps-Akademiens Handlingar. Band 5, No. 6. Stockholm 1878. - (Kjellm. Algenreg. u. Algenform.)

Norra Ishafvets Algflora. - Vega-Expeditionens vetenskapliga iakttagelser. Band 3. Stockholm 1883. - (Kjellm. Ishafsfl.)

Kleen, E. Om Nordlandenes högre Hafsalger. - Öfversigt af Kongl. Vetenskaps-Akademiens Förhandlingar 1877, No. 9. Stockholm. - (Kleen, Nordl. Alg.)

Krogh, J. A. Efterretninger om Provstiet Nordfjord i Bergens Stift i Norge. - Topographisk-Statistiske Samlinger, udgivne af det Kgl. Selskab for Norges Vel. Del 2, Bind 1. Christiania 1813. - (Krogh, Efterretninger.)

Kützing, F. T. Phycologia generalis. Leipzig 1843. - (Kütz. Phyc. gen.) 
in bündigen Beschreibungen. Nordhausen 1845. - (Kütz. Phyc. germ.)

Kützing, F. T. Species Algarum. Lipsiæ 1849. - (Kütz. Spec. Alg.)

Lamouroux, J. V. F. Essai sur les genres de la famille des Thallassiophytes non articulées. -- Annales du Muséum d'Historie Naturelle. Tome 20. Paris 1813. - (Lamour. Essai.)

Le Jolis, A. Examen des espèces confondues sou le nom de Laminaria digitata auct., suivi de quelques observations sur le genre Laminaria. - Nova Acta Academiæ Cesareæ Leopoldino-Carolinæ naturæ curiosorum. Vol. XXV. Pars posterior. Vratislaviæ et Bounæ 1856. - (Le Jol. Examen.)

,

n

Lindman, Carl. Om Drifved och andra af hafsströmmar uppkastade naturföremål vid Norges kuster. Göteborg 1883. - (Lindm. Drifved.)

Linné, C. von. Species Plantarum. Ed. 1. Holmiæ 1753. Flora Svecica. Ed. 2. Stockholmiæ 1755. (L. Fl. Svec.)

Systema Naturæ. Ed. 12. Holmiæ 1767. (L. Syst. Nat.)

Mantissa Plantarum. Holmiæ 1767. - (L. Mant.)

Flora Lapponica. Ed. 2. Londini 1792. (L. Fl. Lapp.)

Lyngbye, H. C. Tentamen Hydrophytologiæ Danicæ. Hafuiæ 1819. - (Lyngb. Hydroph. Dan.) 
Mohr, N. Forseg til en Islandsk Naturhistorie. Kjobenhavn 1786. --. (Mohr. Isl. Naturh.)

Nylander, W. et Sälan, Th. Herbarium Musei Fennici. Helsingfors 1859. - (Nyl. et Säl. Herb. Fenn.)

Olafsen, Eggert. Reise durch Island. Erster Theil. Kopenhagen und Leipzig 1774. - (Olafsen, Reise.)

Postels, A. et Ruprecht, F. J. Illustrationes Algarum Oceani Pacifici imprimis septentrionalis. Petropoli 1840. (Post. et Rupr. Ill, Alg.)

Rajus, J. Synopsis methodica Stirpium Britannicarum. Ed. 2. Londini 1724. - (Raj. Synopsis).

Retzius, A. J. Floræ Scandinaviæ prodromus. Ed. 2. Lipsiæ 1795. - (Retz. Fl. Scand.)

Ruprecht, F J. Bemerkungen über den Bau und das Wachsthum einiger grossen Algen-Stämme, und über die Mittel, das Alter derselben zu bestimmen. - Memoires de l'Academie Impériale des Sciences de St. Petersbourg. Sér. 6. Sciences Naturelles. Tome 6. 1849. - (Rupr. Algenstämme.)

Schübeler, F. C. Die Pflanzenwelt Norwegens, ein Beitrag zur Natur- und Culturgeschichte Nord-Europas. Christiania 1873-1875. - (Schübeler Pflanzenw. Norw.) Algæ (Novaja-Samljas). - Reisen nach dem Nordpolarmeer in den Jahren 1870 und 1871 von M. Th. von Henglin. 'Theil 3. Braunschweig 1874. (Schübeler in Heugl. Reise.)

Shultz-Schultzenstein. Ueber Schichtenbildung im Pflanzenreich mit Beziehung auf die natürliche Classification der Pflanzen. - Flora oder allgemeine botanische Zeitung. XXXVI Jahrg. Regensburg 1853. -- (Schultz, Schichtenbildung.)

Sommerfelt, Chr. Supplementum Eloræ Lapponicæ quam edidit Dr. G. Wahlenberg. Christiania 1826. - (Sommerf. Suppl. Fl. Lapp.) 
Stackhouse, J. Nereis Britannica. Ed. 2. Oxonii 1816. - (Stackh. Ner. Brit.)

Stephens en, M. De til Menneske-Fode i Island brugelige TangArter og i Særdeleshed Söl. - Det Kongelige Danske Landhusholdnings-Selskabs Skrifter. Ny Samling. Bind 1. Kjøbenhavn. 1808. - (Stephensen, Tangarter.)

Strøm, H. Physisk og Oeconomisk Beskrivelse over Fogderiet Sondmore, beliggende i Bergens Stift i Norge. Del 1. Sorøe 1762. - (Strøm, Sondm.)

$\eta$

Beskrivelse over 10 Norske Søe-Væxter. Skrifter, som udi det Kjobenhavnske Selskab af Lærdoms og Videnskabers Elskere ere fremlagte og oplæste i Aarene 1765-1769. Del 10. Kjøbenhavn 1770. - (Strøm, Beskr.)

Tonning, H. Rariora Norvegiæ. - C. von Linné. Amoenitates Academicæ. Vol. 7. Holmiæ 1769. (Tonning, Rar. Norv.)

Turner, D. Fuci, sive plantarum Fucorum generis a botanicis ascriptarum icones, descriptiones et historia. Vol. 3. Londini 1811. - (Turner, Hist. Fuc.)

Wahlenberg, G. Flora Lapponica. Berolini 1812. - (Wahlenb. Fl. Lapp.)

Warming, E. Familien Podostemaceæ. - Det Kgl. Danske Videnskabs-Selskabs Skrifter, 6 R. Naturv. mathem. Afdel. II B. Kjobenhavn 1881. (Warm. Podost.)

Ueber einige bei den Podostemaceen vorkommende Haftorgane. - Botanisches Centralblatt. B. XIII. Cassel 1883. 
CHRISTLANIA VIDENSK.-SELSK, FORHANDL. 188 4, No. 14. 107

\section{Erklärung der Tafeln.}

\section{Tafel I.}

Laminaria hyperborea f. typica. Fig. 1-8.

Fig. 1. Altes Individuum im Blattwechsel. $\frac{1}{8}$.

Berlevaag in Finmarken 28 März.

"2. Quersnitt des Stammes desselben Individuum $2 \mathrm{Cm}$. oberhalb der Wurzel. $\frac{1}{1}$.

3. Der äusserste Theil desselben Querschnittes mit einer Schleimlacune. $\frac{38}{1}$.

4. Theil eines Querschnittes des neuen Blattes mit zwei Schleimlacunen. ${ }^{1} 1^{0}$.

5. Ein entsprechender Theil eines Querschnittes des alten Blattes mit einer Schleimlacune. ${ }^{1}{ }_{1}^{0}$.

"6. Ein ähnlicher Theil eines Querschnittes des Blattes eines alten Exemplars, bei Berlevaag im August gesammelt. $110 / 1$.

"7. Der äusserste Theil eines Quersnittes vom Untertheil des Stammes mit Schleimlacunen. ${ }^{38}$.

Der Stamm volle $1 \mathrm{Cm}$. in Diameter. Das Exemplar von der südöstlichsten Küstenstrecke (Hvalöerne).

"8. Junges Individuum. $\frac{1}{5}$.

Berlevaag im August.

Laminaria hyperborea f. compressa. Fig. 9.

Fig. 9. Querschnitt des Stammes $10 \mathrm{Cm}$. unterhalb des Blattes. 1 .

Der Stamm am Unterende $4.5 \mathrm{Cm}$. in Diameter. 


\section{Tafel 2.}

\section{Laminaria Gunneri.}

Fig. 1. Ausgewachsene Individuen (an Alaria). $\frac{1}{3}$.

Berlevaag 12 October.

"2. Querschnitt des Stammes $2 \mathrm{Cm}$. oberhalb der Wurzel. $\frac{1}{1}$.

"3. Der äusserste Theil desselben Querschnitt mit Schleimlacunen. $\frac{38}{1}$.

" 4. Der äusserste Theil eines Längenschnittes desselben Stammtheils mit drei Schleimlacunen. $3_{\overline{\mathrm{i}}}^{8}$.

"5. Ein Theil eines Querschnittes des Blattes mit zwei Schleimlacunen. ${ }^{1} \frac{1}{1}{ }^{0}$.

"6. Ein ähnlicher Theil eines Längenschnittes des Blattes mit einer Schleimlacune. ${ }^{1} \frac{1}{1}^{0}$.

"7. Querschnitt am Unterende des Stammes eines anderen Exemplars mit deutlichen Schichtringen. $\frac{1}{1}$.

\section{Tafel 3.}

Laminaria digitata f. valida. Fig. 1-4.

Fig. 1. Älteres ausgewachsenes Exemplar. $\frac{1}{8}$.

Borgevär in Lofoten 30 September.

"2. Querschnitt am Unterende des Stammes. ${ }_{1}^{1}$.

"3. Ein Theil eines Querschnittes des Blattes. ${ }^{1} 1^{0}$.

"4. Junges Individuum im Blattwechsel. $\frac{1}{3}$.

Gjesvär beim Nordcap 24 August.

Laminaria digitata f. stenophylla. Fig. 5-9.

Fig. 5. Ausgewachsenes Individuum. $\frac{1}{8}$.

Berlevaag 7 August.

"6. Querschnitt am Unterende des Stammes. $\frac{1}{1}$.

"7. Ein Theil eines Querschnittes des Blattes. ${ }^{1}{ }_{1}^{0}$.

" 8-9. Junge Individuen. $\frac{1}{2}$.

Laminaria digitata f. typica. Fig 10-11.

Fig. 10. Querschnitt am Unterende des Stammes eines etwas verkrüppelten Individuums mit undeutlichen Schichtringen. $\frac{1}{1}$. indiztinet lawer 
CHRISTIANIA VIDENSK.-SELSK. FORHANDL. 1884. No. 14. 109

Fig. 11. Querschnitt am Unterende des Stammes eines anderen Exemplars mit deutlichen, scharf abgesonderten, Schichtringen. $\frac{1}{1}$.

Inderöen September.

\section{Tafel 4 .}

\section{Laminaria digitata f. typica.}

Fig. 1. Älteres ausgewachsenes Exemplar im Blattwechsel. ${ }^{1} \quad \frac{1}{1}$.

Berlevaag 6 August.

"2. Querschnitt des Stammes 5 Cm. oberhalb der Wurzel. 1.

3. Theil eines Querschnittes des neuen Blattes. ${ }^{1 \frac{1}{1}}$.

4. Ein entsprechender Theil eines Querschnittes des alten Blattes. ${ }^{1} 1^{0}$.

"5. Junges Individuum. $\frac{1}{3}$.

Berlevaag 6 August.

"6. Querschnitt am Unterende des Stammes eines älteren Exemplars. $\frac{1}{1}$.

"7. Das Haftorgan eines älteren Exemplars. Die zwei äussersten Kränze regelmässig, die übrigen (hier verdeckt) unregelmässig. $\frac{1}{3}$.

"8. Theil eines Exemplars mit Hapteren gleich oberhalb der Basis des Stammes. $\frac{1}{3}$.

Inderöen September.

" 9. Theil eines anderen Exemplars von demselben Orte mit Hapteren am Stamme. $\frac{1}{3}$.

\section{Tafel 5.}

Laminaria digitata f. typica. Fig. 1.

Fig. 1. Älteres Exemplar im Blattwechsel. $\frac{1}{5}$.

Berlevaag 20 Februar.

Laminaria digitata f. ensifolia. Fig. 2-5.

Fig. 2. Ausgewachsenes Individuum im Blattwechsel. $\frac{1}{5}$.

1 Cberall giebt $g$ die Grenze zwischen dem alten und neuen Blatt an. 
Fig. 3. Querschnitt am Unterende des Stammes. $\frac{1}{1}$.

"4. Querschnitt der Mitte des Stammes. $\frac{1}{1}$.

"5. Theil eines Querschnittes des alten Blattes mit zwei Schleimlacunen. ${ }^{11}{ }^{1}$.

\section{Tafel 6.}

Laminaria digiata f. ensifolia. Fig. 1-9.

Fig. 1. Ausgewachsenes Individuum. $\frac{1}{5}$.

Lödingen in Nordland 28 October.

”2. Theil eines Querschnittes des Blattes. ${ }^{110}$.

" 3. Jüngeres Individuum im Blattwechsel. $\frac{1}{8}$.

Lödingen 28 März.

" 4-5. Junge Individuen. $\frac{1}{3}$.

Lödingen October.

"6. Junges Individuum. $\frac{1}{3}$.

Skarsvaag beim Nordcap September.

"7. Junges Individuum. $\frac{1}{3}$.

Lödingen April.

" 8. Junges Individuum im Blattwechsel. $\frac{1}{3}$.

Skarsvaag September.

"9. Junges Individuum. $\frac{1}{3}$.

Skarsvaag September.

Laminaria digitata f. debilipes. Fig. 10-11.

Fig. 10. Ausgewachsenes Individuum. $\frac{1}{5}$.

Christiansund September.

"11. Theil eines Querschnittes des Blattes mit zwei Schleimlacunen. ${ }^{1} \frac{1}{1}^{0}$.

\section{Tafel 7.}

Laminaria intermedia f. longipes.

Fig. 1. Ausgewachsenes Individuum, die Formextreme hinsichtlich der Spaltung des Blattes darstellend. $\frac{1}{\mathbf{8}}$. 
Fig. 2. Querschnitt am Unterende des Stammes. $\frac{1}{1}$.

"3. Querschnitt der Mitte des Stammes. $\frac{1}{1}$.

"4. Theil eines Querschnittes des Blattes mit drei Schleimlacunen. ${ }^{1} \frac{1}{1} \mathrm{O}$.

"5. Ausgewachsenes Individuum. $\frac{1}{8}$.

"6. Jüngeres Individuum im Blattwechsel. $\frac{1}{3}$.

"7. Junges Individuum. $\frac{1}{3}$.

Sämmtliche bei Berlevaag in Ost-Finmarken am $9 \mathrm{Au}-$ gust gesammelt.

\section{Tafel 8.}

Laminaria intermedia f. longipes.

Fig. 1. Ausgewachsenes Individuum. $\frac{1}{5}$.

"2. Querschnitt am Unterende des Stammes. $\frac{1}{1}$.

"3. Theil eines Querschnittes des Blattes mit einer Schleimlacune. ${ }^{1} \frac{1}{1}{ }^{\circ}$.

"4. Jüngeres Individuum. $\frac{1}{3}$.

" 5-8. Junge Individuen. $\frac{1}{3}$.

Sämmtliche bei Russemark in Porsanger-Fjord am 15 August gesammelt.

\section{Tafel 9.}

Laminaria intermedia f. longipes. Fig. 1.

Fig. 1. Jüngeres Exemplar, den typischen Exemplaren der f. cucullata ziemlich sich nähernd. $\frac{1}{5}$.

Russemark 15 August.

Laminaria intermedia f. cucullata. Fig. $2-5$.

Fig. 2. Ausgewachsenes Individuum mit gespaltetem Blatt, das Formextrem darstellend. $\frac{1}{8}$.

Gjesvär beim Nordcap 18 August.

"3. Querschnitt am Unterende des Stammes. $\frac{1}{1}$.

"4. Theil eines Querschnittes des Blattes mit einer Schleim. lacune. $1 \frac{1}{10}$.

"5. Jüngeres Individuum von demselben Orte. $\frac{1}{3}$. 


\section{Tafel 10.}

Laminaria intermedia f. cucullata. Fig. 1-16.

Fig. 1. Ausgewachsenes Exemplar mit konkavem ungetheiltem Blatte. $\frac{1}{5}$.

Gjesvär 18 August.

"2. Jüngeres Exemplar. $\frac{1}{3}$.

Havösund 20 August.

"3. Jüngeres Individuum im Blattwechsel. $\frac{1}{3}$.

"4-16. Jüngere Individuen, von denen einige im Blattwechsel. $\frac{1}{3}$.

Gjesvär und Havösund 18-20 August.

Laminaria intermedia f. ovata. Fig. 17-18.

Fig. 17. Ausgewachsenes Individuum. $\frac{1}{5}$.

Gjesvär 18 August.

„18. Theil eines Querschnittes des Blattes mit zwei Schleimlacunen. ${ }^{1} 1_{1}^{0}$.

Durch ein Versehen des Lithographen und speciell des Drückers stimmt das Verhältniss der Farben bei verschiedenen Figuren nicht genau mit den Farbenverhältniss der Originalzeichnungen übercin und entspricht darum auch nicht ganz den Angaben des Textes in dieser Beziehung. Dies gilt besonders von den Querschnitten der Blätter. Auch die Dicke der Zellenwände ist nicht immer correct wiedergegeben. In solchen Fällen bittet man den Leser, sich an die Angabe des Textes, als die zuverlässigere, zu halten. 


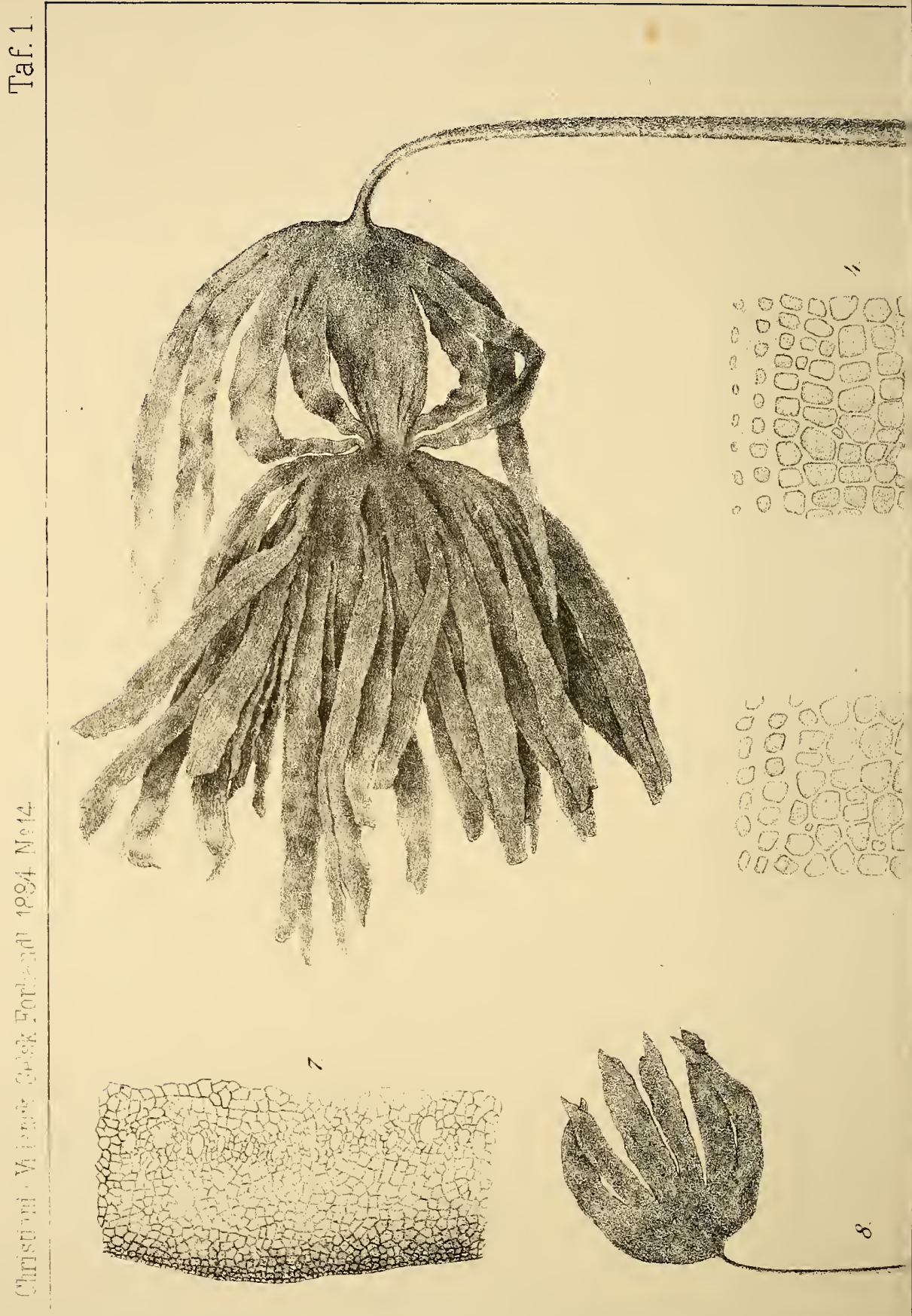




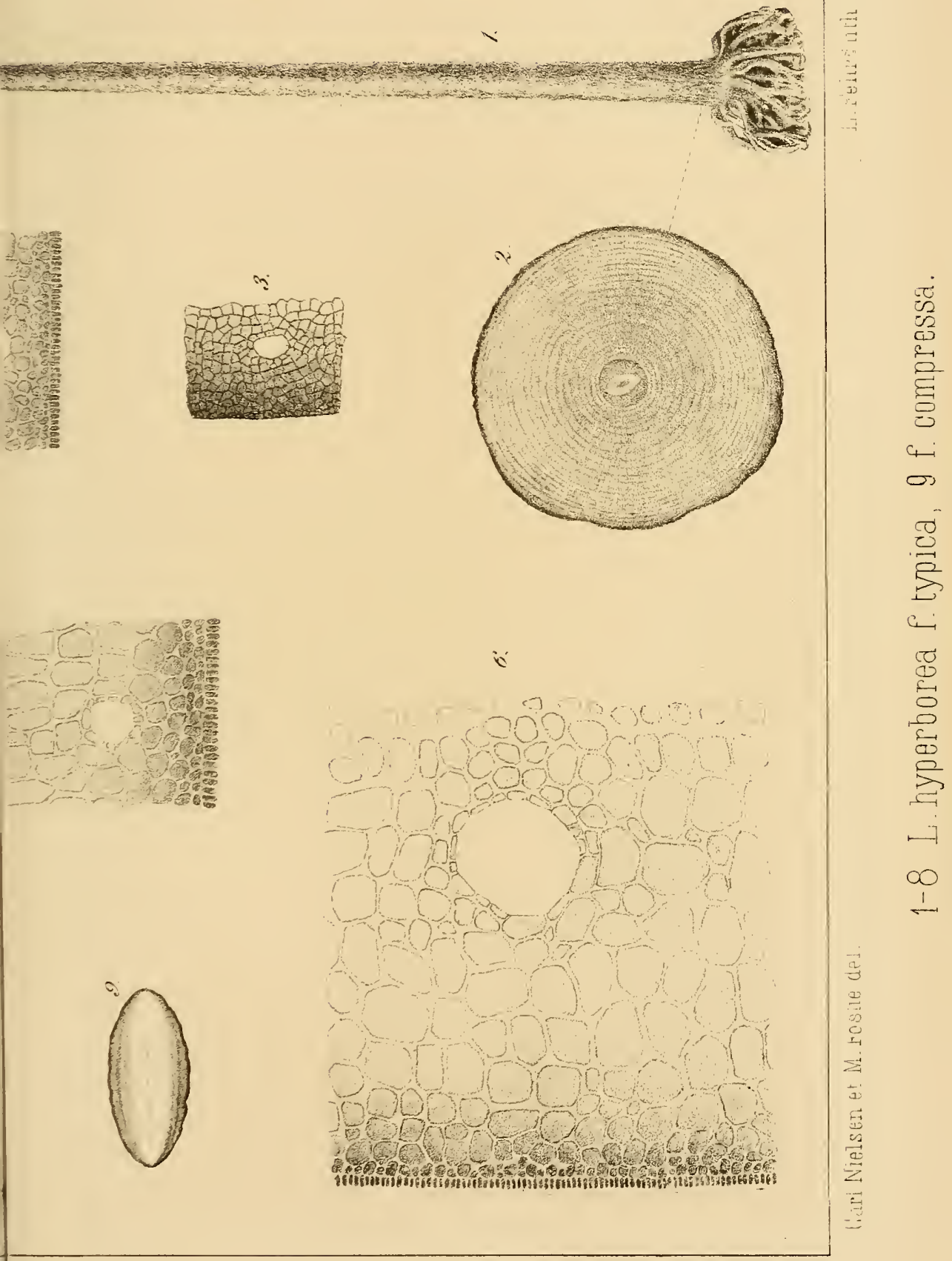




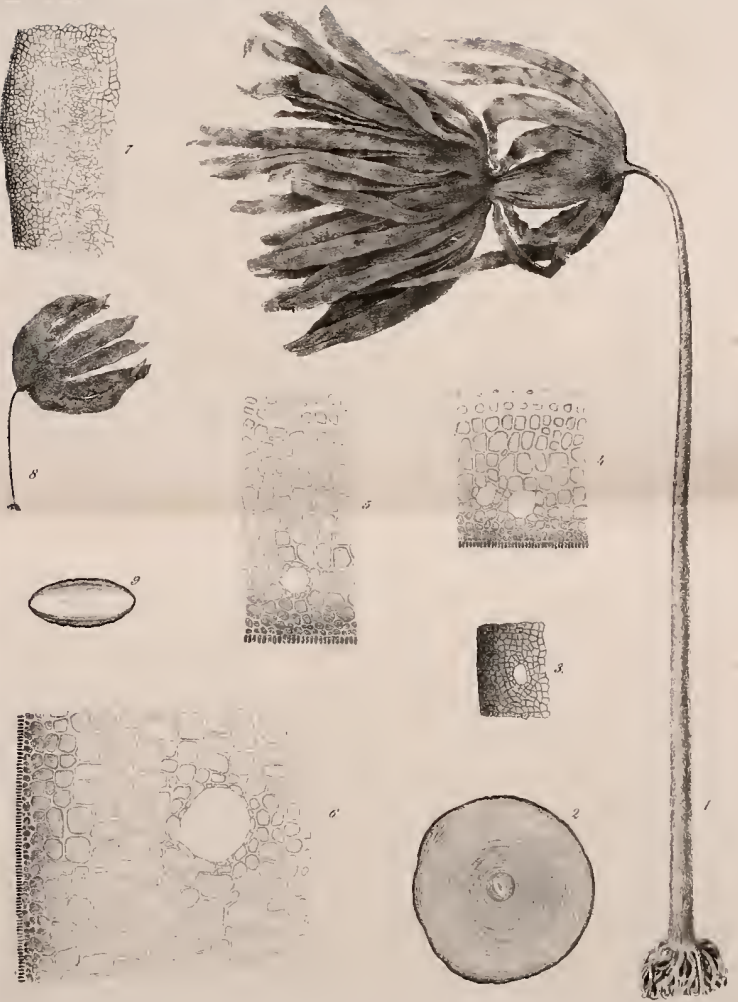

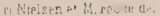






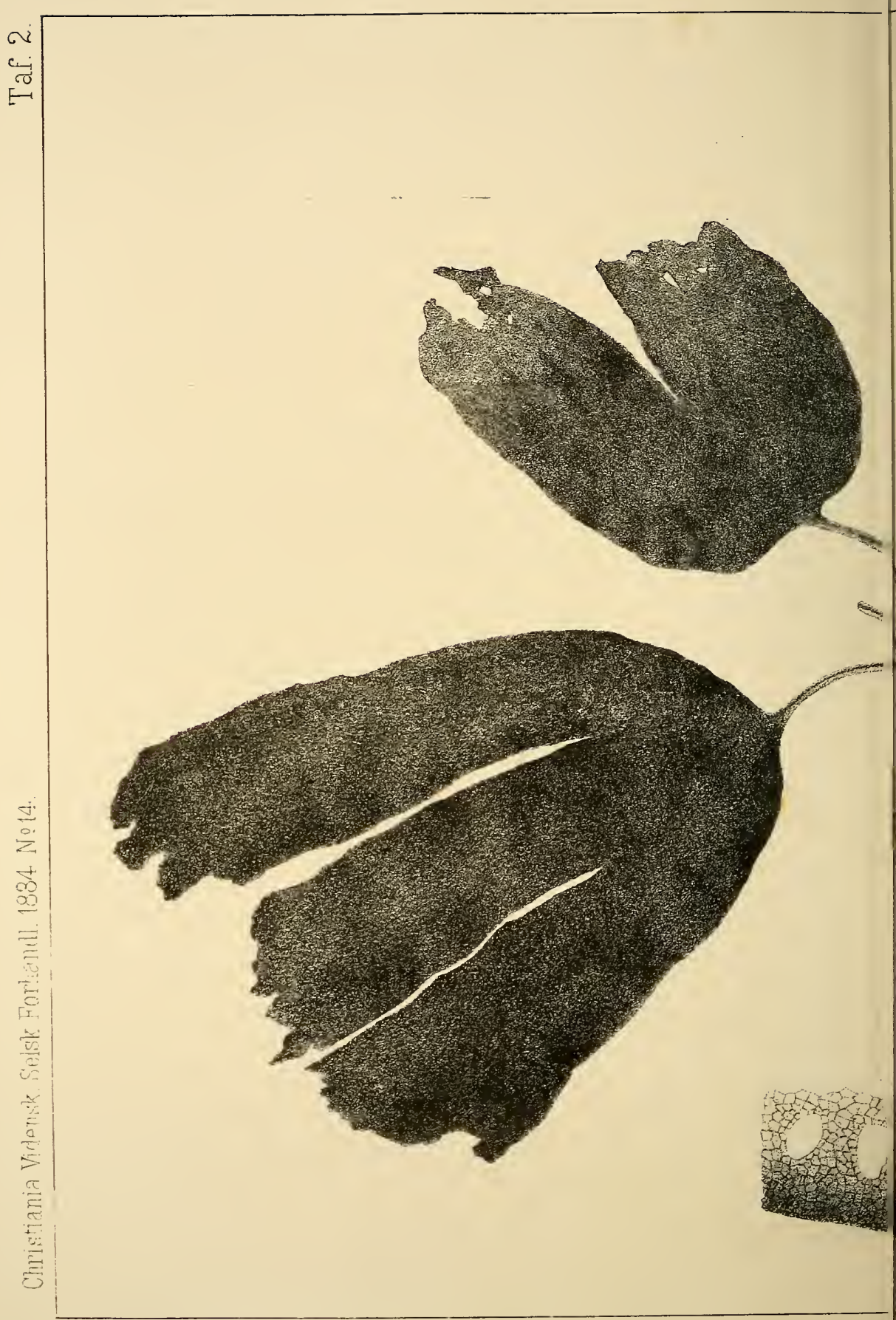



23:

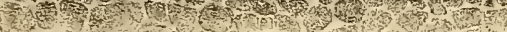
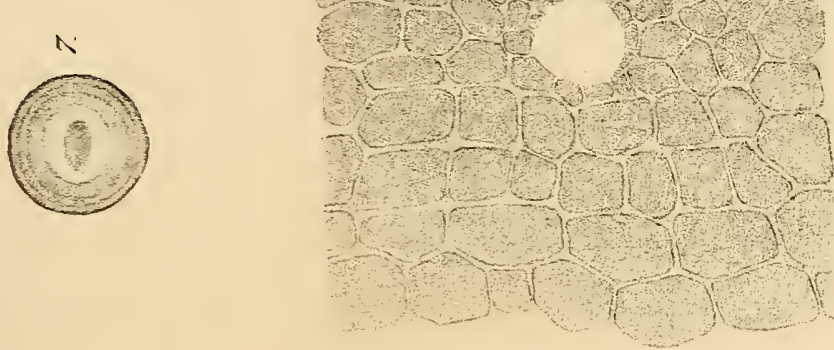

6 Mind D

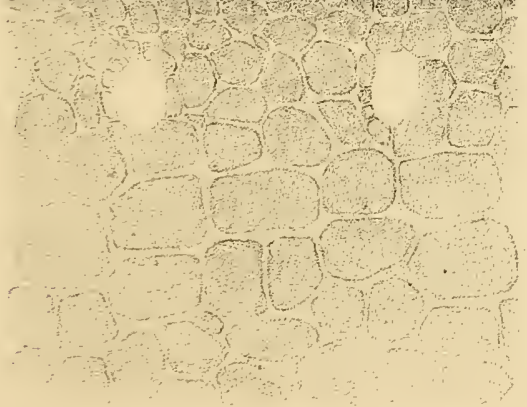

ij

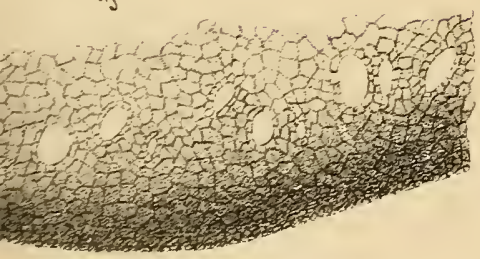

巨్

$-1$ 



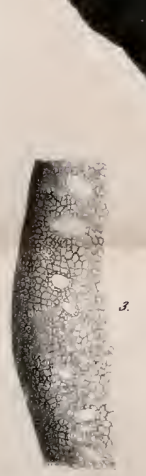

(2)
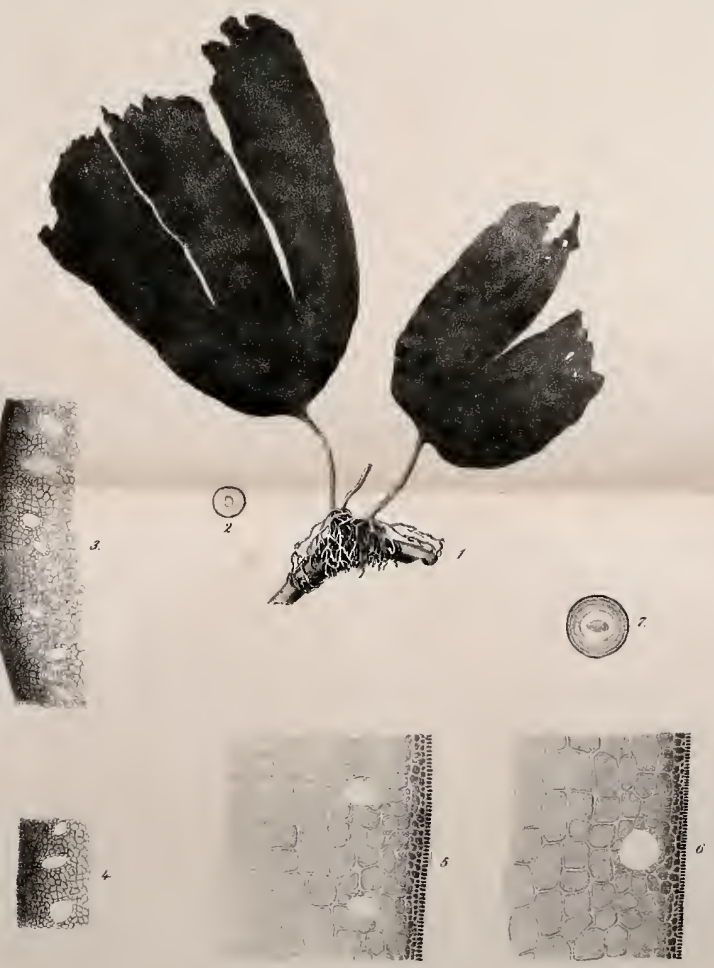

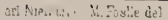






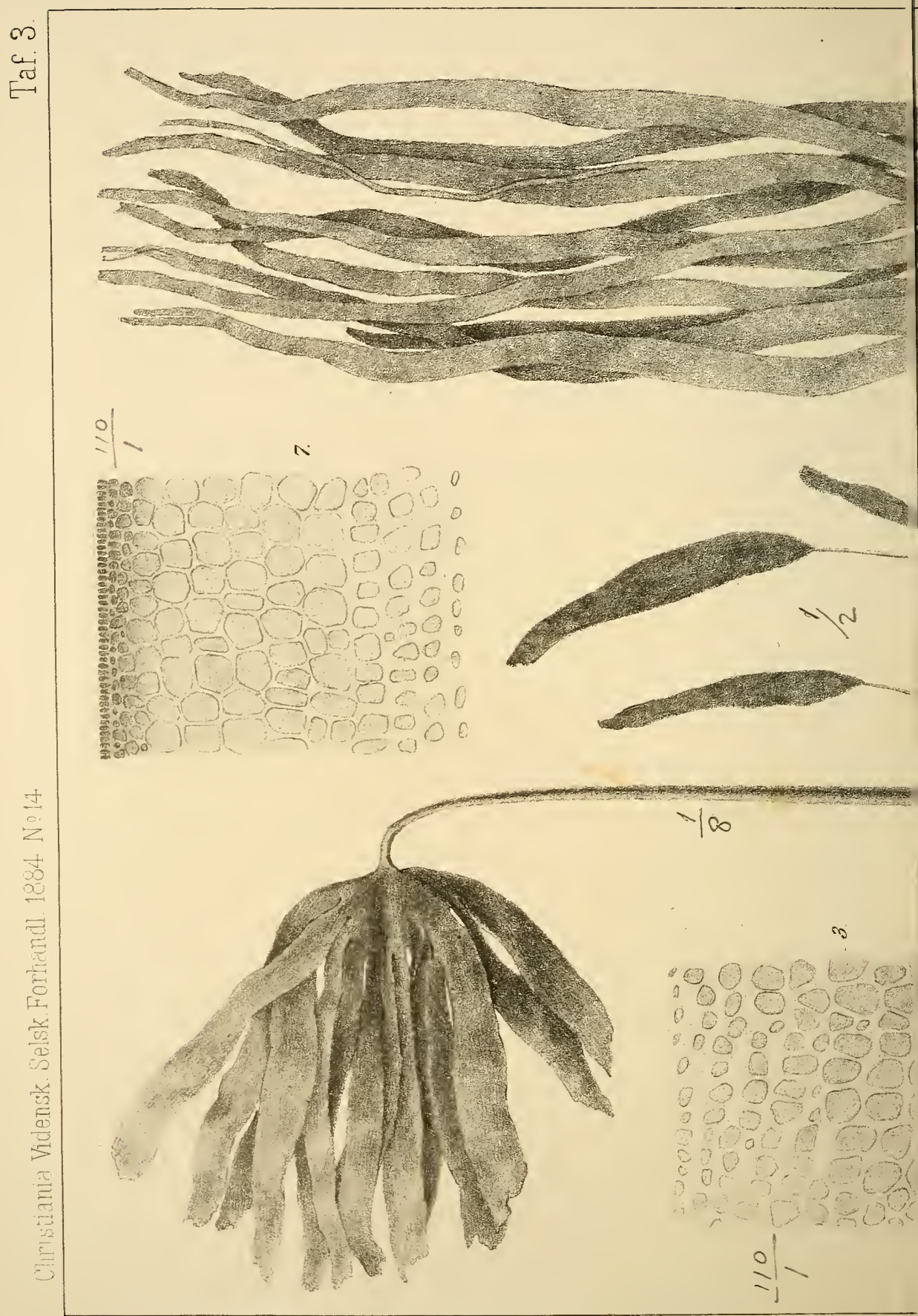




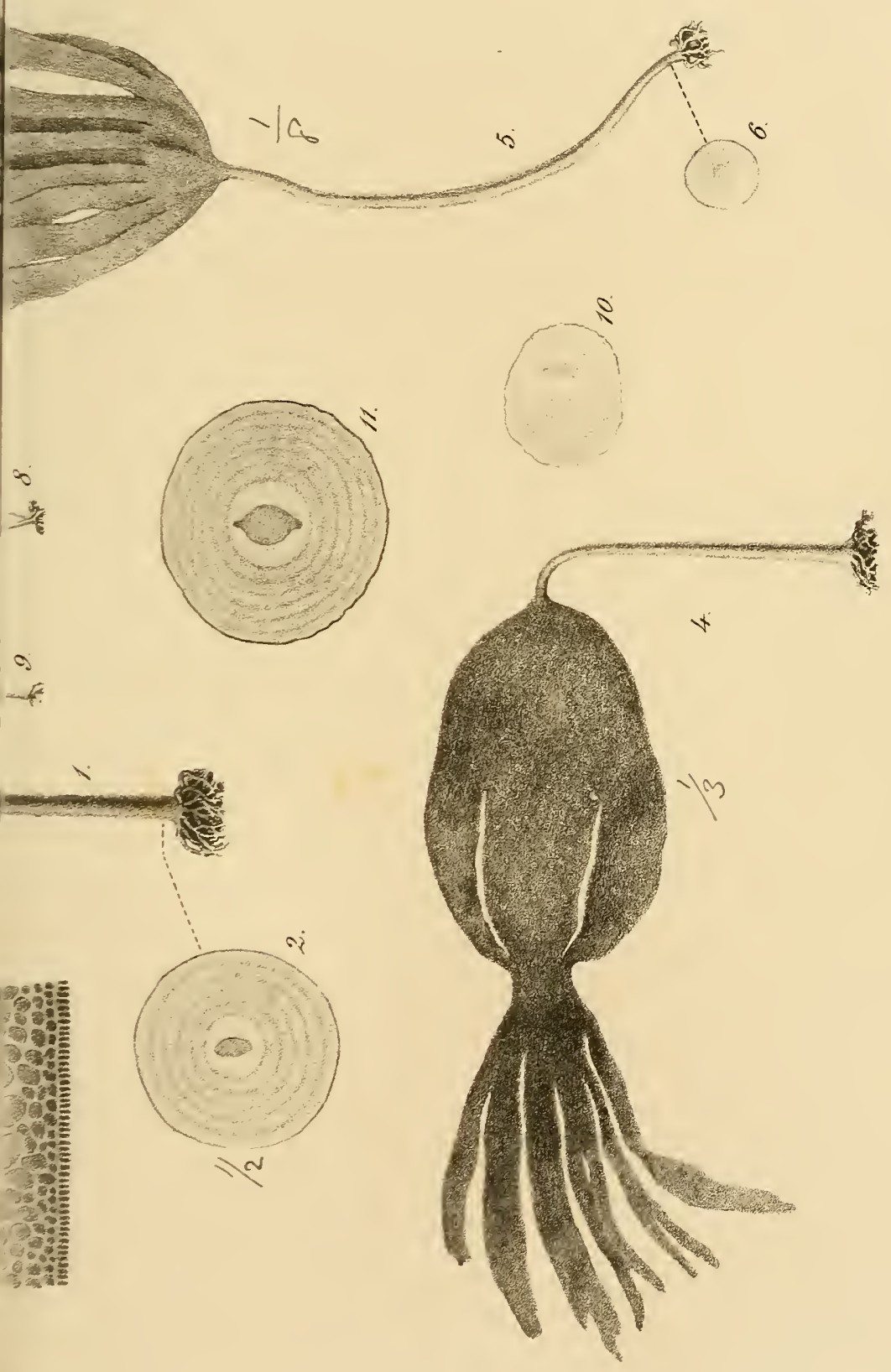

0
0
0
0
1
0
5

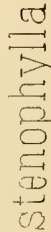

L

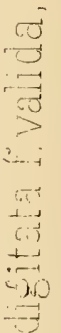

$\rightarrow$

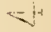

$\stackrel{1}{3}$ 



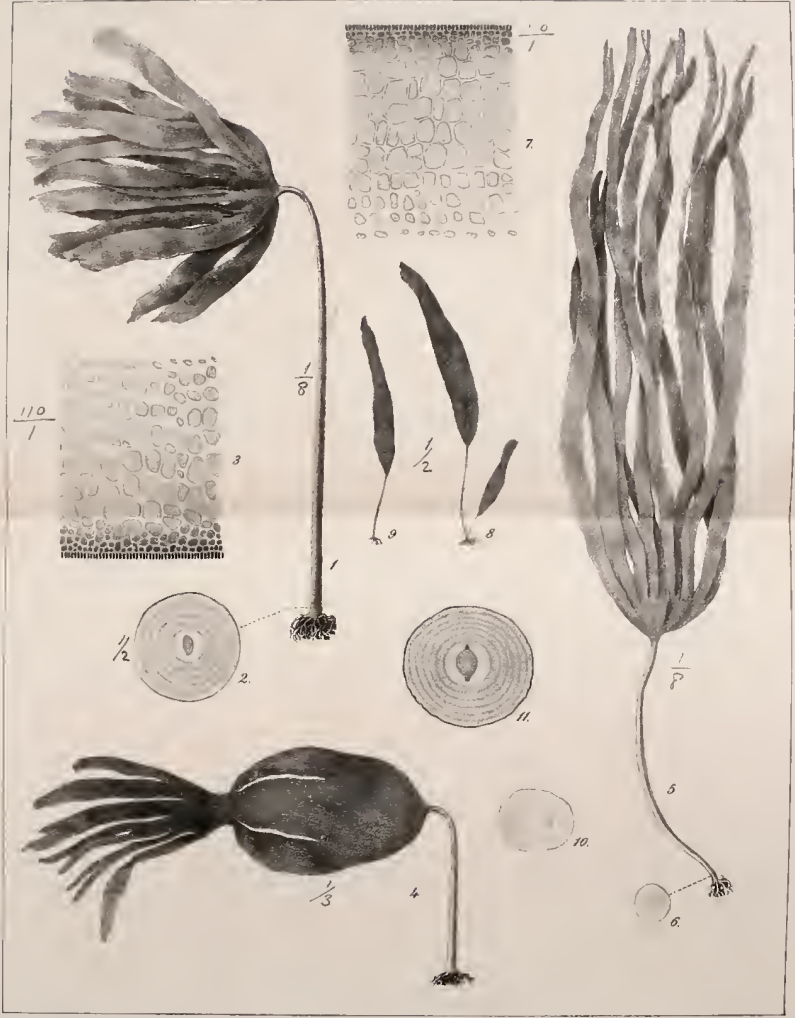





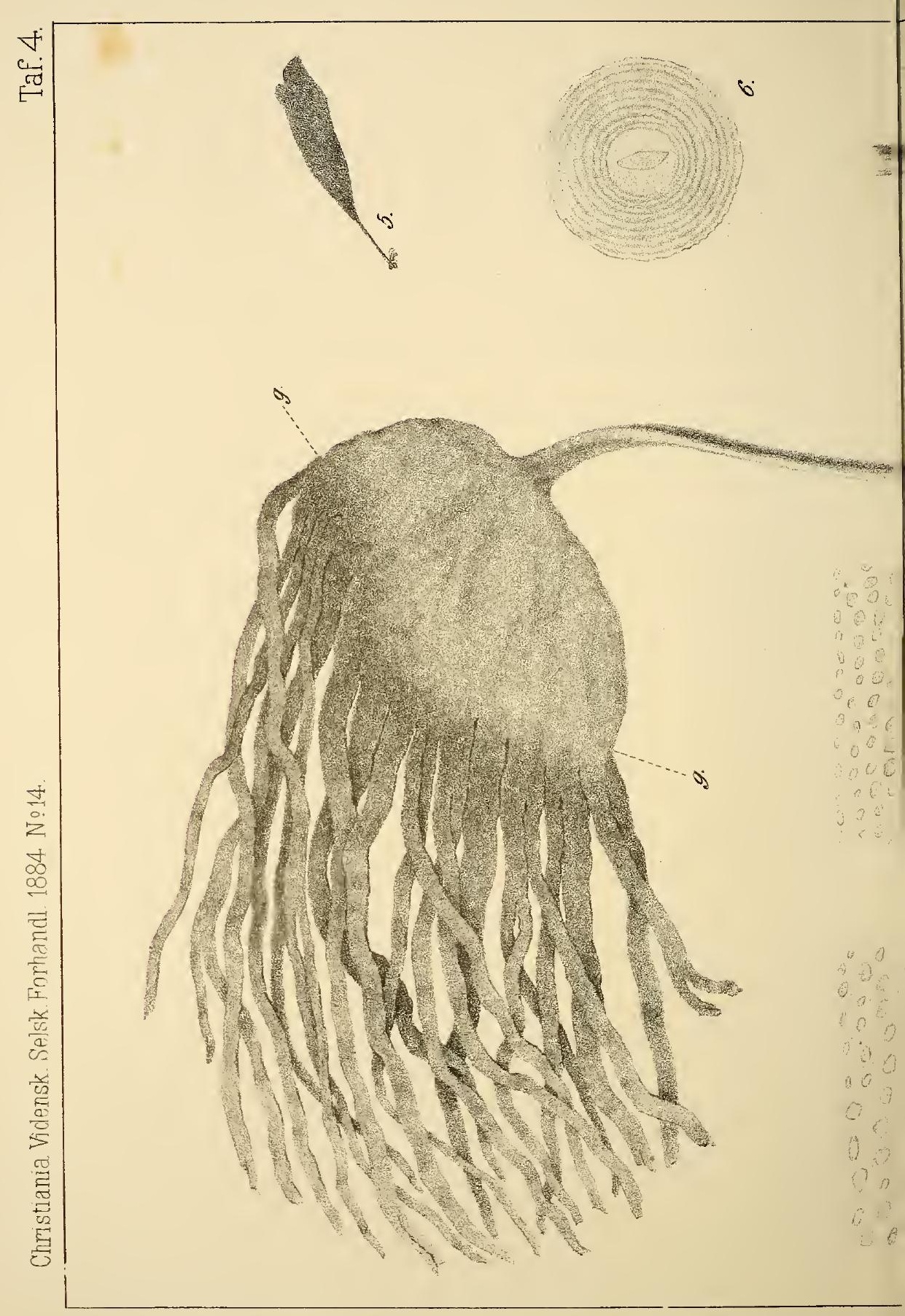




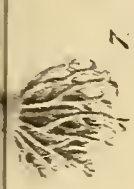
की

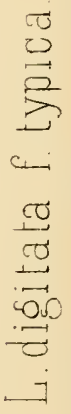

$x$

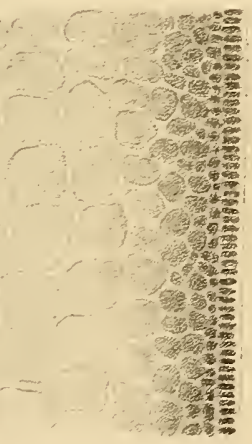

vi

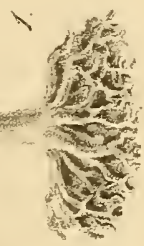

s

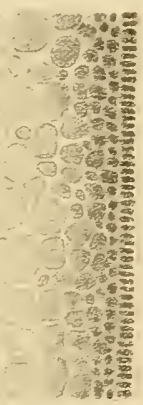

$\infty$

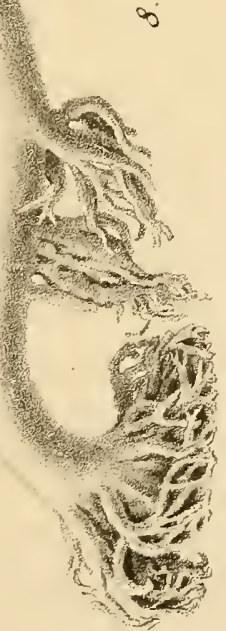

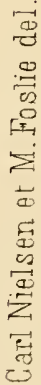





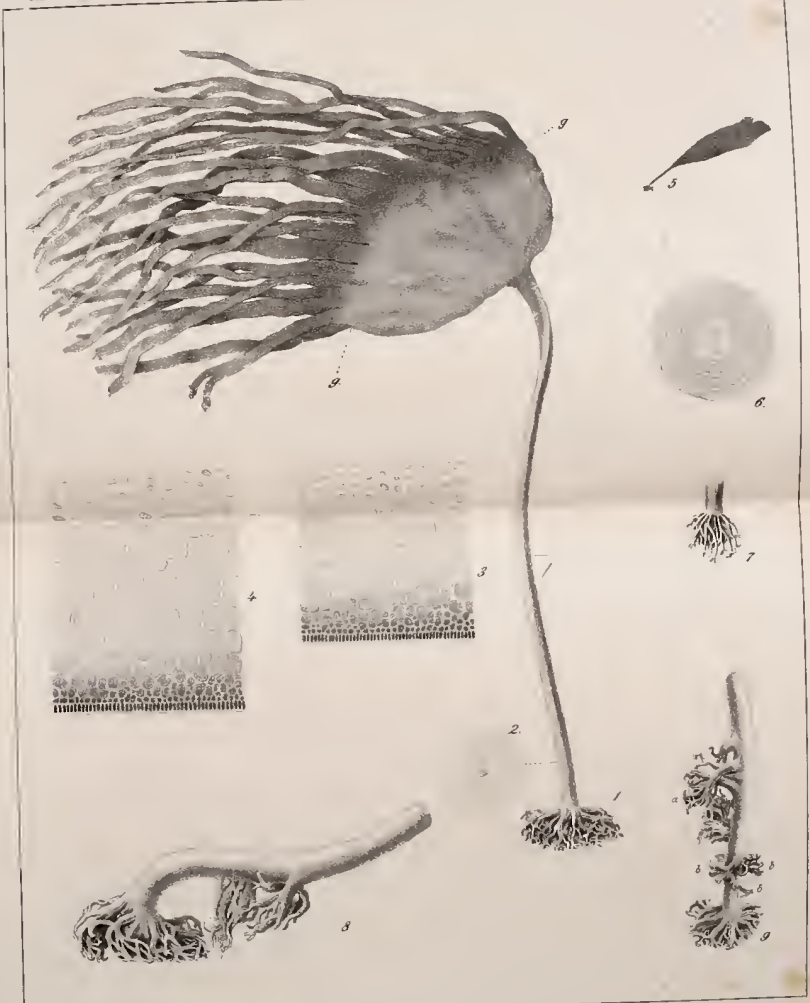

Carl Nielsen et M Foshe del 



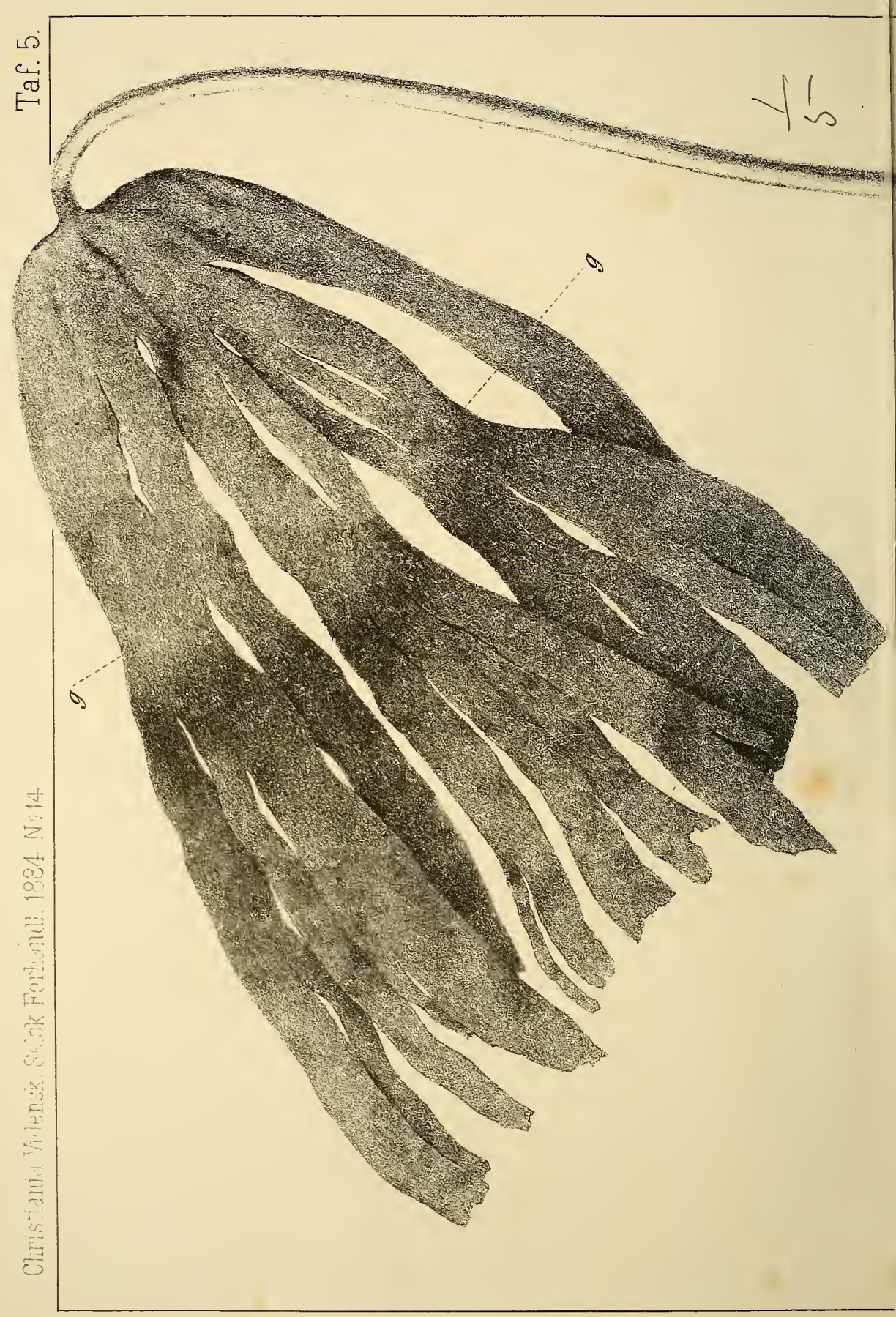




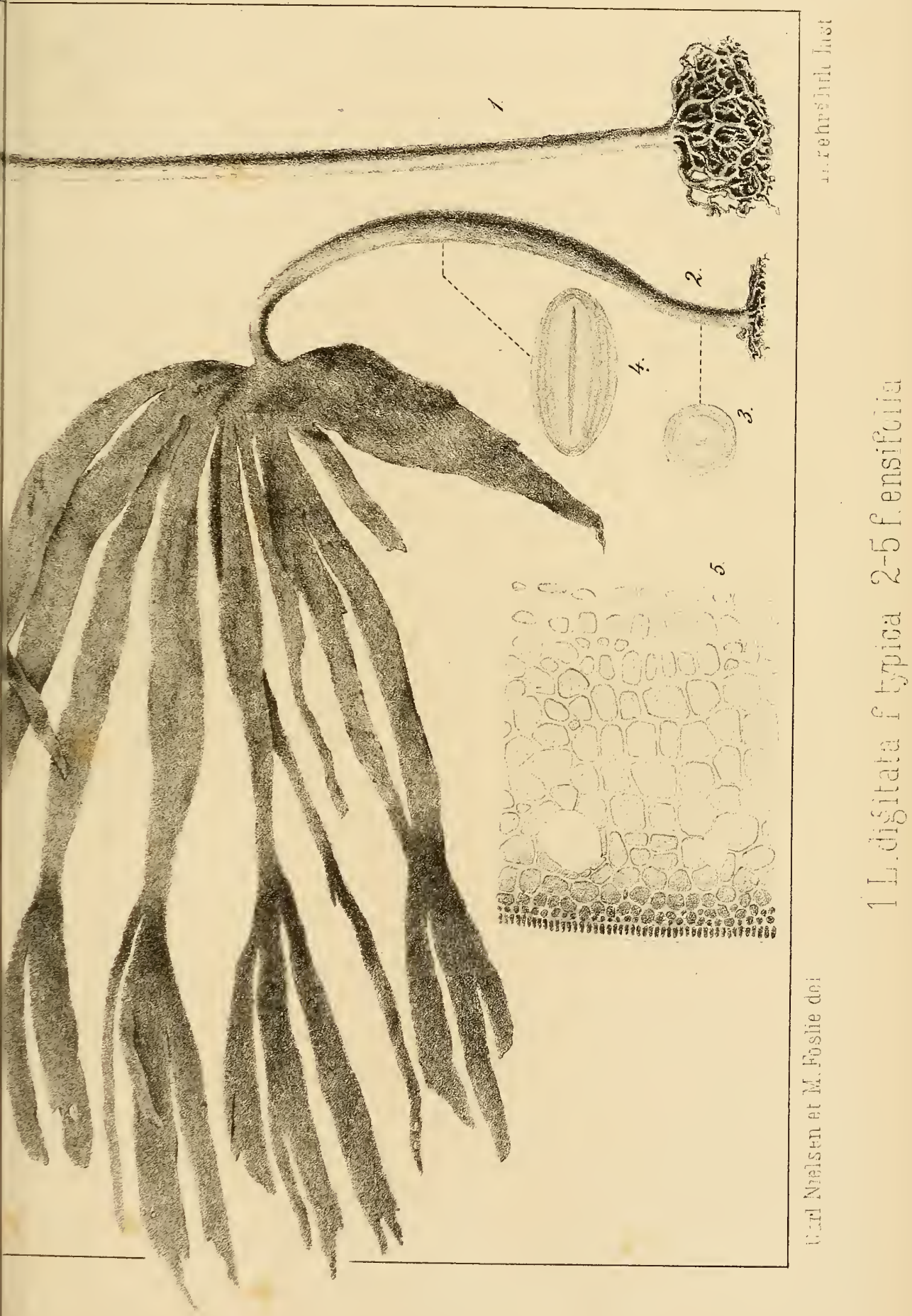





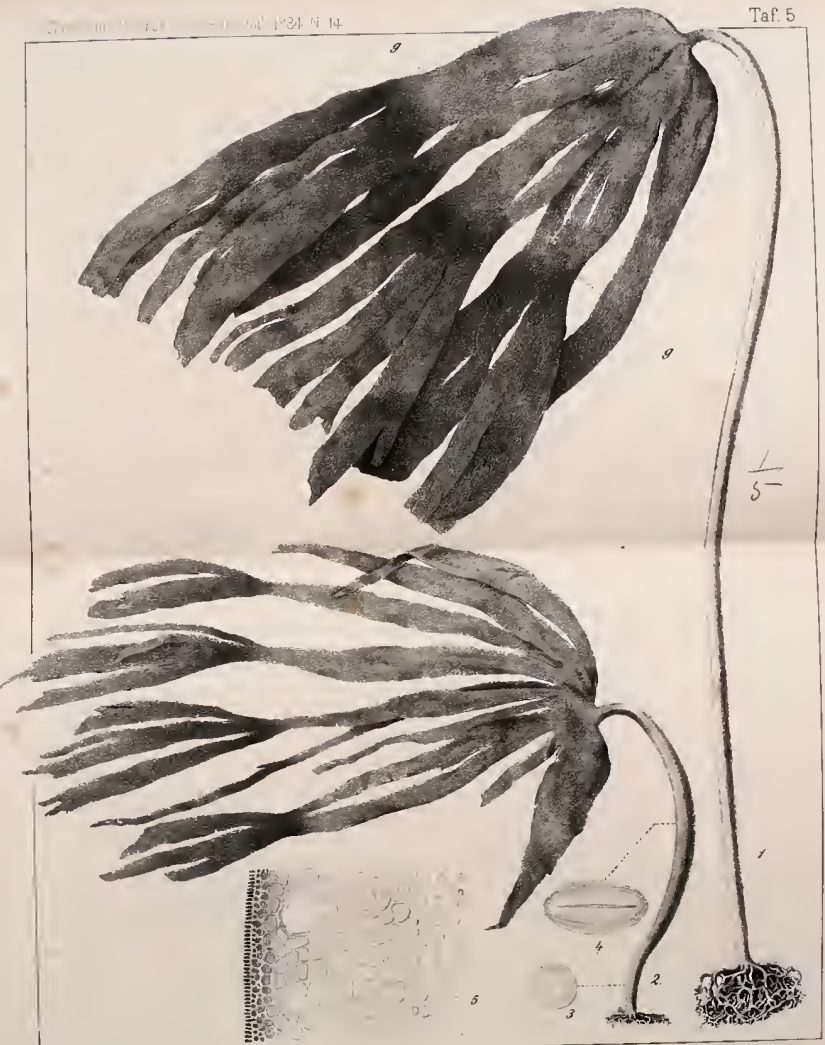

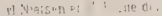






$$
7
$$




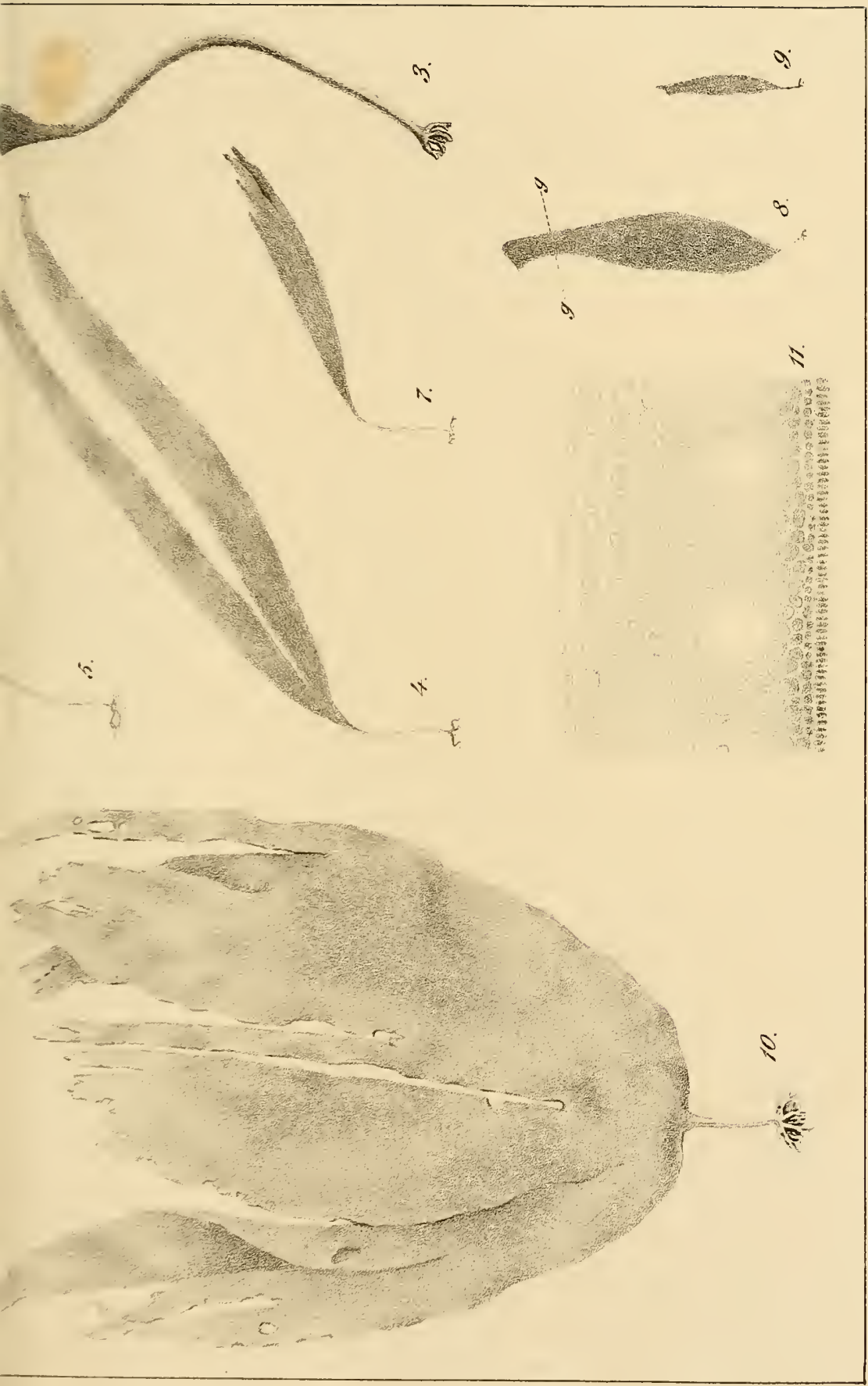

至 



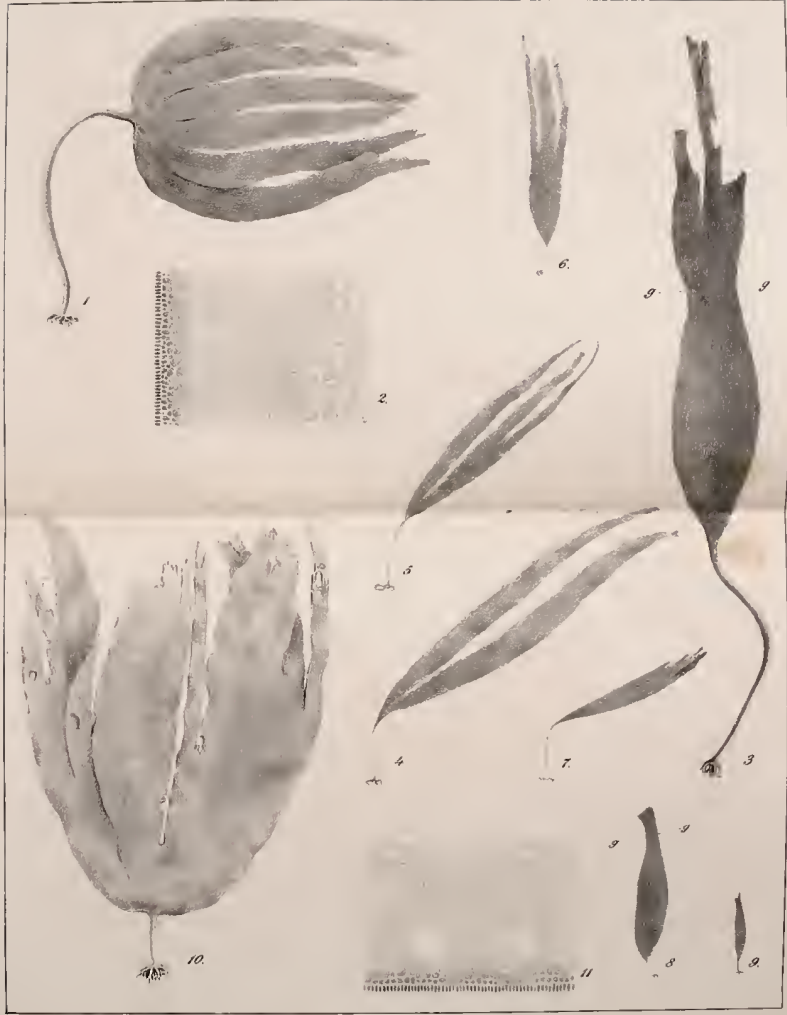

Garl Nielsen et M. Foshe del 




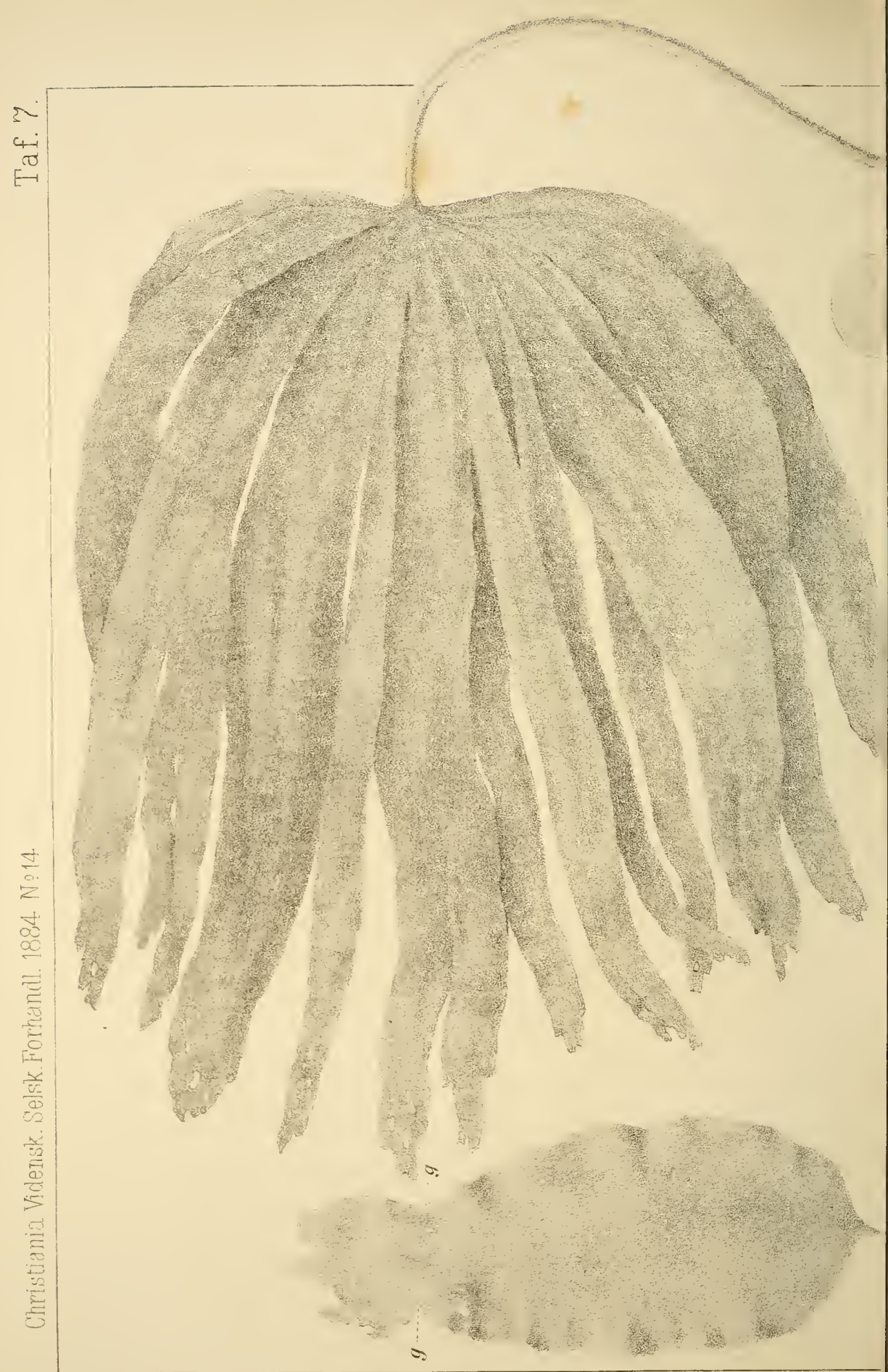





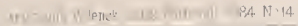

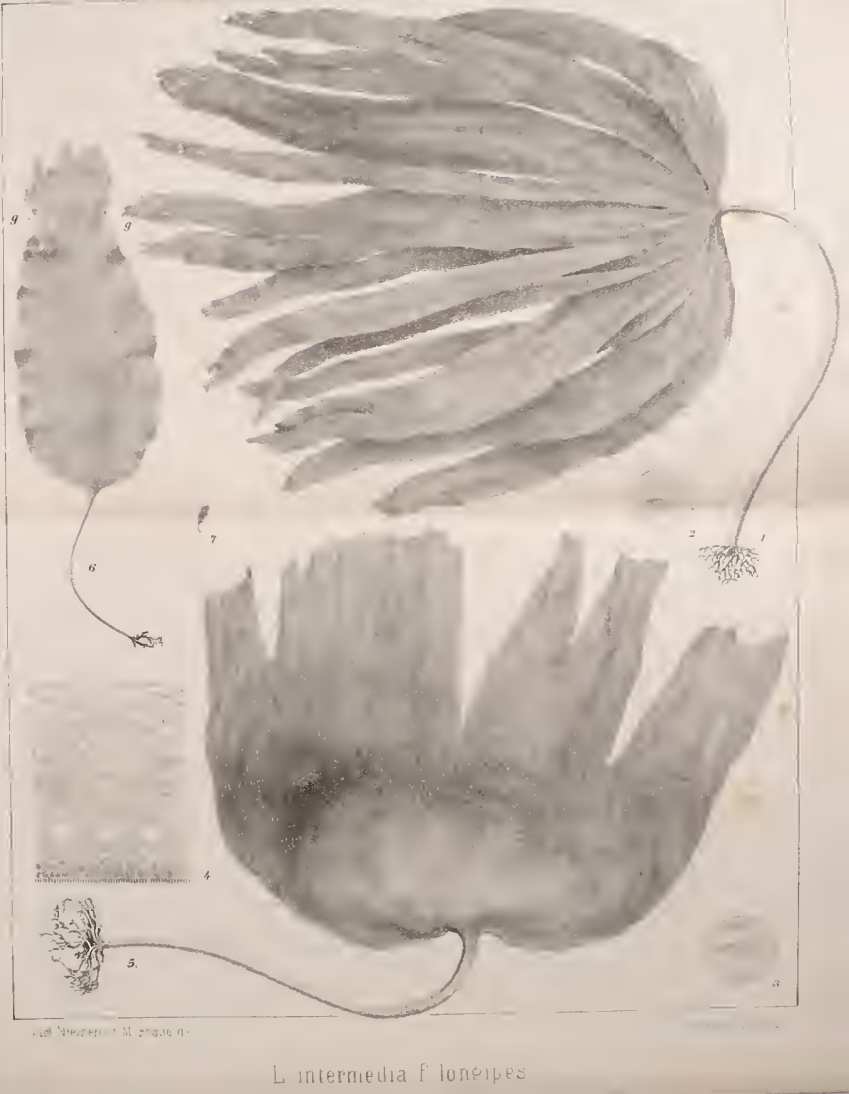





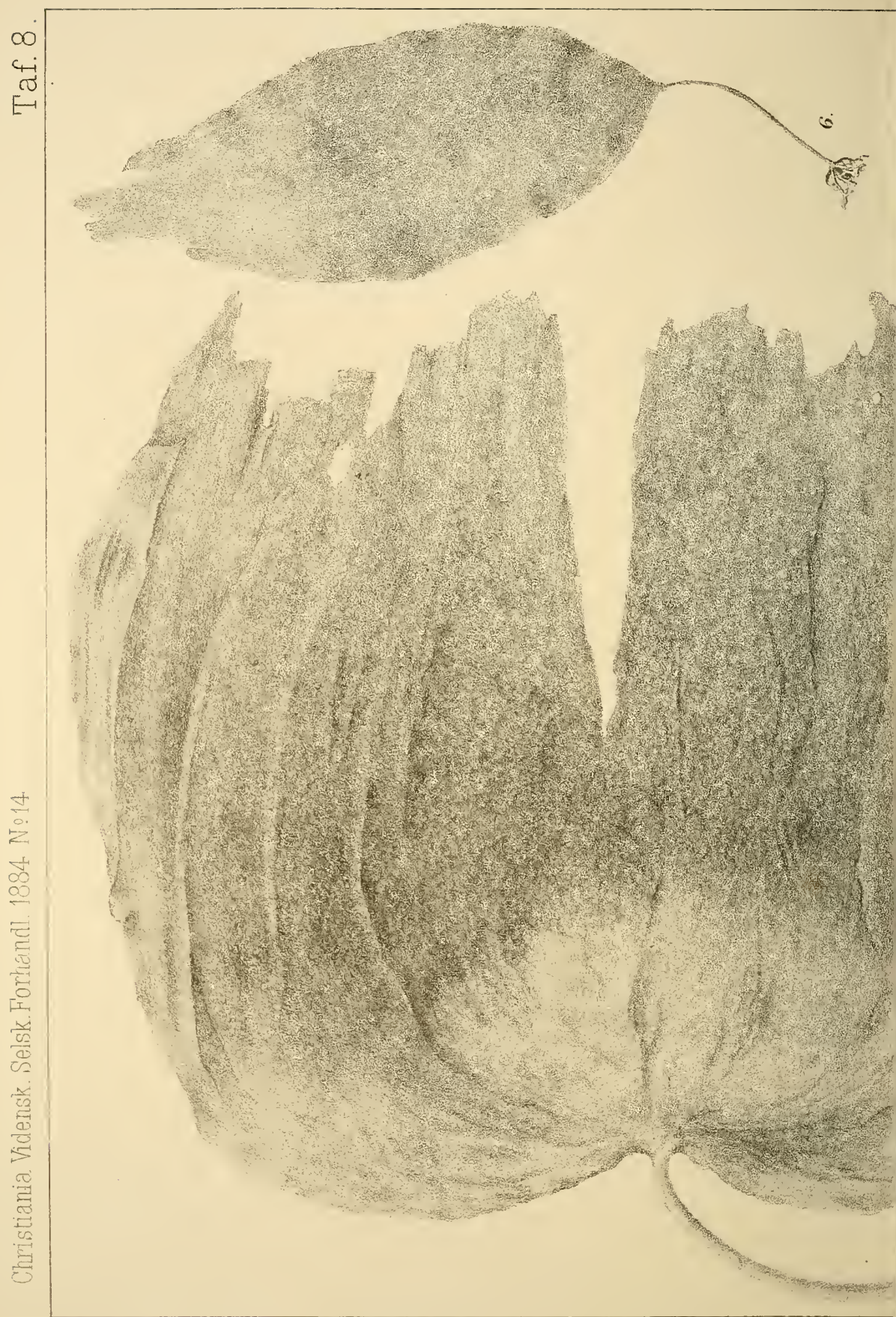




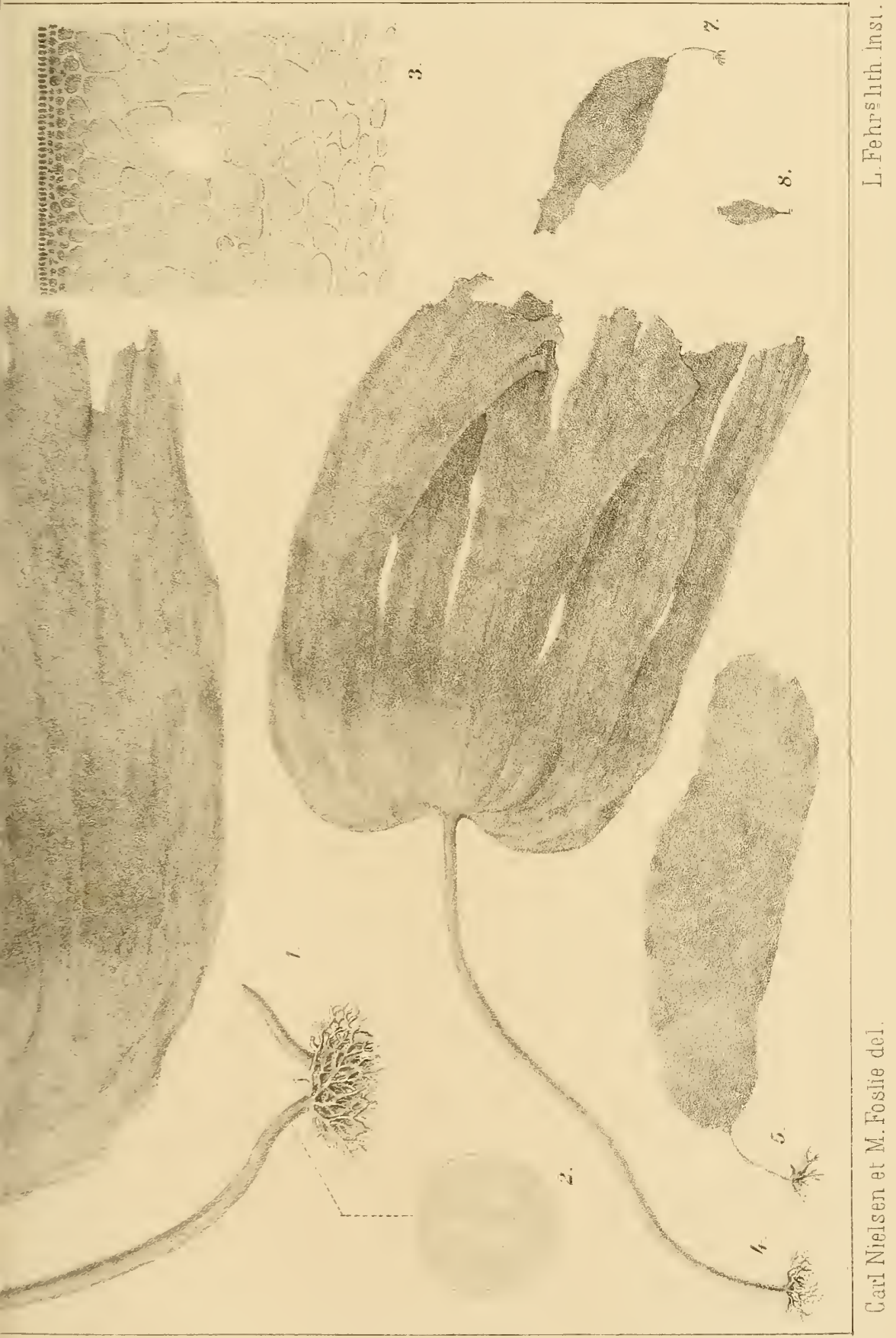

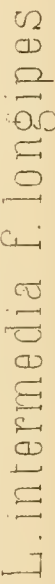





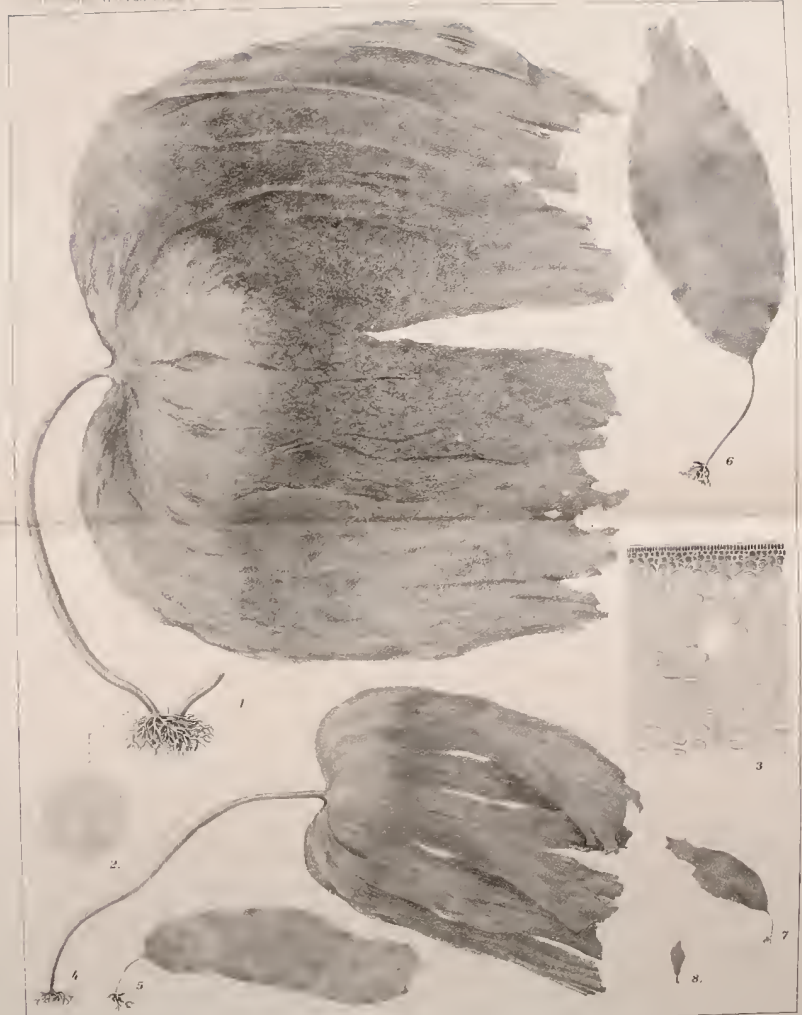

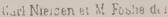





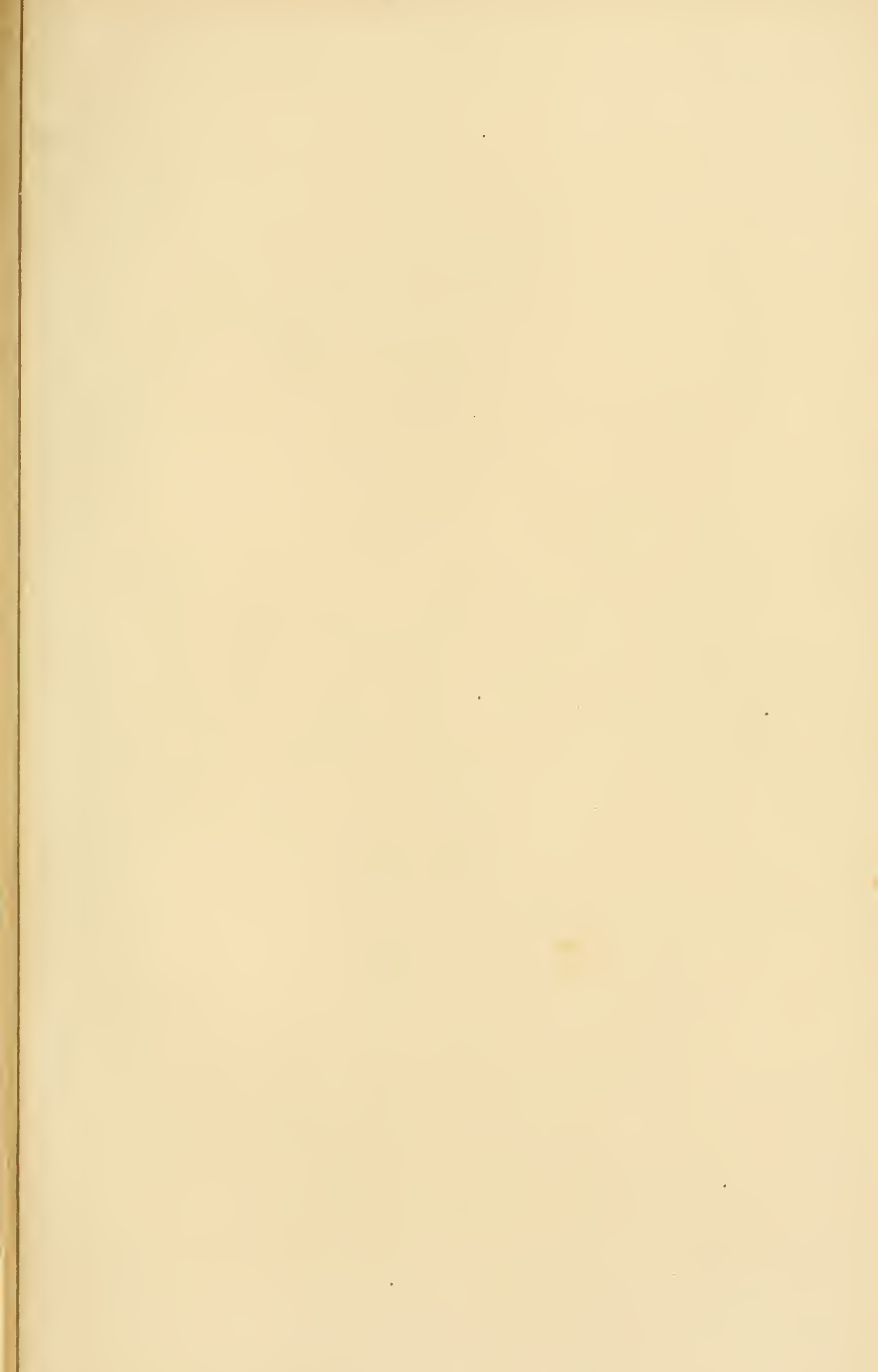




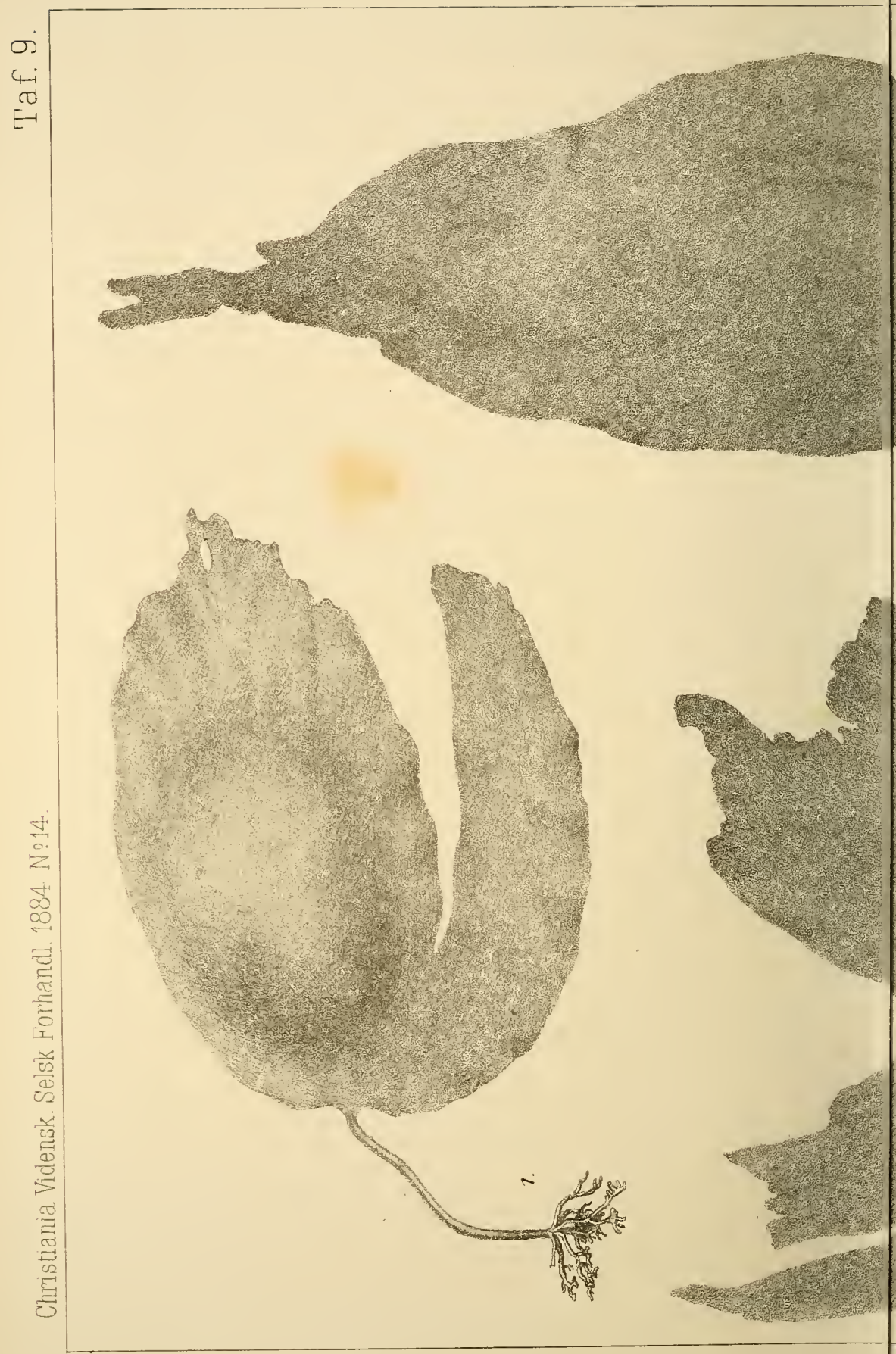




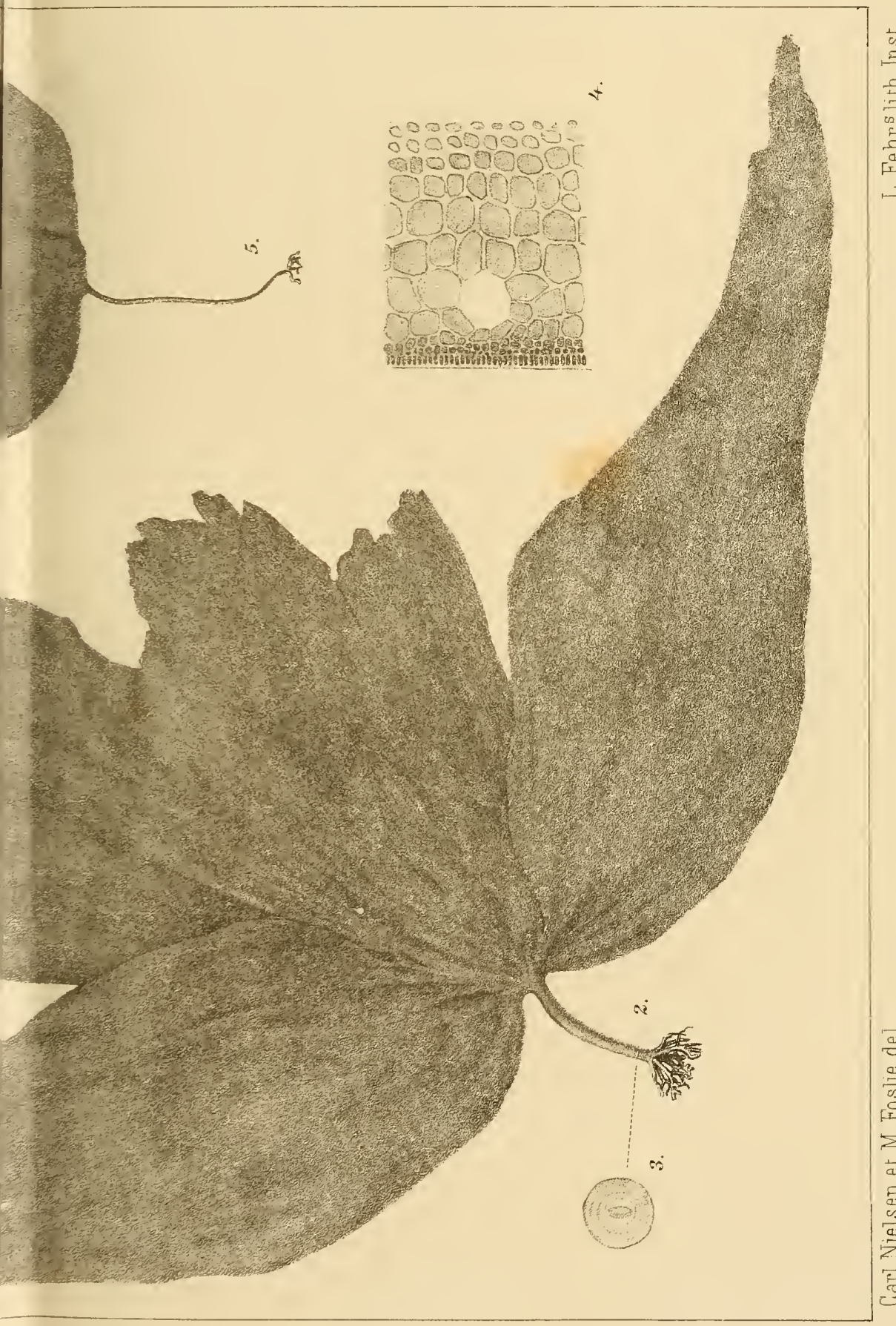





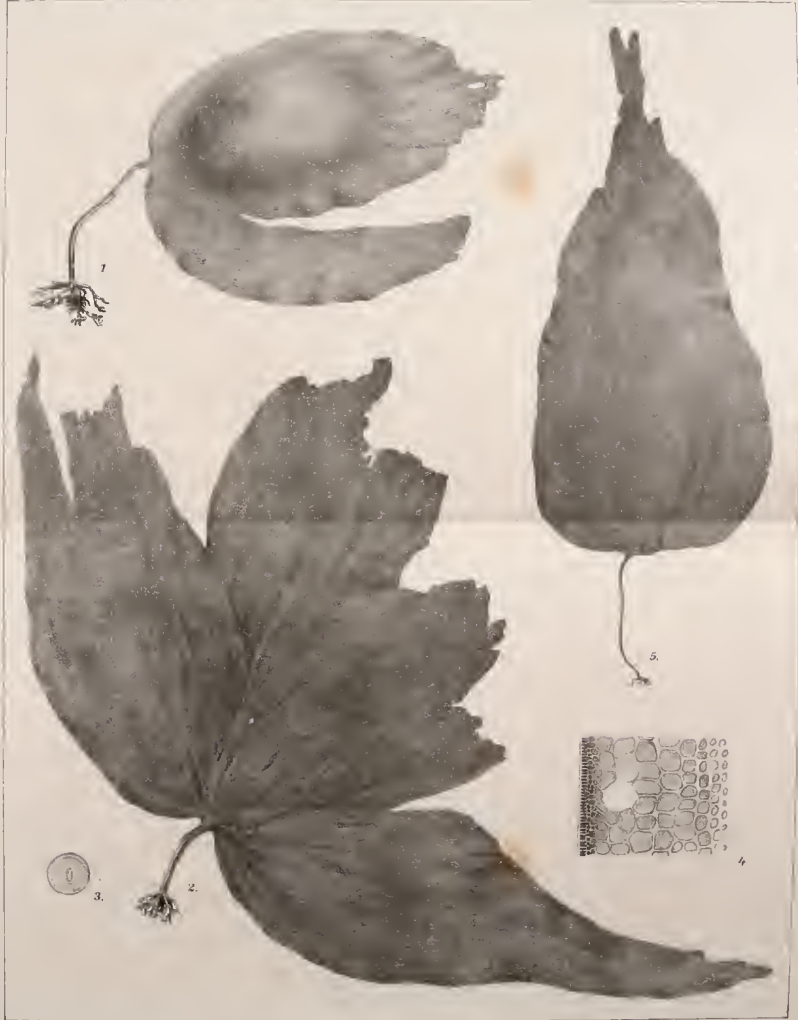





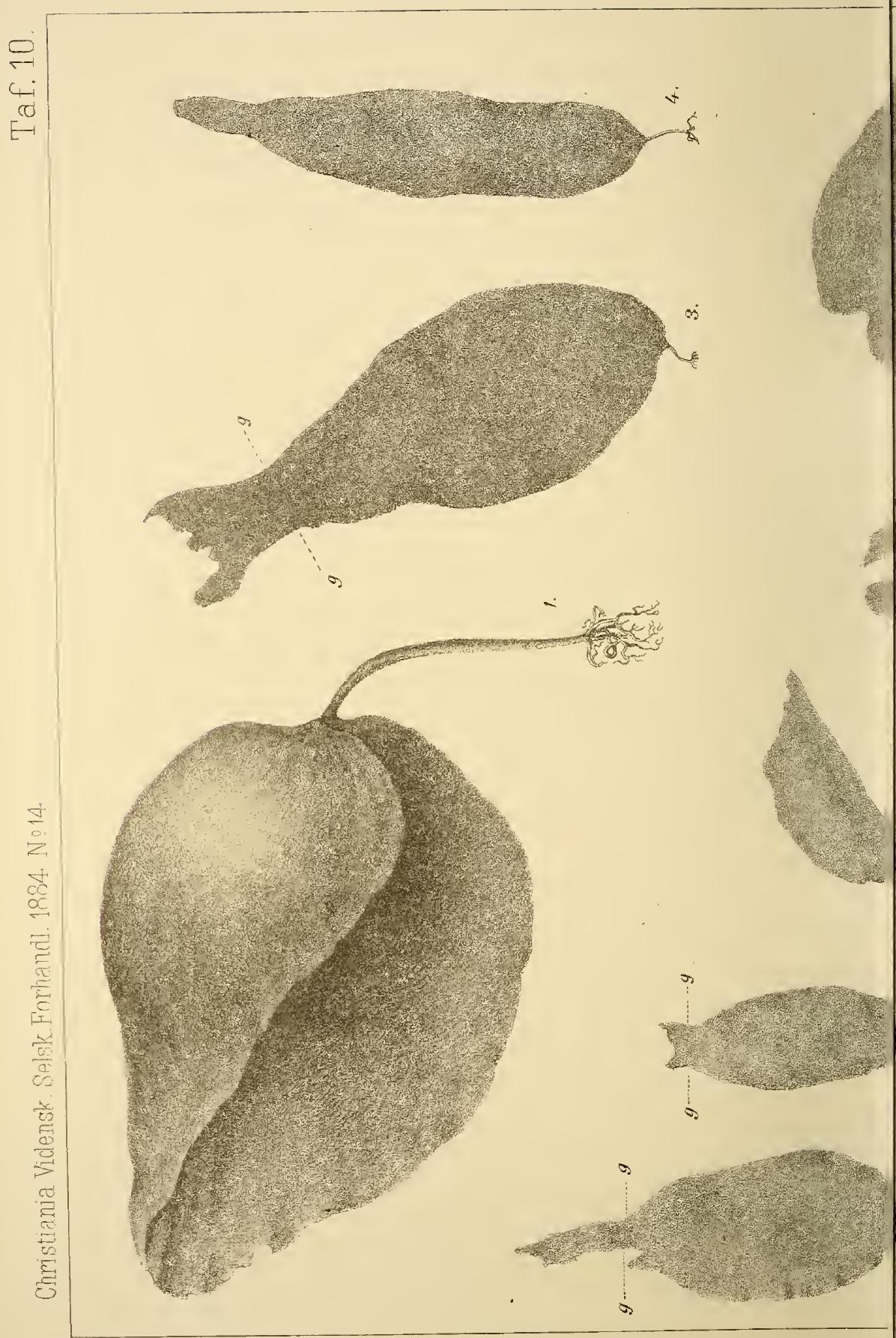



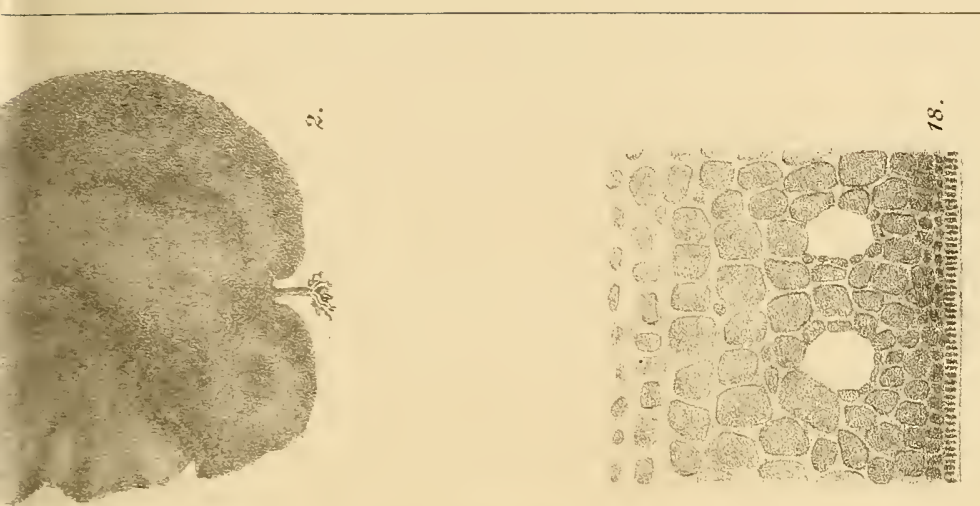

焉
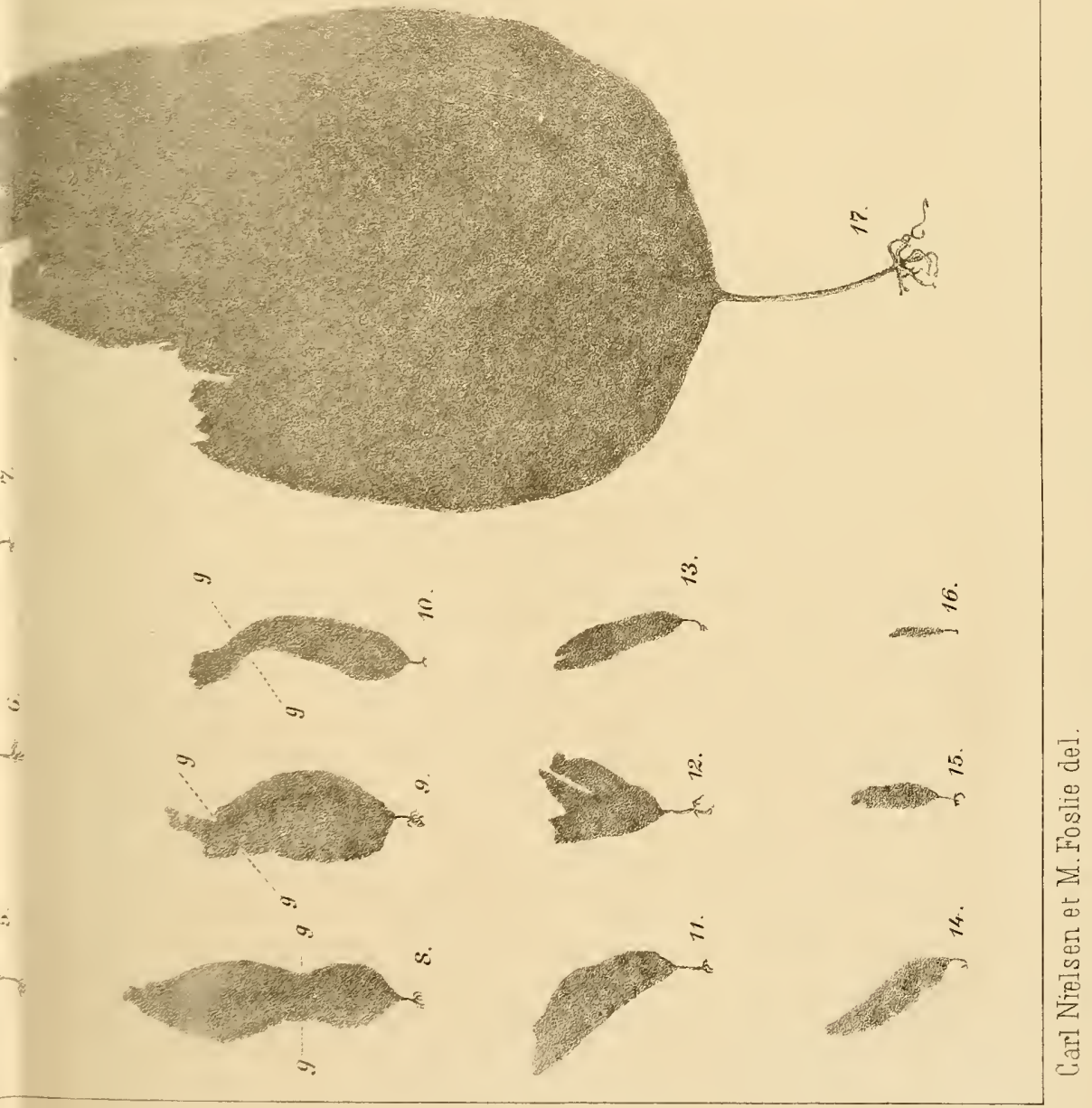



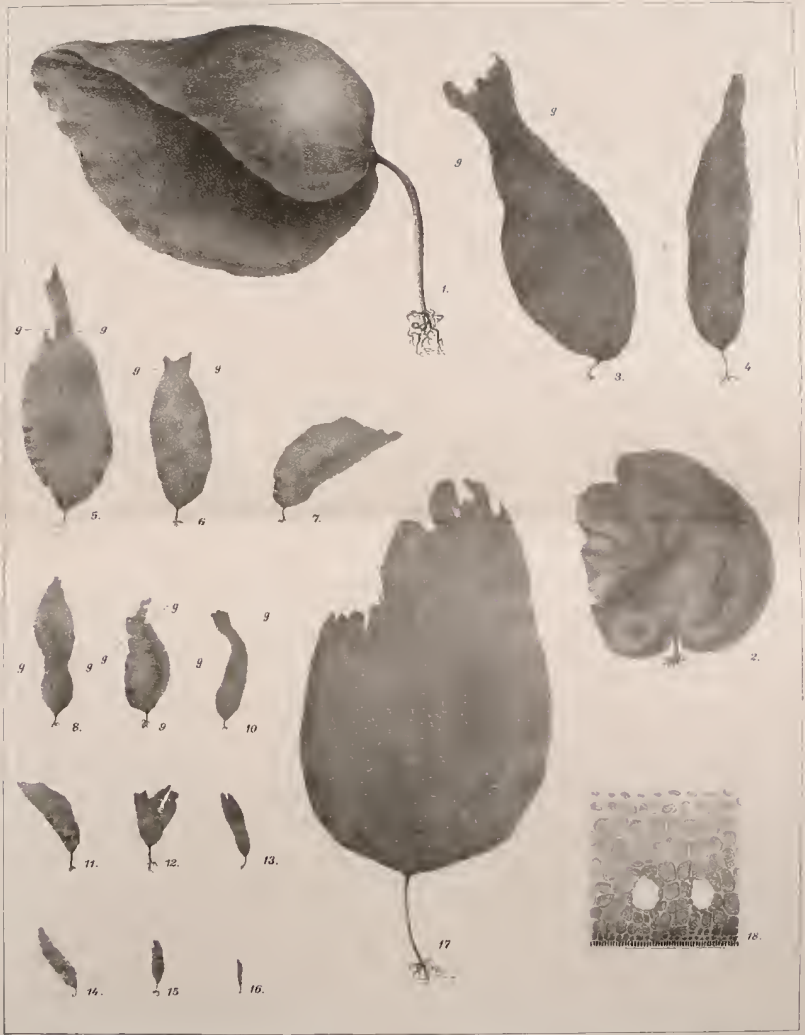








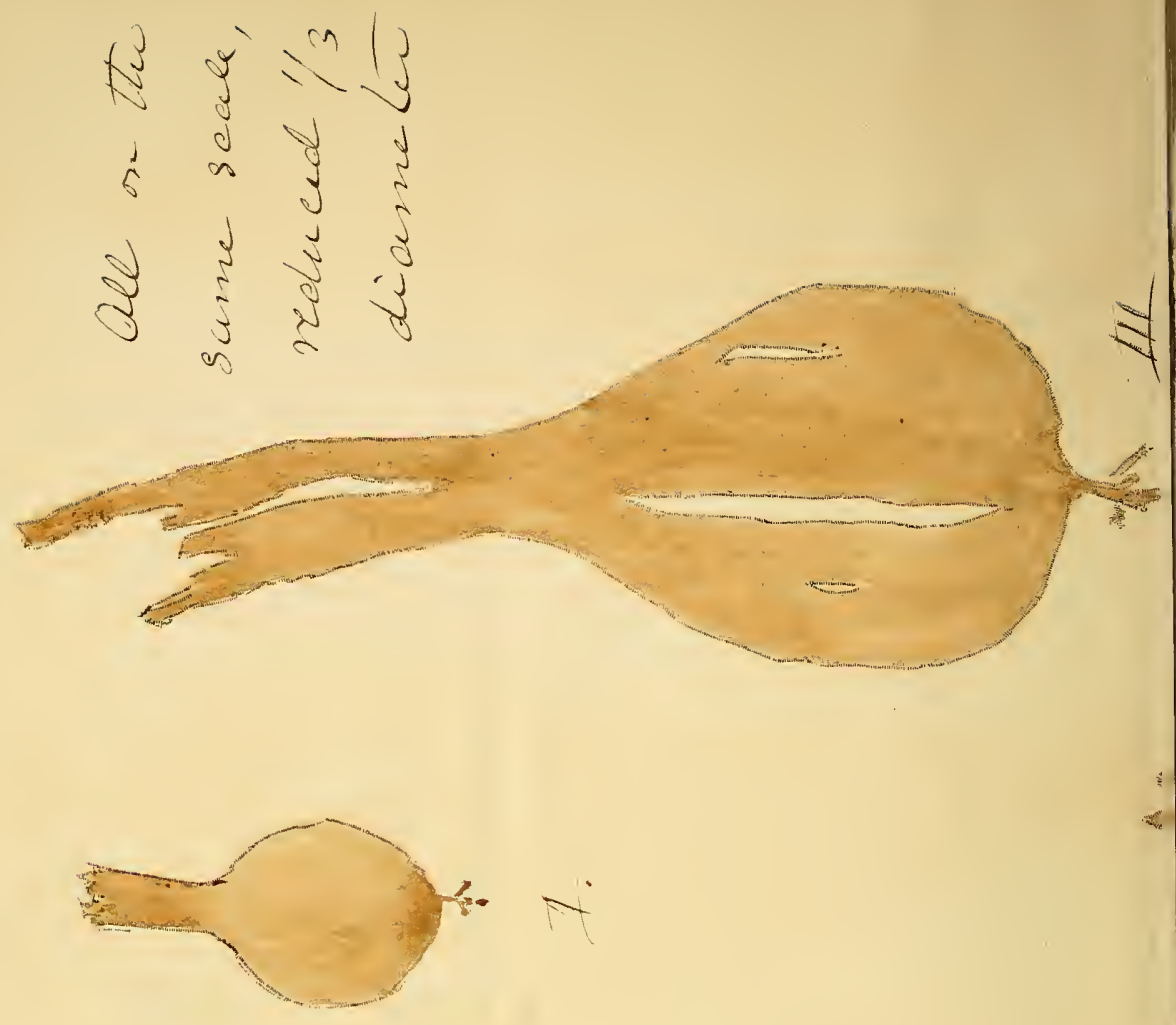




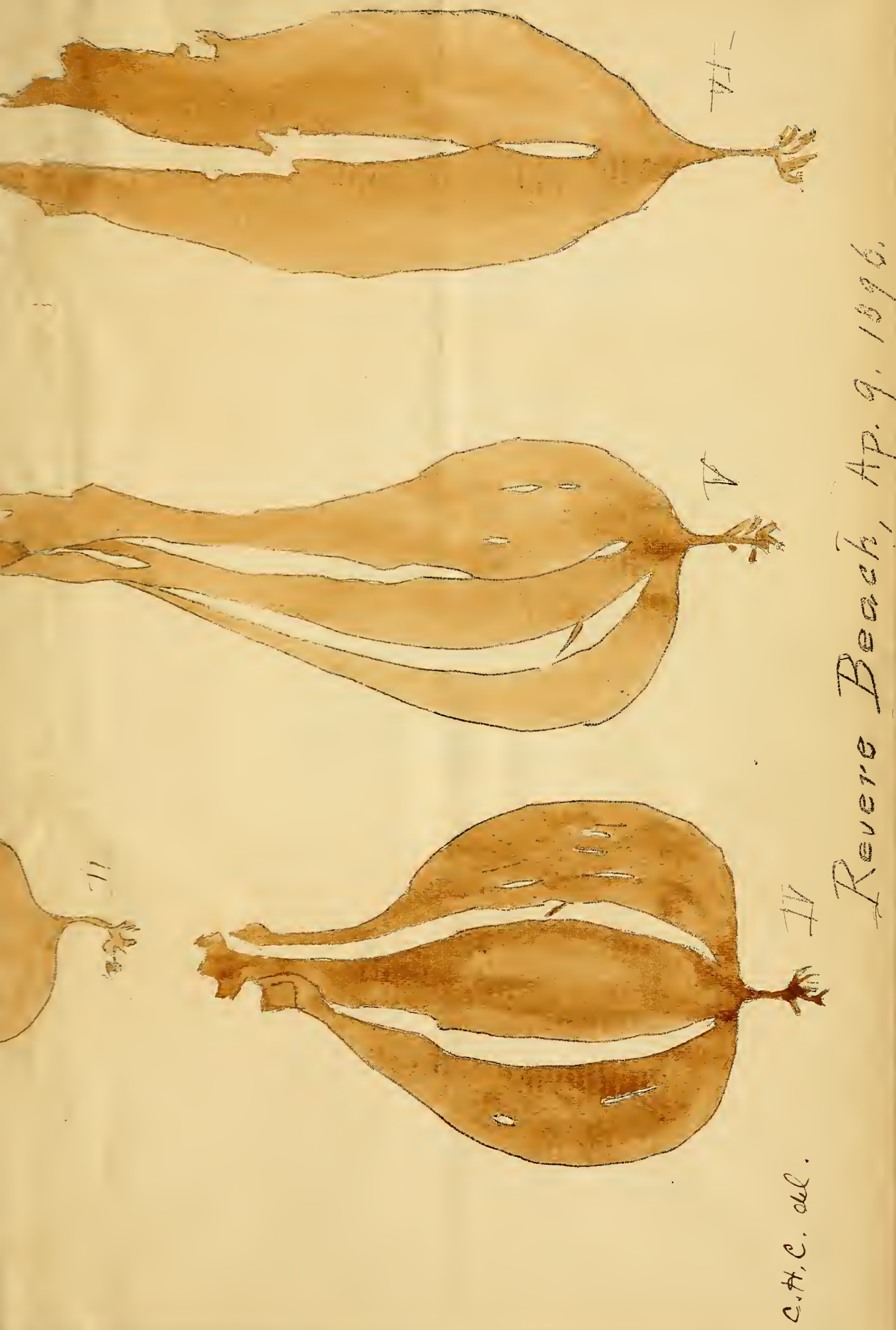




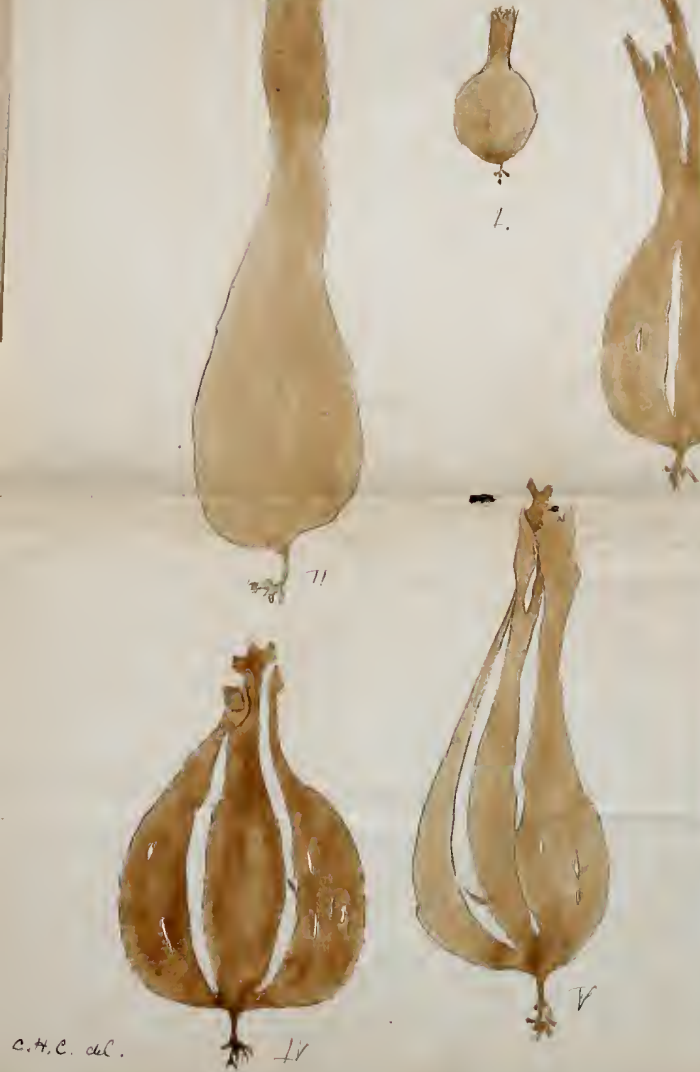

Mie s. Th

Gutre senti,

ycalcent?;

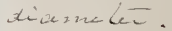

1.

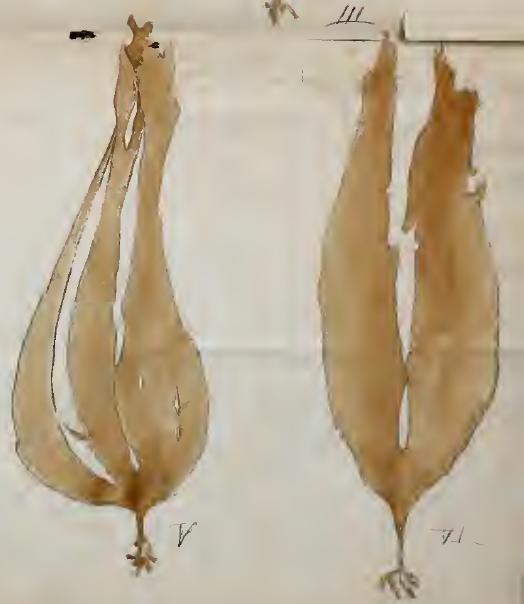

Revere Beach, Ap. 7 ligo. 



\section{DIGEST OF THE LIBRARY REGULATIONS.}

No book shall be taken from the Library without the record of the Librarian.

No person shall be allowed to retain more than five volumes at any one time, unless by special vote of the Council.

Books may be kept out one calendar month; no longer without renewal, and renewal may not be granted more than twice.

A fine of five cents per day incurred for every volume not returned within the time specified by the rules.

The Librarian may demand the return of a book after the expiration of ten days from the date of borrowing.

Certain books, so designated, cannot be taken from the Library without special permission.

All books must be returned at least two weeks previnus to the Annual Meeting.

Persons are responsible for all injury or loss of books charged to their name. 
